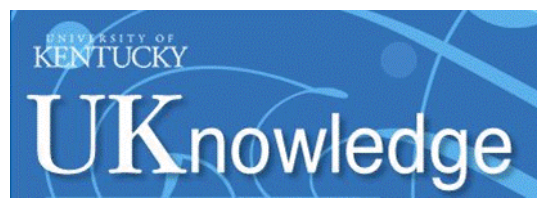

University of Kentucky

UKnowledge

\title{
SURFACE TEXTURES FOR ENHANCED LUBRICATION: FABRICATION AND CHARACTERIZATION TECHNIQUES
}

\author{
Sriram Venkatesan \\ University of Kentucky
}

Right click to open a feedback form in a new tab to let us know how this document benefits you.

\author{
Recommended Citation \\ Venkatesan, Sriram, "SURFACE TEXTURES FOR ENHANCED LUBRICATION: FABRICATION AND \\ CHARACTERIZATION TECHNIQUES" (2005). University of Kentucky Master's Theses. 342. \\ https://uknowledge.uky.edu/gradschool_theses/342
}

This Thesis is brought to you for free and open access by the Graduate School at UKnowledge. It has been accepted for inclusion in University of Kentucky Master's Theses by an authorized administrator of UKnowledge. For more information, please contact UKnowledge@lsv.uky.edu. 


\begin{abstract}
OF THESIS
SURFACE TEXTURES FOR ENHANCED LUBRICATION: FABRICATION AND CHARACTERIZATION TECHNIQUES
\end{abstract}

Theoretical and experimental results show that the performance of a load-bearing surface in hydrodynamic lubrication may be enhanced by 'engineering' a definable surface texture onto the surface. These surface textures are in the form of protrusions (positive asperities) or cavities (negative asperities) of known size and geometry. The benefits of such surface textures include lower friction torque, higher load capacity and lower operating temperatures. This Thesis details a fabrication process to manufacture such surface textures/asperities on flat surfaces. The asperities are fabricated using a UV photolithography process followed by electroplating. A complete surface characterization is done to evaluate the effectiveness of the manufacturing process. From the characterization results, some errors in asperity geometry are identified and statistically quantified. These errors are found to be normally distributed and the random surface roughness is 1 to 3 orders of magnitude less than the deterministic feature size. The accuracy of the manufacturing process for fabricating the asperities was found to lie within $6.5 \%$ of the desired value over all the errors studied. Finally, a sensitivity analysis is done to theoretically evaluate the effect of some of these errors in the hydrodynamic lubrication regime.

KEYWORDS: Engineered Surface Textures, Microfabrication, Hydrodynamic Lubrication, Surface Characterization.

Sriram Venkatesan

June 13, 2005

(Date) 


\title{
SURFACE TEXTURES FOR ENHANCED LUBRICATION: FABRICATION AND CHARACTERIZATION TECHNIQUES
}

\author{
By
}

Sriram Venkatesan

Dr. Lyndon Scott Stephens

(Director of Thesis)

Dr. George Huang

(Director of Graduate Studies)

June 13,2005

(Date)

Copyright $\odot$ Sriram Venkatesan, 2005 


\section{RULES FOR THE USE OF THESES}

Unpublished Thesis submitted for the Master's degree and deposited in the University of Kentucky Library are as a rule open for inspection, but are to be used only with due regard to the rights of the authors. Bibliographical references may be noted, but quotations or summaries of parts may be published only with the permission of the author, and with the usual scholarly acknowledgements.

Extensive copying or publication of the Thesis in whole or in part also requires the consent of the dean of the Graduate School of the University of Kentucky.

A Library that borrows this Thesis for use by its patrons is expected to secure the signature of each user.

$\underline{\text { Name }}$

$\underline{\text { Date }}$ 


\section{THESIS}

Sriram Venkatesan

The Graduate School

University of Kentucky

2005 
SURFACE TEXTURES FOR ENHANCED LUBRICATION: FABRICATION AND CHARACTERIZATION TECHNIQUES

\title{
THESIS
}

\author{
By \\ Sriram Venkatesan \\ Lexington, Kentucky \\ Director: Dr. Lyndon Scott Stephens \\ Lexington, Kentucky \\ 2005
}

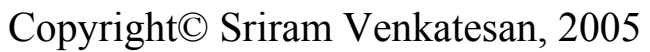




\title{
MASTER'S THESIS RELEASE
}

\author{
I authorize the University of Kentucky \\ Libraries to reproduce this thesis \\ in whole or in part for purposes of research
}

Signed: Sriram Venkatesan

Date: June 13, 2005 
To my loving parents and family 


\section{ACKNOWLEDGEMENTS}

I thank Dr. L.S Stephens, Director of the Bearings and Seals Laboratory at the University of Kentucky, for his guidance and giving me the freedom to use expensive laboratory equipment. I learnt a lot from him both at the professional and research front.

I thank Dr. M.P Menguc and Dr. K.E Rouch for judging this work as members of the Thesis committee. I acknowledge the National Science Foundation (NSF) for funding this research work under the 'Surface Engineering and Materials Design Program' Award \# CMS-0201445. Much of the experimental work presented in this Thesis was carried out at the Center for Nano-scale Science and Engineering (CeNSE) at the University of Kentucky and I thank the support of the faculty and staff associated with the center. I also thank Mr. Larry Mcnabb and Mr. Larry Crockett of the Mechanical Engineering department machine shop for their timely help in fabrication. I thank all the member of the Bearings and Seals Laboratory for all their useful insights and I would also like to thank Mr. Sarang Kortikar for introducing me to the various micro-fabrication techniques.

Last but not least, I am fortunate to have very understanding parents and family who always supported me in my endeavors and I never would have been what I am today without their love and support. Finally, a special thanks to all my friends for keeping me engaged during my leisure time. 


\section{TABLE OF CONTENTS}

ACKNOWLEDGEMENTS ................................................................................................III

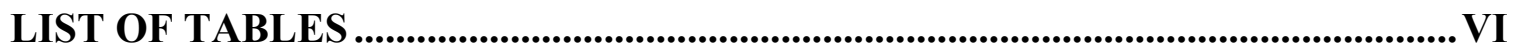

LIST OF FIGURES ..........................................................................................

CHAPTER 1 - INTRODUCTION............................................................................... 1

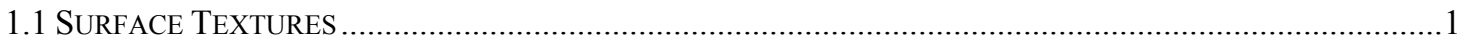

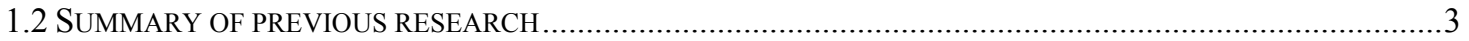

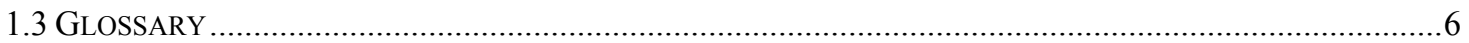

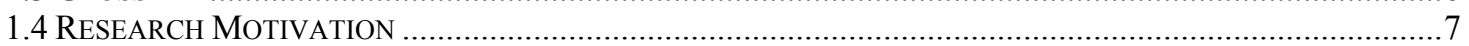

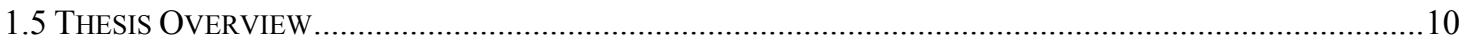

CHAPTER 2- SURFACE TEXTURE FABRICATION .............................................. 11

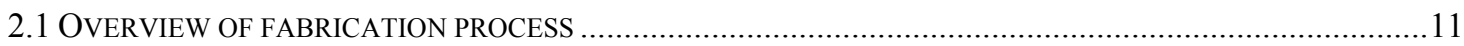

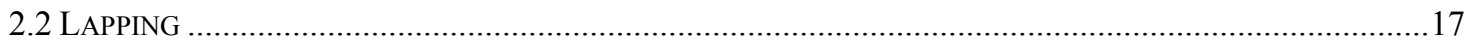

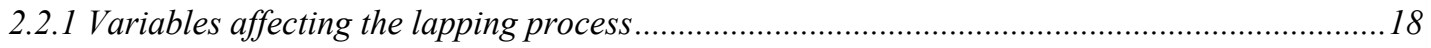

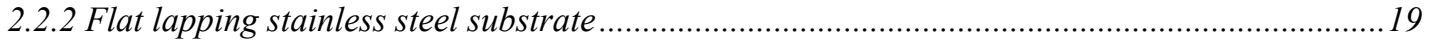

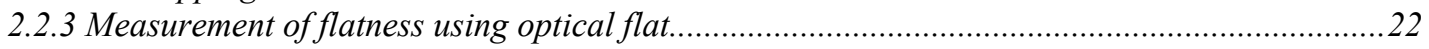

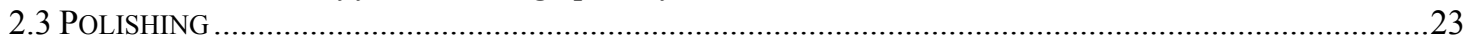

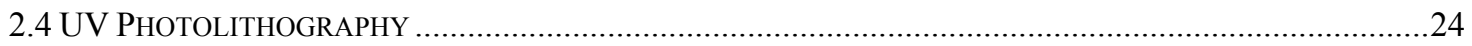

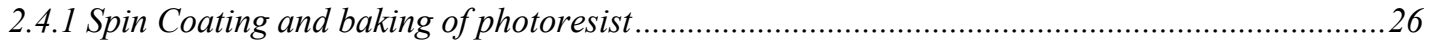

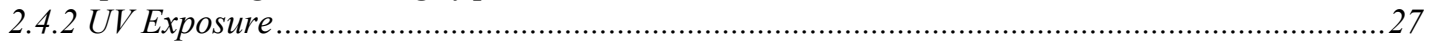

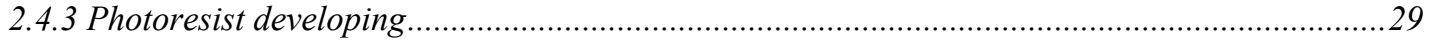

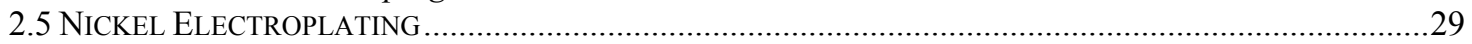

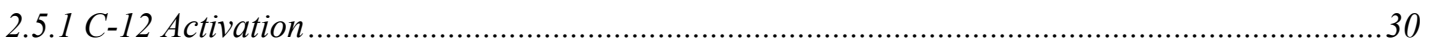

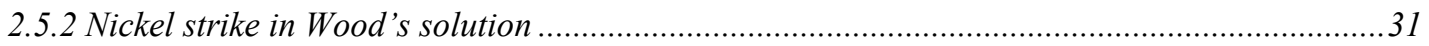

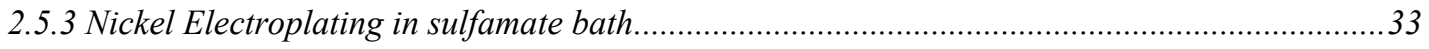

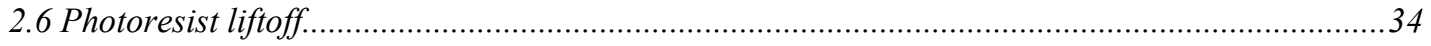

CHAPTER 3 - SURFACE CHARACTERIZATION................................................... 36

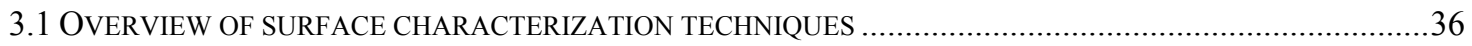

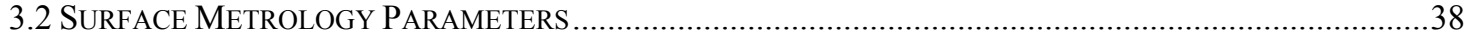

3.3 CHARACTERIZATION OF DETERMINISTIC SURFACE TEXTURE ..........................................................

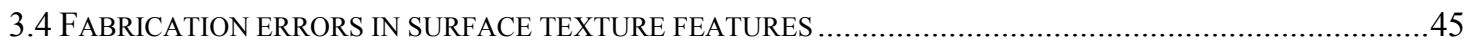

CHAPTER 4 - STATISTICAL ANALYSIS OF FABRICATION ERRORS............ 49

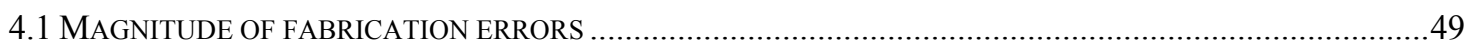

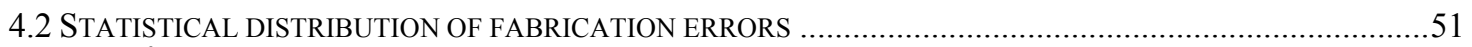

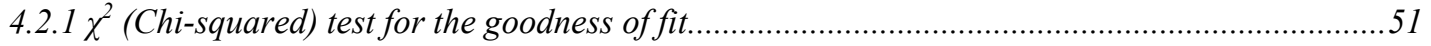

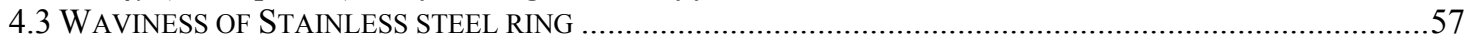

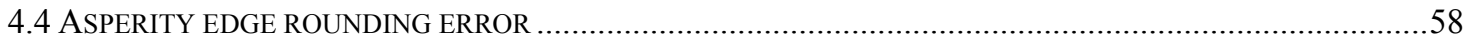

CHAPTER 5 - SENSITIVITY ANALYSIS OF FABRICATION ERRORS ............ 60

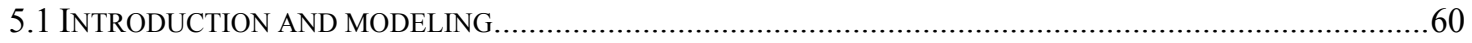

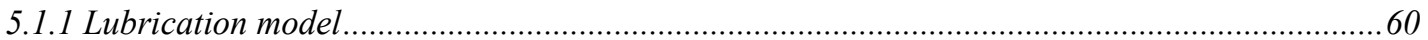

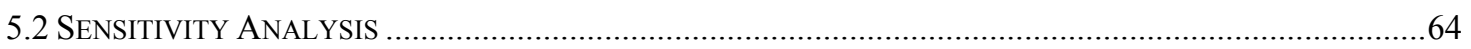

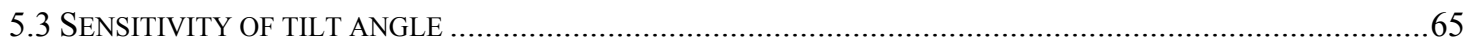

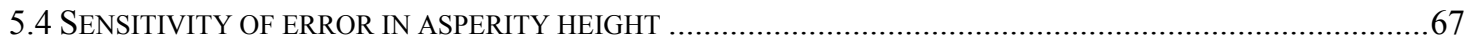

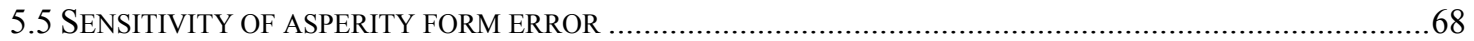

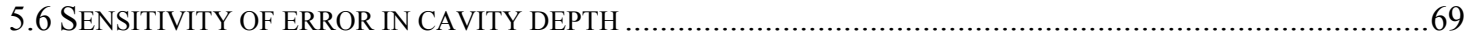

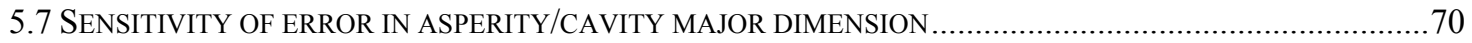

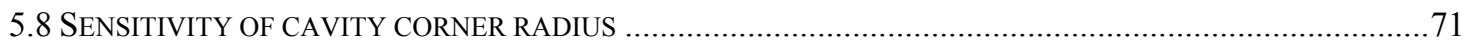


CHAPTER 6- CONCLUSIONS AND FUTURE WORK

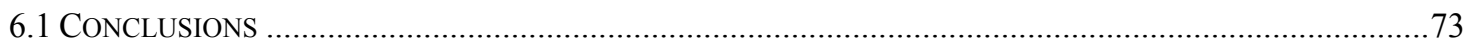

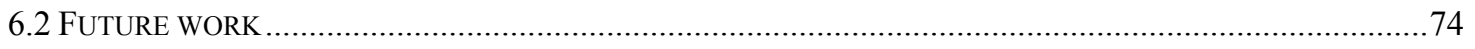

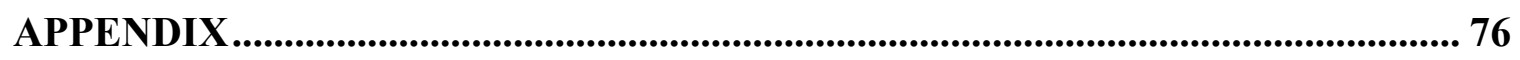

A.1 MATLAB ${ }^{\circledR}$ SCRIPT TO SOLVE GENERAL 2D LUBRICATION PROBLEM FOR DETERMINISTIC MICROASPERITIES PATTERNED ONTO A SURFACE IN A SQUARE ARRAY ……................................................

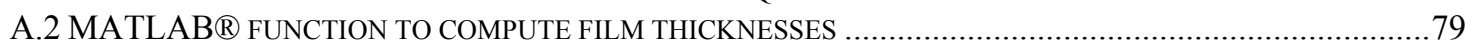

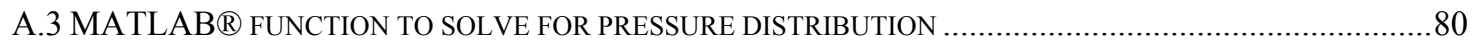

A.4 MATLAB ${ }^{\circledR}$ FUNCTION TO COMPUTE LOAD CAPACITY AND FRICTION COEFFICIENT …….....................82

REFERENCES....................................................................................................................... 83

VITA 


\section{LIST OF TABLES}

Table 2-1 Properties of experimental thrust surfaces (Rectangles/Squares) ................... 14

Table 2-2 Properties of experimental thrust surfaces (triangles)................................. 14

Table 2-3 Fabrication parameters for Positive asperities............................................. 34

Table 2-4 Fabrication parameters for Negative asperities ......................................... 35

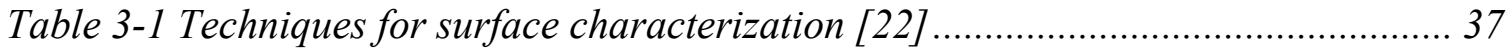

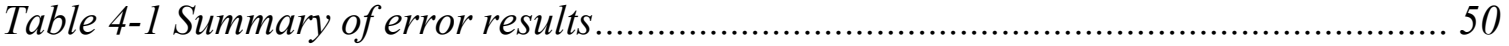

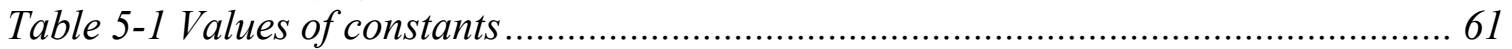




\section{LIST OF FIGURES}

Figure 1-1 Examples of machined surfaces [2] .......................................................... 2

Figure 1-2 Deterministic Micro asperities .................................................................... 7

Figure 1-3 Structured and Random surfaces.............................................................. 8

Figure 2-1 Surface texture patterns studied in this Thesis ......................................... 12

Figure 2-2 Distribution of asperities on SS thrust ring (not to scale) ............................ 13

Figure 2-3 Schematic of surface texture fabrication process ...................................... 15

Figure 2-4 LAPMASTER Model 15 lapping machine .................................................. 17

Figure 2-5 Checking lap plate flatness ........................................................................ 20

Figure 2-6 Mounting substrate in conditioning ring ............................................... 21

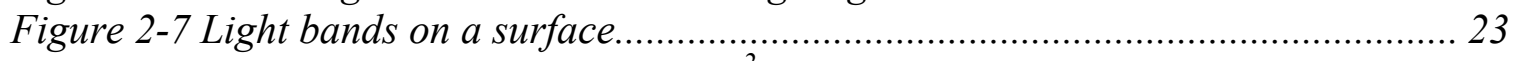

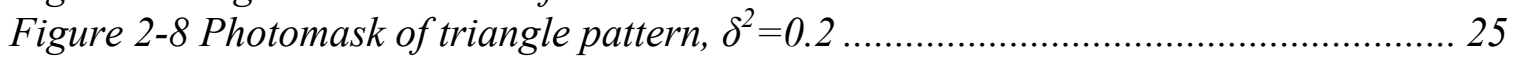

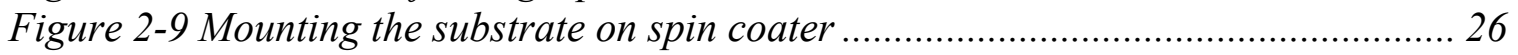

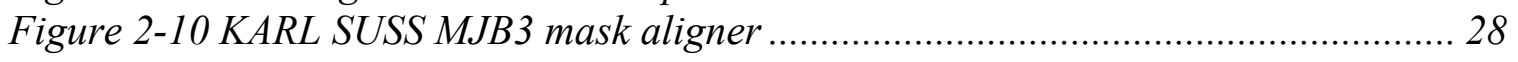

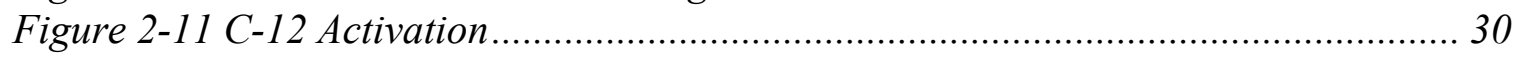

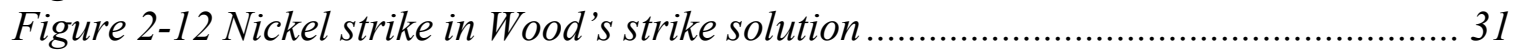

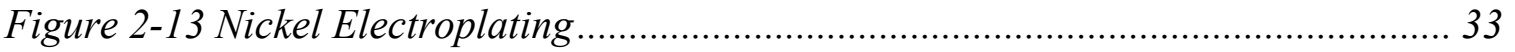

Figure 3-1 Components of a surface profile .................................................................. 38

Figure 3-2 Average Roughness .................................................................................. 39

Figure 3-3 Average Waviness .......................................................................................... 39

Figure 3-4 SEM micrograph of an SU-8 Structure Corner ........................................ 42

Figure 3-5 SEM Micrograph of an array of rectangular SU-8 structures ...................... 43

Figure 3-6 Optical micrograph of triangular negative asperities $\delta^{2}=0.2 \ldots \ldots \ldots \ldots \ldots \ldots . . . .44$

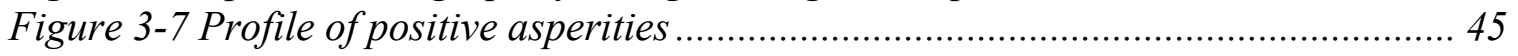

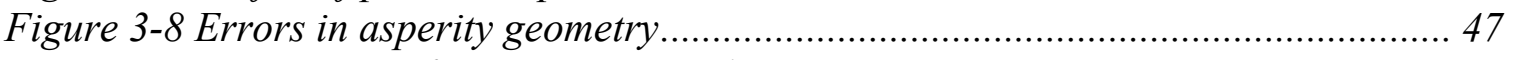

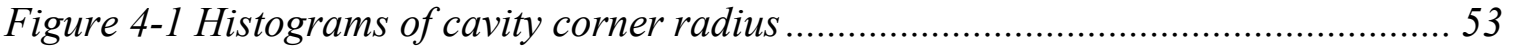

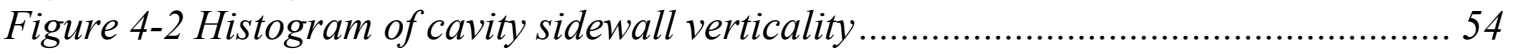

Figure 4-3 Histogram of asperity form error ............................................................... 54

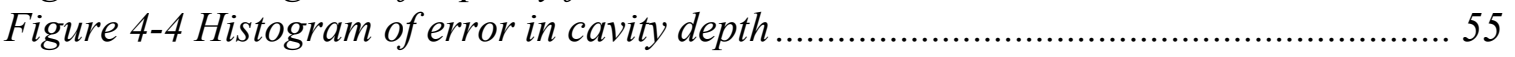

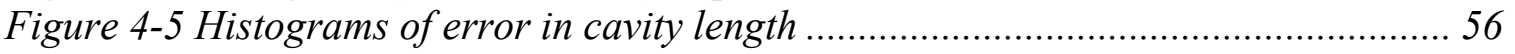

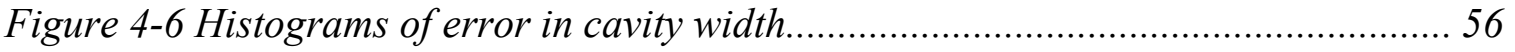

Figure 4-7 Substrate waviness before lapping ..................................................... 57

Figure 4-8 Substrate waviness after lapping and polishing ...................................... 58

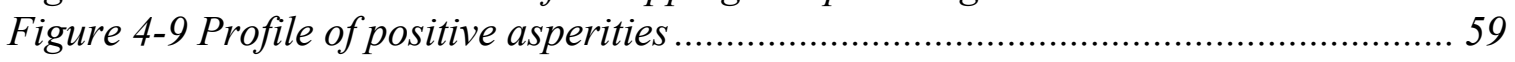

Figure 4-10 Profile of positive asperities after polishing............................................ 59

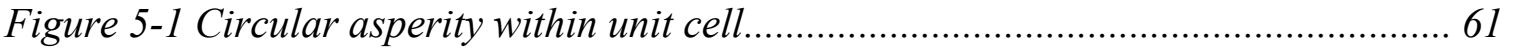

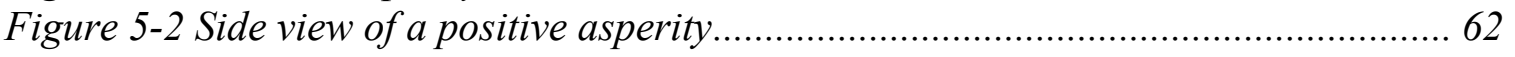

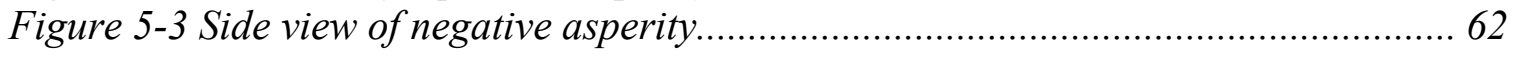

Figure 5-4 Sensitivity of tilt angle, vs load capacity (circle positive asperity) ................ 66

Figure 5-5 Sensitivity of tilt angle, vs coefficient of friction (circle positive asperity) .... 67

Figure 5-6 Sensitivity of error in asperity height (circle positive asperity) .................... 68

Figure 5-7 Sensitivity of asperity form error (circle negative asperity)......................... 68

Figure 5-8 Sensitivity of error in cavity depth (circular negative asperity) .................... 69

Figure 5-9 Sensitivity of asperity major dimension (Positive asperities)........................ 70

Figure 5-10 Sensitivity of cavity major dimension (Negative asperities)....................... 71 
Figure 5-11 Sensitivity of corner radius, positive asperities......................................... 72

Figure 5-12 Sensitivity of corner radius, negative asperities........................................ 72 


\section{CHAPTER 1 - INTRODUCTION}

\subsection{Surface Textures}

The texture of any surface is defined by the inherent surface topography it exhibits. All surfaces have a unique texture and structure and all manufactured surfaces are 'engineered' [1]. Design engineers have an understanding of the relationship between surface texture and its function. Deterministic surface textures are those that have a specific structured pattern and that are amenable to a sensible description. Such deterministic surface textures are deliberately manufactured in order to improve the functionality of any surface. Everyday examples of such deterministic surface textures include tire treads on automobile wheels that are engineered to enhance road grip, dimpled surfaces of golf balls used to reduce drag and reflective road signs used to improve visibility. Machined surfaces give required performance by altering the surface and sub-surface layer of the machined material. Typical examples of such surfaces include sand blasted surfaces, shot peened surfaces and polished surfaces. Figure 1 shows typical three dimensional profiles of some machined surfaces. Each of these surfaces exhibits a unique texture directionality or lay. Lay is largely dependant and is inherent to the machining process used to manufacture the surface. Face turned, milled and shaped surfaces have a specific texture direction and are said to exhibit a unidirectional lay. The other type of lay is the multi-directional lay in which the texture is unbiased to a specific direction as represented by the ground, spark eroded and shot peened surfaces.

In the field of Tribology, engineered surfaces are found to be beneficial in many contact applications with or without the presence of any lubricant [3-6]. Applications of engineered surfaces are found in mechanical face seals, thrust bearing pads and journal 


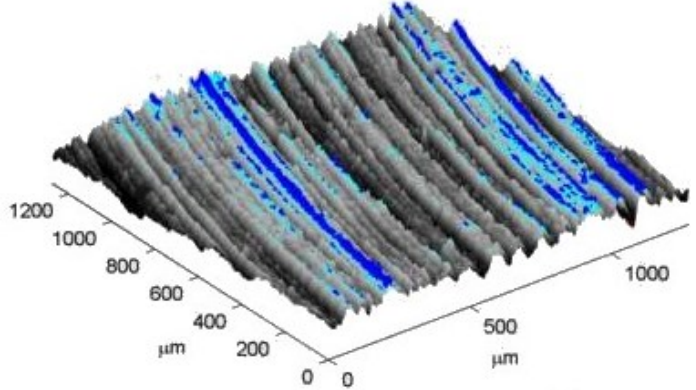

(a) Face Turned

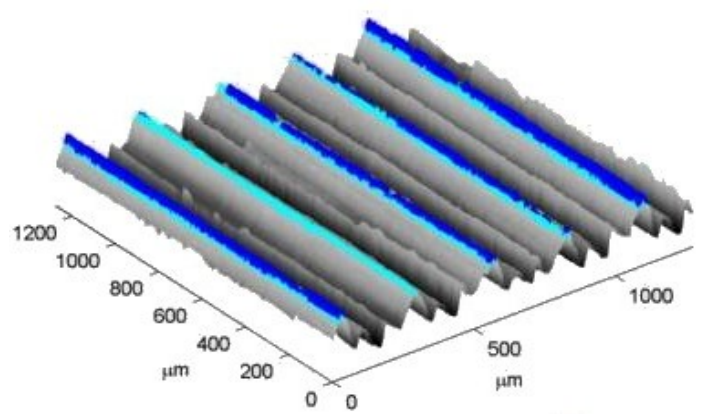

(c) Shaped

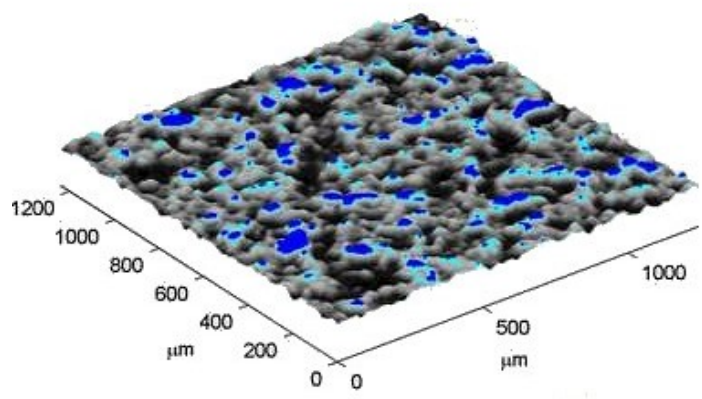

(e) Shot Peened

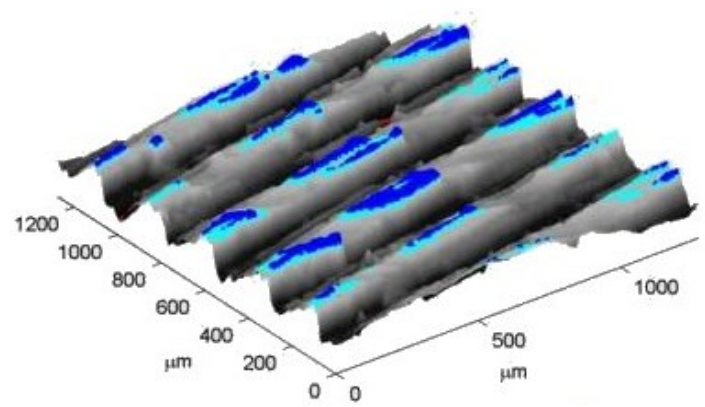

(b) Milled

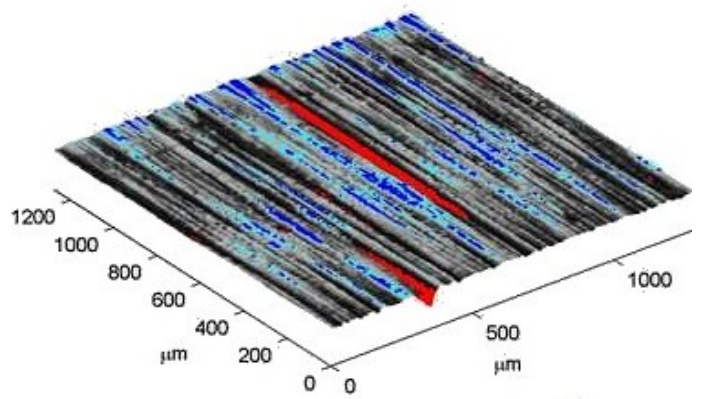

(d) Ground

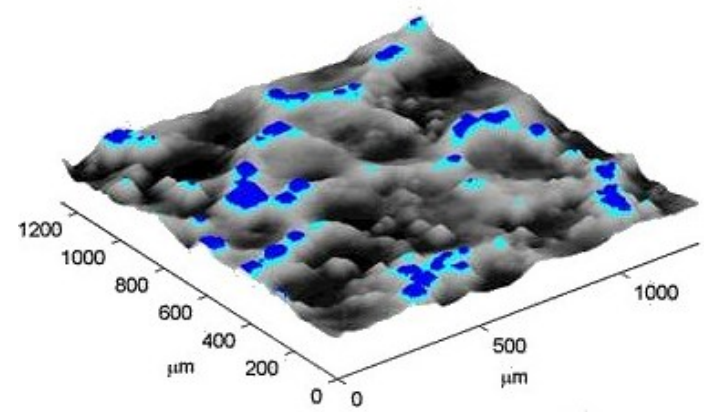

(f) Spark Eroded

Figure 1-1 Examples of machined surfaces [2]

bearings to name a few. In the above mechanical components, reduction in friction and the generation of load support is of paramount interest for most applications. Understanding the relationship between the surface topography and its functionality is vital for the design of a deterministic surface texture that is used to enhance functionality. 
In these cases, the deterministic surface textures/features are patterned surface features having arbitrarily specified geometries, low aspect ratios and having dimensions of the order of $10^{-5}$ to $10^{-6} \mathrm{~m}$. These surface features are also known as micro asperities. On fluid bearings and seals, control of lubrication properties using micro asperities can alter load capacity, friction torque, dynamic stiffness and damping coefficients among others. This in turn significantly affects energy consumption, reliability and vibrations in rotating machinery. The use of such deterministic surface features on mechanical components is one of the myriad ways available to the design engineer to improve its functionality and/or performance but if done correctly, has far reaching benefits above all other means. Although the micron scaled deterministic surface textures have shown to be of considerable use in certain applications, some macro scaled surface features have found widespread applications in mechanical face seal designs. Examples include sinusoidal waves [3], spiral grooves [4], radial grooves [5] and hydropads [6].

\subsection{Summary of previous research}

Hamilton et al.[7] published one of the earliest works on the application of deterministic surface features in 1966. That research described a theory of liquid lubrication applicable to parallel surfaces of a rotary shaft face seal. The lubrication mechanism was based on surface micro-irregularities and associated film cavities. A theoretical model for deterministic micro asperities was presented. Three surface texture patterns were photoetched onto the stator surface and load capacities were found experimentally. The theoretical results agreed quantitatively with the experiments for these asperity distributions. 
Anno et al. [8] published further research succeeding their previous work in 1966. In this work the theory of load support for micro asperity lubrication was further revised by hypothesizing small tilts on asperity tops. This hypothesis was attributed to the fact that for certain deterministic asperities, the authors found a huge difference between the theory and experimental results. Although direct evidence of the tilt hypothesis was lacking at that time, the authors demonstrated that the load support is even further increased when the tops of asperities are purposefully rounded and thus suggested the use of planned micro asperities as an effective method for lubricating the parallel faces of seals and thrust bearing surfaces.

Anno et al. [9] published further research on micro asperity lubricated face seals. In this work, theory and experimental work on the leakage of lubricant from micro asperity covered faces was reported. It was concluded that the leakage from micro asperity lubricated seals follows the predictions of Poiseuille flow, with the exception that a significant effect of rotor rotation is observed. However, significantly low leakage, typically of the order of $0.2 \mathrm{in}^{3} / \mathrm{hr}$ for a channel height of $10^{-4}$ in and a pressure drop of 10 psi across the seal face, was recorded due to the micro asperity lubricated seal face.

Etsion and Burstein [10] developed a mathematical model to allow performance prediction of all non-contacting mechanical seals having a regular micro-surface structure in the form of hemispherical pores. Seal performance such as equilibrium face separation, friction torque and leakage across the seal are calculated for a range of seal pressures, pore sizes and pore ratio of the ring surface area. An optimum pore size was found that depends on other variables and corresponds to maximum axial stiffness and minimum friction torque. 
Etsion et al. [11] developed a laser texturing method for fabricating hemispherical pores on the surface of a mechanical seal. Analytical and experimental investigation on the textured pore surface was done and the results of theory were in good agreement with experimental results. Also, the authors showed that a laser textured mechanical face seal was efficient in reducing the friction torque compared to an un-textured seal having same face pressure.

Wang and Kato [12] presented their work on texturing Silicon Carbide ( $\mathrm{SiC}$ ) seals operating in water for better performance. In this work, the stationary surface of the seal is textured using a Reactive Ion Etching (RIE) process. Experiments were carried out to evaluate the effect of micro-pits on the critical seizure load. The authors found that surface texturing is an effective way to stabilize friction, reduce friction coefficient and to expand the low-friction range of $\mathrm{SiC}$ seals working in water.

Stephens et al. [13] published numerical study, fabrication process and experimental results for a thrust surface. The fabrication process to manufacture such asperities were modified forms of the well know LIGA (a german acronym for Lithography, Electroforming and molding) process. Tribology tests in a non-pressurized oil bath indicated full-film conditions and show a $14-22 \%$ reduction in friction coefficient for a thrust surface covered with micro asperities. The numerical model confirms experimental trends and indicates potential to further reduce the friction coefficient through optimization of asperity geometry and layout.

Siripuram and Stephens [14] published a through numerical study of various types of deterministic asperities used throughout this thesis. The deterministic asperities found in this work were both positive (protruding) and negative (recessed) asperities on the 
surface. The results indicated that the friction coefficient is insensitive to asperity/cavity shape but quite sensitive to the size of the cross-section. The leakage rates are found to be quite sensitive to both cross-sectional size and shape with triangular asperities giving the smallest leakage rate and square asperities giving the largest leakage rate. The optimum asperity sizes that yielded lowest values of friction coefficients are reported.

\subsection{Glossary}

This section provides a succinct definition of commonly used terms found throughout this thesis.

Positive Asperities: These are micron scaled surface features of any arbitrary geometry that are in the form of protrusions on a surface.

Negative Asperities: These are micron scaled surface features of any arbitrary geometry that are in the form of cavities on a surface. Both positive and negative asperities usually have heights/depths in the range of 1-50 $\mu \mathrm{m}$.

Figure 1-2 illustrates typical profiles of positive and negative asperities. In this figure, ho is the film thickness of any lubricant film, $\mathrm{U}$ is the linear velocity of the slider, $\mathrm{t}$ and $\mathrm{s}$ are the dimensions of the unit cell and asperity respectively.

Unit Cell: A unit cell is an imaginary area surrounding a single asperity. In fig 1-2(c), the square forms a unit cell for the circular asperity. The concept of unit cell is particularly useful in theoretical modeling of the deterministic micro asperities. Note here that that unit cell may be of any geometric shape, a square is shown here for convenience. 


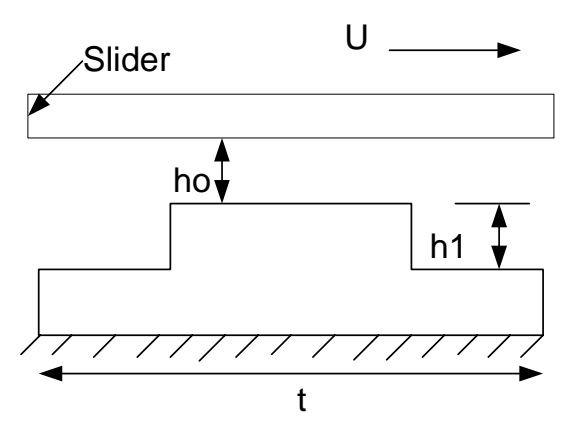

(a) Profile view of a positive asperity

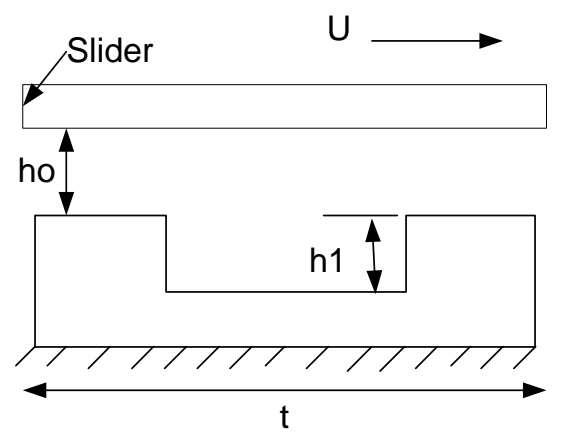

(b) Profile view of a negative asperity

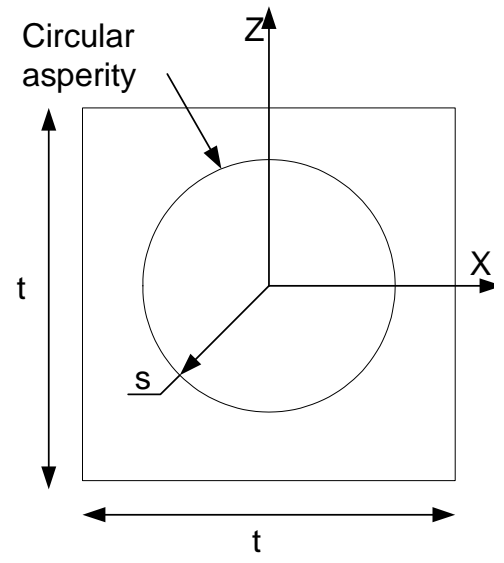

(c) Plan view of a single asperity showing unit cell

\section{Figure 1-2 Deterministic Micro asperities}

Asperity Area Fraction $\left(\delta^{2}\right)$ : This defines the relative size of any micro asperity. It is defined as the ratio of the area of the asperity to the area of its corresponding unit cell. In fig $1-2(\mathrm{c}), \delta^{2}$ is the ratio of the area of the circle to the area of the square.

Asperity Aspect Ratio: This is defined as the ratio of the asperity to its largest lateral dimension. In Fig 1-2, the aspect ratio of the circular asperity is $\frac{h_{1}}{2 s}$.

Asperity Density: is the number of asperities per unit area of the textured surface.

\subsection{Research Motivation}

It is of interest in this research work to characterize the surface textures on thrust load bearing surfaces. Earlier research at the Bearings and Seals Laboratory, University of 


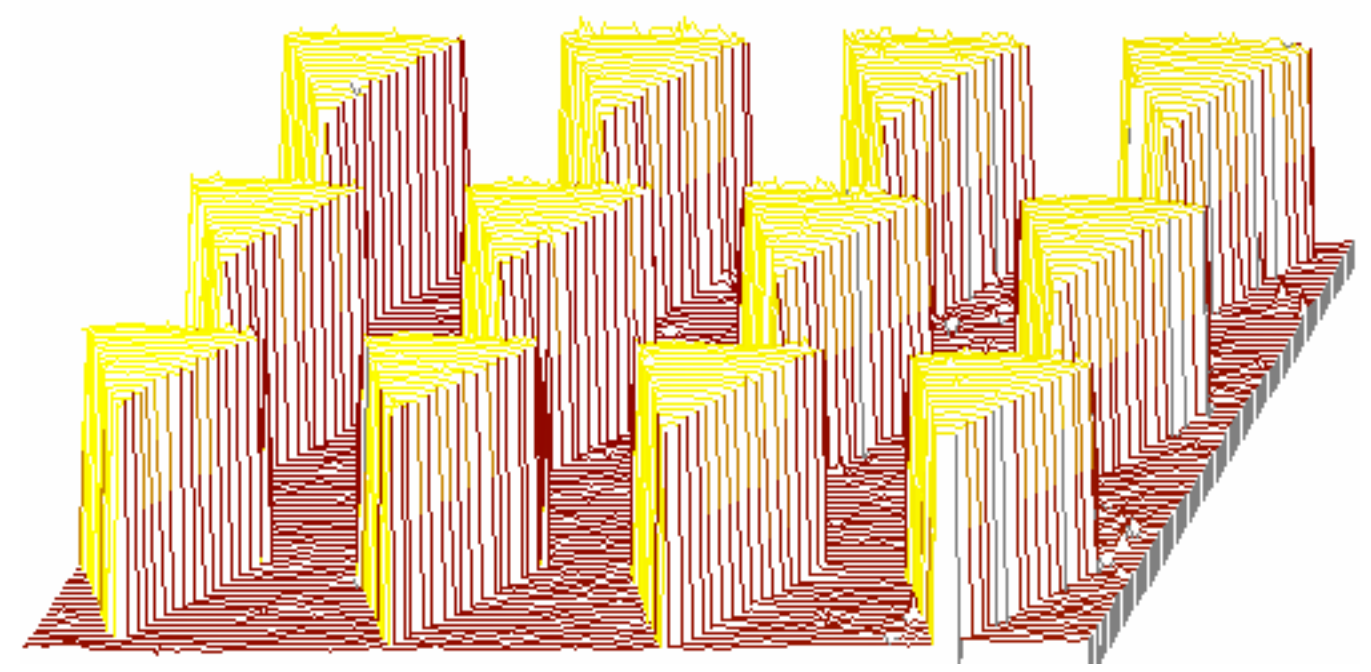

(a) Structured/deterministic surface texture

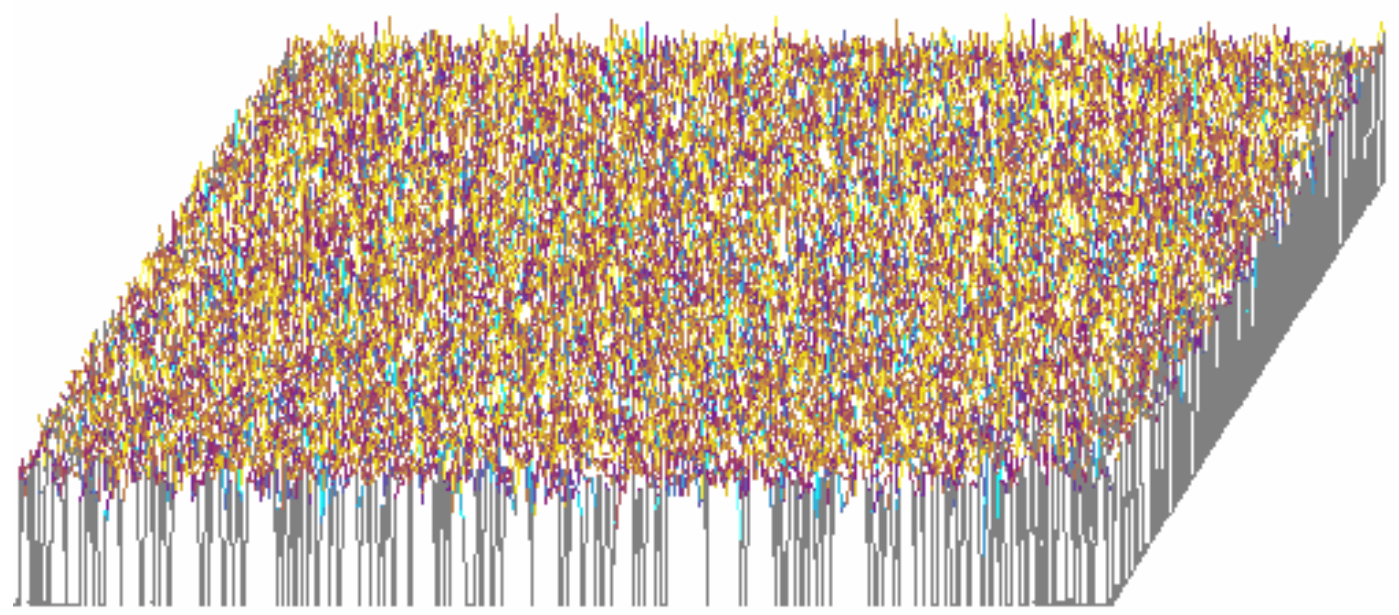

(b) Random surface texture

Figure 1-3 Structured and Random surfaces

Kentucky showed the benefits of a micron scaled deterministic surface texture operating under thrust load conditions [13]. The deterministic surface features were low aspect ratio structures with a repeatable pattern having dimensions in the micron scale. Further research resulted in a manufacturing process for the generation of such surface features [15] and theoretical modeling of the deterministic surface texture geometry [14]. These earlier works outlined a manufacturing process for fabricating the surface textures on a flat surface but a complete characterization of the manufacturing process and 
deterministic surface texture was not reported. Any metallic machined surface is comprised of random surface roughness that is characterized by random peaks and valleys. The difference between such a surface texture and a deterministic surface texture is that the deterministic surface has a well defined repeatable pattern of peaks and valleys that may be geometrically defined and the whole surface has a specific structure i.e. the surface is said to have a structured roughness. The randomly rough surface is not structured in that its peaks and valleys are randomly distributed and do not have a specific size or shape. Figure 1-3 are oblique plots obtained from an optical profiler showing the distinction between a structured/deterministic and a random surface. The deterministic surface texture consists of vertical peaks having a triangular cross section so that the geometry of the peaks is definable. Random surface roughness exhibit peaks and valleys that are randomly oriented having varying heights. The peaks here are also called asperities and the morphology of these asperities depend on the manufacturing process used to fabricate the surface.

Even a structured surface contains random surface roughness component that is impossible to eliminate but needs to be minimized. So in effect a deterministic surface texture is in reality a combination of a deterministic structure and the random surface roughness. In order to experimentally evaluate the effectiveness of the deterministic surface texture, the random surface roughness components have to be minimized so as to mitigate its effects on the surface functionality evaluation.

The deterministic micro asperities fabricated on thrust bearing surfaces typically have dimension in the range of $10^{-5}$ to $10^{-6} \mathrm{~m}$. This warrants an accurate and repeatable manufacturing process to successfully engineer the features onto the surface keeping in 
mind the stringent requirements for minimizing the random surface roughness. The deterministic texture fabrication process has to be thoroughly characterized through a detailed surface characterization of the deterministic features. This research presents a manufacturing procedure to fabricate deterministic micro asperities by reducing the random surface roughness. Also a detailed surface characterization of the fabricated surface texture is done to evaluate the effectiveness of the manufacturing process.

\subsection{Thesis Overview}

This thesis presents a detailed manufacturing process for the fabrication of deterministic asperities of arbitrary geometries on flat metallic surfaces (Chapter 2). A thorough surface characterization of the textured surface is performed (Chapter 3) outlining the tools and methods used to characterize the surface. During the surface characterization, certain errors in asperity geometry are identified and a statistical analysis is presented to evaluate the distribution of these errors and ascertain the process capability of the manufacturing process (Chapter 4). A sensitivity analysis of the effect of some of the errors on hydrodynamic lubrication of the textured surface is done to evaluate the impact of these errors hydrodynamic lubrication (Chapter 5). Finally main conclusions of this study and recommendations for future work are outlined (Chapter 6).

Copyright $\subset$ Sriram Venkatesan, 2005 


\section{CHAPTER 2- SURFACE TEXTURE FABRICATION}

\subsection{Overview of fabrication process}

Deterministic surface textures/microasperities on flat surfaces are manufactured by a variety of methods. Some of the techniques include photo-etching [7], Laser ablation [11], Reactive ion etching (RIE) [12] and LIGA [13]. Deterministic microasperities typically have low height to diameter ratio (aspect ratio) of the order of $0.001-10$ as compared to more commonly known radial grove, spiral groves and hydropads on mechanical seal faces, which may be classified as macroasperities. The low aspect ratio of these structures combined with its micron size make them impossible to fabricate using conventional machining and fabrication processes. The fabrication process developed in this thesis is largely based on improvements to earlier works presented in references [13] and [15]. The microasperities in this study are thousands in number and are in the form of oriented triangles and rectangles on the surface. The fabrication process is tailored from the well known standard MEMS fabrication processes.

The microasperities in this Thesis are fabricated on a Type 304 stainless steel disc having a diameter of $76.2 \mathrm{~mm}$. Figure 2-1 shows the surface texture patterns studied in this Thesis. Figure 2-1 shows triangular and square asperities having a $\delta^{2}$ value of 0.2 are fabricated using a process that is presented later in this Thesis. Figure 2-1(a) shows the thrust ring on which the textures are manufactured. Both positive and negative asperities having different shapes are fabricated. The area in-between and on asperities are polished smooth and has an average roughness of about $20 \mathrm{~nm}$. Scratches on these surfaces are clearly visible due to the high reflectivity of the surface. All visible scratches have dimensions in the sub nanometer range. 


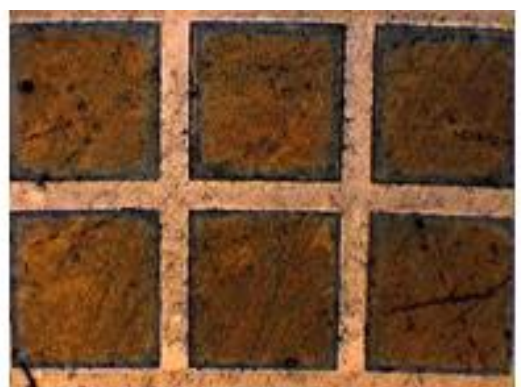

(b) Square Positive

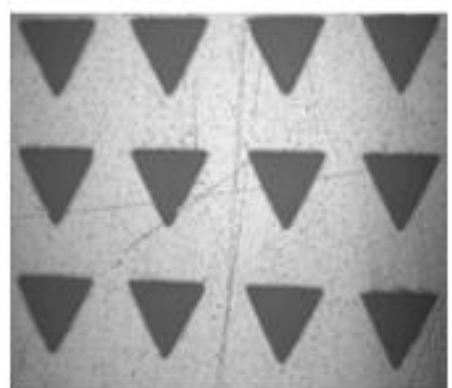

(c) Triangle Negative

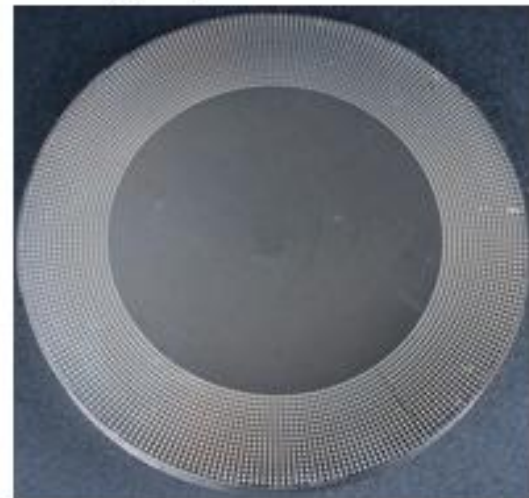

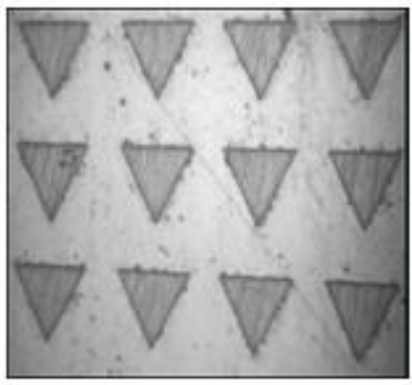

(d) Triangle Positive

(a) Thrust ring with surface textures

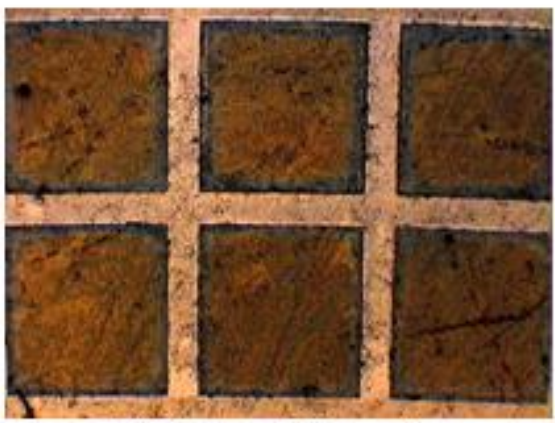

(e) Square Negative

Figure 2-1 Surface texture patterns studied in this Thesis

The specification for the thrust ring on which the deterministic surface texture is fabricated is shown in fig 2-2. A stainless steel disc having a diameter of $76.2 \mathrm{~mm}$ and a thickness of $6.35 \mathrm{~mm}$ is the substrate on which the deterministic features are to be fabricated. Note in fig 2-2 that the size of the square microasperities shown increase in the radial direction so that the asperity area fraction of each asperity remains constant from ID to OD. There are 4680 asperities in all that are arranged in 18 rows and 260 columns. The asperity area fractions $\left(\delta^{2}\right)$ for rectangular asperities are $0.1,0.4$, and 0.7 . 
For the triangular asperities, the $\delta^{2}$ values that are used in this study are $0.05,0.2$ and 0.3 . Complete specifications of both rectangle and triangle deterministic asperities are summarized in tables 2-1 and 2-2. These dimensional values are as specified by authors in [13] and [14] based on theoretical modeling and experience.

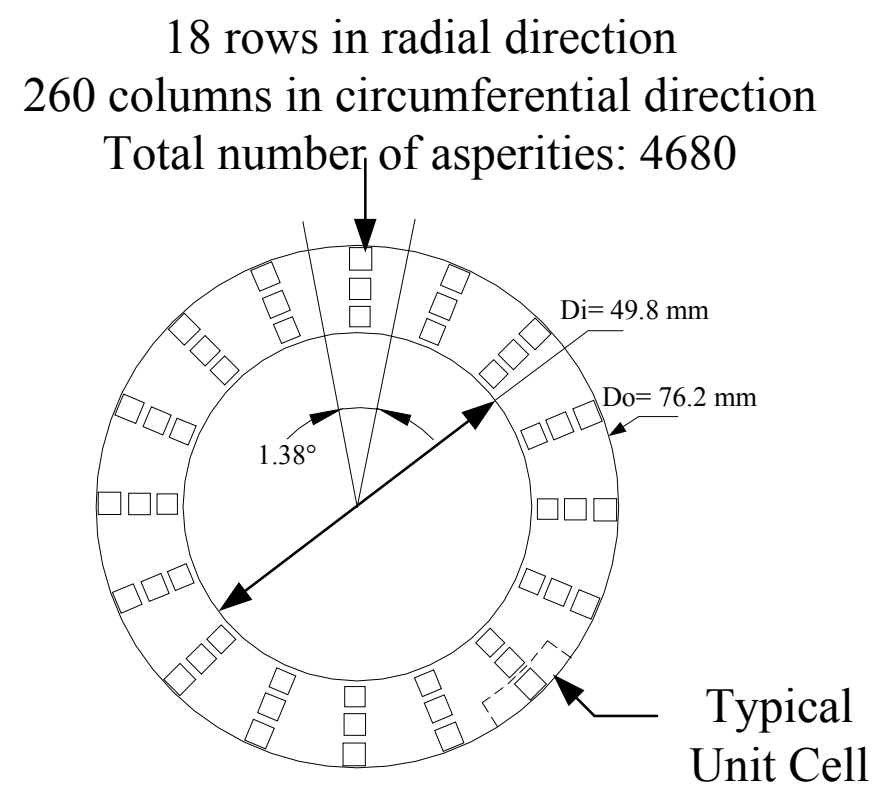

Figure 2-2 Distribution of asperities on SS thrust ring (not to scale)

The asperity density of the thrust surface is $1.71 / \mathrm{mm}^{2}$ and is constant for all the asperity shapes and sizes and hence the edge to edge spacing is different for each asperity. The asperity spacing decreases with increasing size of asperities in both radial and circumferential directions. The asperity area fraction indicates the coverage area of the asperities on the thrust ring. Note here that the fabricated asperities are concentrated on an annular region of the thrust ring having inner and outer radii of 38.1 and $24.9 \mathrm{~mm}$, respectively. The row of asperities near the average radii of the annular region denotes the average asperity dimensions. The area between the asperities is the surface area of the solid SS ring minus the surface of the asperities. 
Table 2-1 Properties of experimental thrust surfaces (Rectangles/Squares)

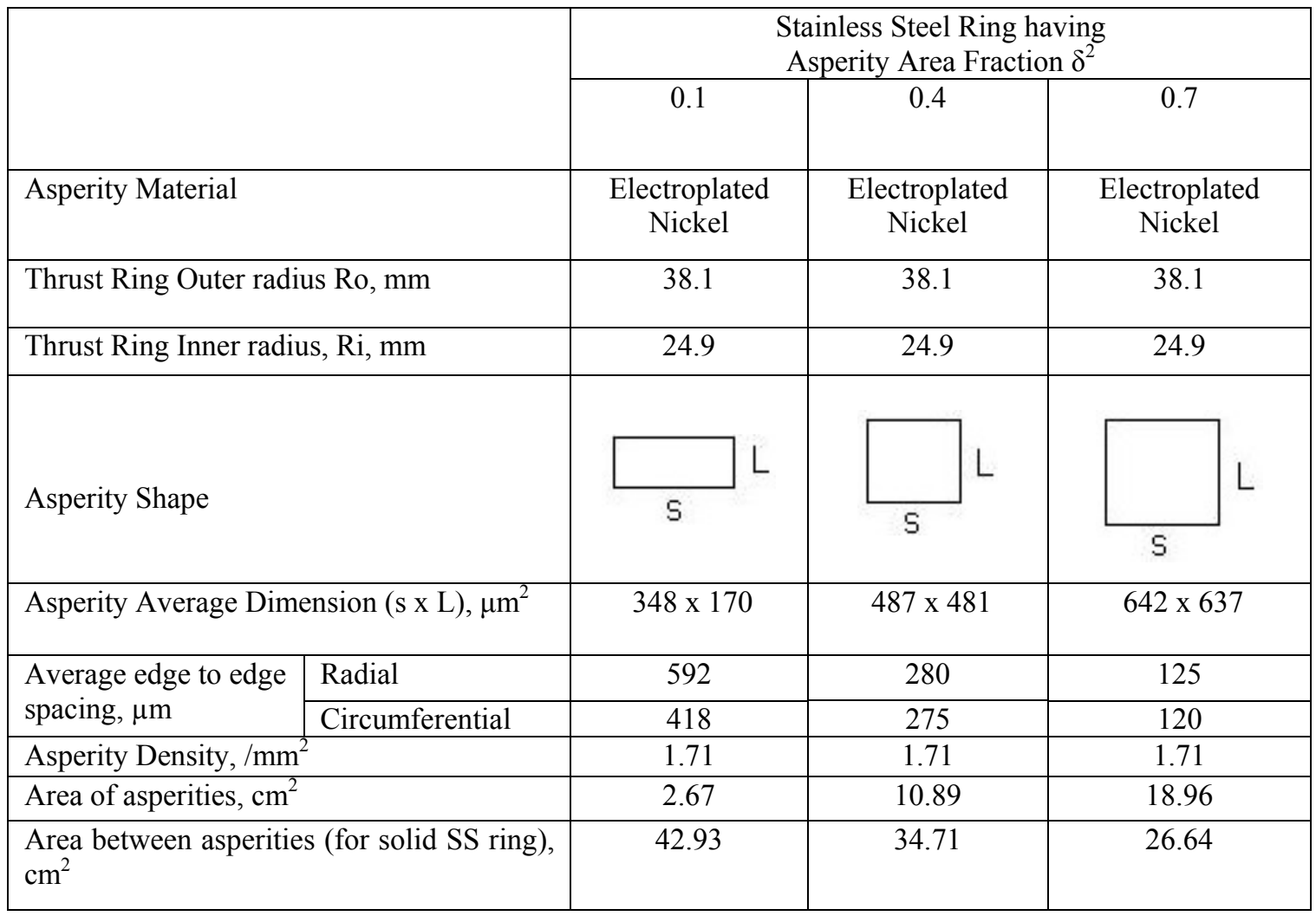

Table 2-2 Properties of experimental thrust surfaces (triangles)

\begin{tabular}{|c|c|c|c|c|}
\hline & \multicolumn{3}{|c|}{$\begin{array}{l}\text { Stainless Steel Ring having } \\
\text { Asperity Area Fraction } \delta^{2}\end{array}$} \\
\hline & & 0.05 & 0.2 & 0.3 \\
\hline \multicolumn{2}{|l|}{ Asperity Material } & $\begin{array}{l}\text { Electroplated } \\
\text { Nickel }\end{array}$ & $\begin{array}{l}\text { Electroplated } \\
\text { Nickel }\end{array}$ & $\begin{array}{l}\text { Electroplated } \\
\text { Nickel }\end{array}$ \\
\hline \multicolumn{2}{|c|}{ Thrust Ring Outer radius Ro, mm } & 38.1 & 38.1 & 38.1 \\
\hline \multicolumn{2}{|c|}{ Thrust Ring Inner radius, $\mathrm{Ri}, \mathrm{mm}$} & 24.9 & 24.9 & 24.9 \\
\hline \multicolumn{2}{|l|}{ Asperity Shape } & & & \\
\hline \multicolumn{2}{|c|}{ Asperity Average Dimension (s ), $\mu \mathrm{m}$} & 260 & 515 & 632 \\
\hline \multirow{2}{*}{$\begin{array}{l}\text { Average edge to edge } \\
\text { spacing, } \mu \mathrm{m}\end{array}$} & Radial & 502 & 243 & 127 \\
\hline & Circumferential & 780 & 764 & 749 \\
\hline \multicolumn{2}{|l|}{ Asperity Density, $/ \mathrm{mm}^{2}$} & 1.71 & 1.71 & 1.71 \\
\hline \multicolumn{2}{|l|}{ Area of asperities, $\mathrm{cm}^{2}$} & 1.28 & 5.37 & 8.1 \\
\hline \multicolumn{2}{|c|}{$\begin{array}{l}\text { Area between asperities (for solid SS } \\
\text { ring), } \mathrm{cm}^{2}\end{array}$} & 44.32 & 40.23 & 37.5 \\
\hline
\end{tabular}




\section{Electroplated Nickel}

Lapped Stainless Steel Ring

(A) NICKEL ELECTROPLATING

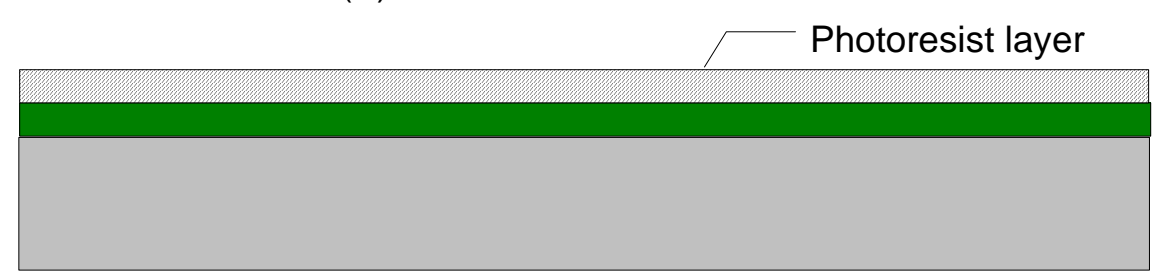

(B) SPIN COATING OF PHOTORESIST

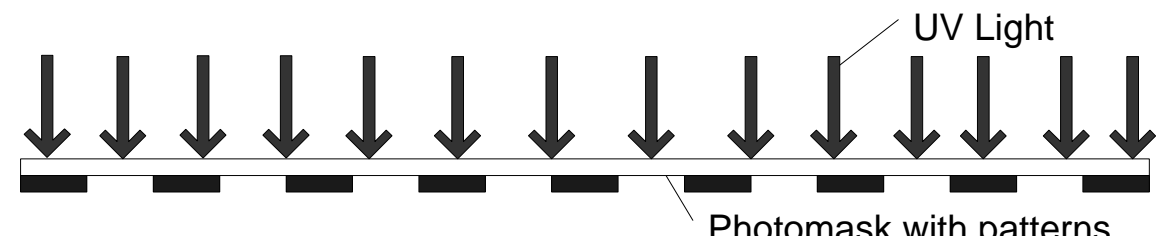

Photomask with patterns

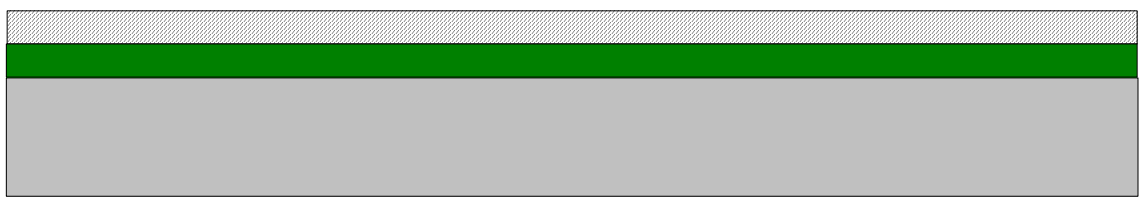

(C) PHOTORESIST EXPOSURE

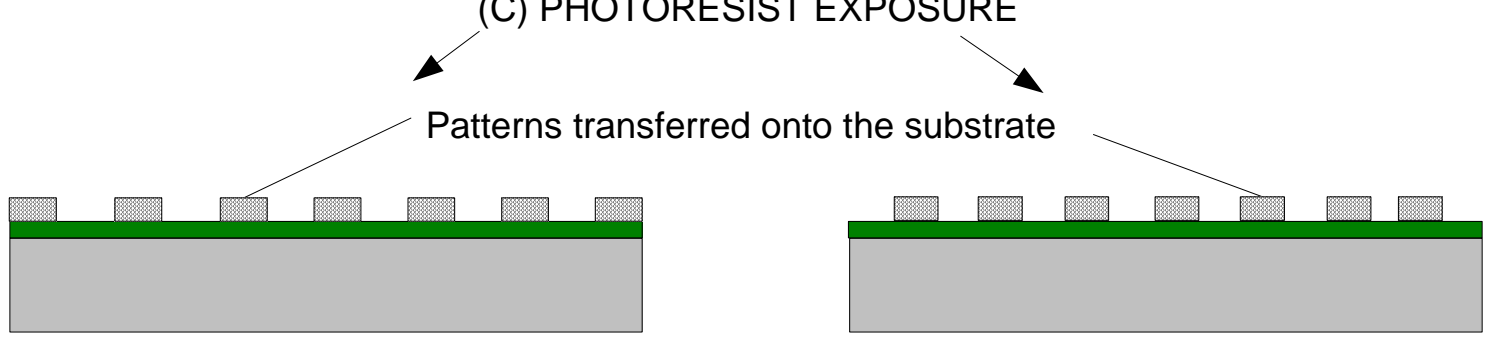

(D) PHOTORESIST DEVELOPING

Electroplated Nickel

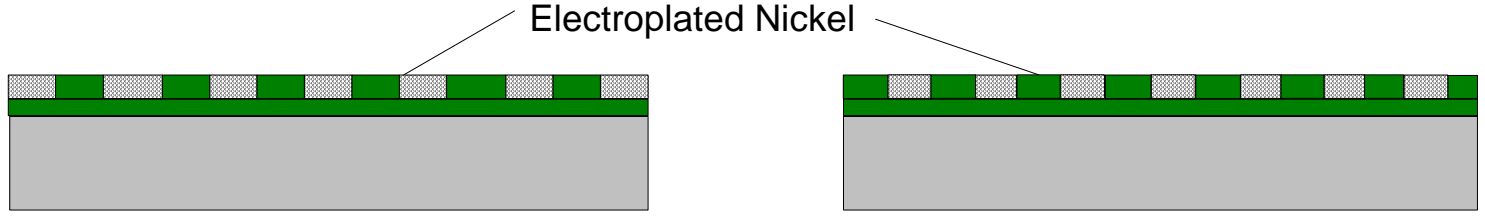

(E) NICKEL ELECTROPLATING

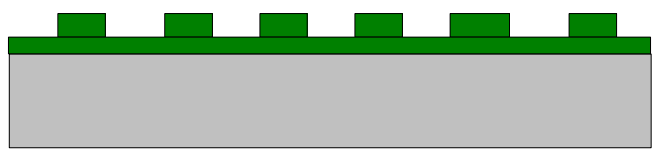

Positive Asperities

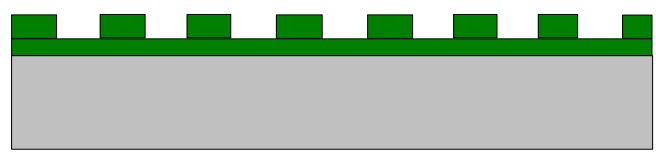

Negative Asperities

Figure 2-3 Schematic of surface texture fabrication process 
Figure 2-3 shows a schematic of the surface texture fabrication process. Both positive and negative asperities are fabricated on a stainless steel thrust ring. The features are nickel asperities on a nickel base layer. The nickel base layer is deposited to improve the adhesion of the asperities to the metallic substrate. The process starts by lapping the SS ring flat to within $0.5 \mu \mathrm{m}$. Then a nickel layer is electrodeposited onto the substrate. After lapping, the substrate surface is roughened by sand blasting or is polished using an abrasive grit sand paper. This improves nickel layer adhesion to steel through mechanical locking. The substrate is then coated with a photoresist which is a photo-polymer that is sensitive to Ultra violet light energy. A photomask made of ultra low expansion (ULE) glass having transparent regions similar to asperity patterns (triangular or rectangular array) is made and is aligned above the substrate using a specialized mask aligning machine. This setup is exposed to ultra violet (UV) rays having a wavelength of $365 \mathrm{~nm}$ generally known as i-line exposure. Due to the presence of the patterned mask, only certain area of the photoresist layers are exposed to UV light/energy viz, the area of the asperity pattern array on the mask. Depending on the type of photoresist, the exposed layer becomes stronger through chemical cross-linking or weaker due to breakage of molecular bonds in the polymer. The developing step uses a proprietary developer solution for the corresponding photoresist to wash away weaker sections of the photoresist layer. This leads to the possibility of two sets of pattern configurations after nickel electro deposition, positive asperities and negative asperities. When the exposed photoresist layer becomes weak, the exposed part is dissolved after UV exposure and developing and nickel electro deposition yields positive nickel asperities and vice versa. The height of these asperities is determined by the rate of nickel electroplating and the 
height is further controlled using polishing techniques. Each step in the above process is further detailed in subsequent sections.

\subsection{Lapping}

Lapping is a process of material removal done by means of loose abrasive applied between the surface of the work and tool, without positive guidance of the work and usually resulting in a finish of multi-direction lay [16]. The lapping process also makes any workpiece flat and parallel. Figure 2-4 shows a photograph of a LAPMASTER ${ }^{\circledR}$

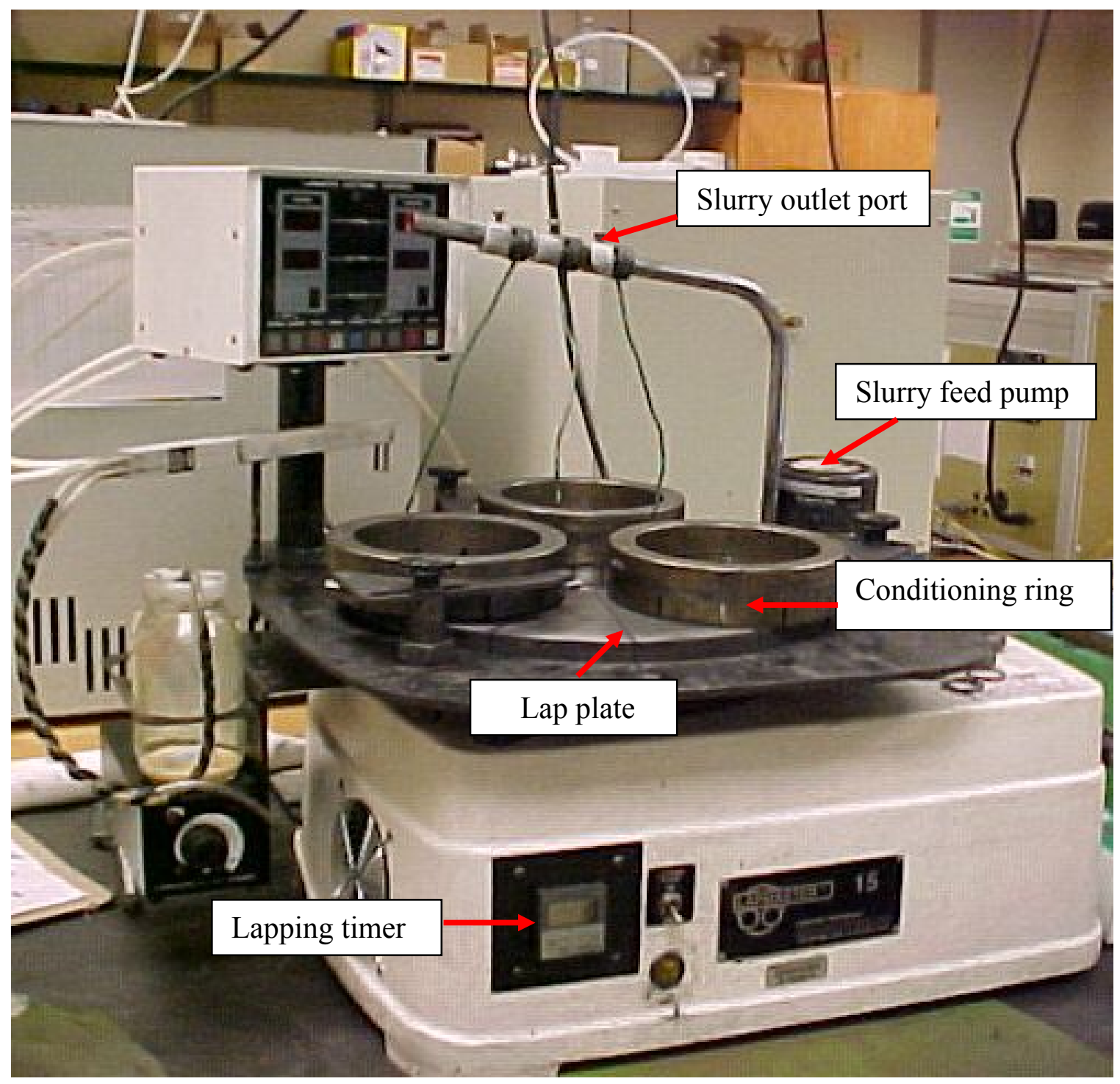

Figure 2-4 LAPMASTER Model 15 lapping machine 
Model 15 bench lapping machine. The main components of a lapping machine are a base, a lap plate and a motor to drive the lap and a pump to feed the abrasive slurry. The workpiece to be lapped is mounted on the lap plate by means of a 'conditioning ring' that basically restrains the motion of the workpiece. As the lap rotates, the friction between the lap and the conditioning ring causes the ring to rotate. The abrasive/lapping slurry is a mixture of Aluminum oxide and a proprietary oil based 'vehicle' in the ratio of 1 pound of abrasive per gallon of vehicle. The average size of aluminum oxide particles is $12 \mu \mathrm{m}$ and these particles act as tiny micro tools having sharp edges that aid in stock removal. An abrasive having a smaller particle size is chosen to obtain finer surface finishes at the expense of removal rate. A pressure of 2-3 psi is applied on the workpiece and the lapping slurry is squeezed between the lap plate and the workpiece resulting in stock removal from the work surface. The 'vehicle' acts as a lubricant to reduce heat generated by the work being performed and slows down the rate at which the abrasive wants to roll off the lap due to centrifugal force.

The lapping process is a little more complicated than rubbing two metal plates together with abrasive between them. Lapping is more an art than it is a conventional machining process. A number of parameters affect the consistency of results obtained when lapping parts for flatness. It is often difficult to derive numbers for optimum machining condition and use them to obtain consistent results. However, ballpark estimates of near optimum conditions are available from lapping equipment manufacturers based on experience.

\subsubsection{Variables affecting the lapping process}

The most important variables that are critical during flat lapping of any workpiece are 
1. Flatness of the lapping plate- the flatness of a lapped sample is only as good as the flatness of the lapping plate.

2. Application of uniform and predictable pressure- Pressure on the workpiece must be uniform and quantifiable based on the surface area of the workpiece to be lapped. As stated earlier, an optimum pressure of around 2-3 psi produces consistent results.

3. Applying and maintaining a uniform flow of abrasive [17].

Apart from these three important variables, flatness is also affected by quality of abrasive used, temperature fluctuations, cleanliness of lap plate, conditioning rings and workpiece and operator skill.

\subsubsection{Flat lapping stainless steel substrate}

A perfectly flat surface is a geometric plane on which a pair of randomly selected points is connected by a straight line such that the line is entirely contained in the plane. In other words a flat surface is a two dimensional figure with zero thickness. In practice it is impossible to achieve a perfectly flat surface but out of flat tolerances of the order of millionths of an inch or sub-micron scale is achievable. Any surface having a tolerance of this order is considered a 'flat' surface. A procedure followed to flat lap a SS substrate is detailed in this section.

Before even lapping the substrate on the machine, the lap plate flatness has to be checked and the profile of the lap plate has to be quantitatively ascertained. The lap plate may be concave, convex or toroidal depending on prior use of the machine or on the previous sample lapped. A flatness gauge is used to measure the out of flatness of the lap plate. 


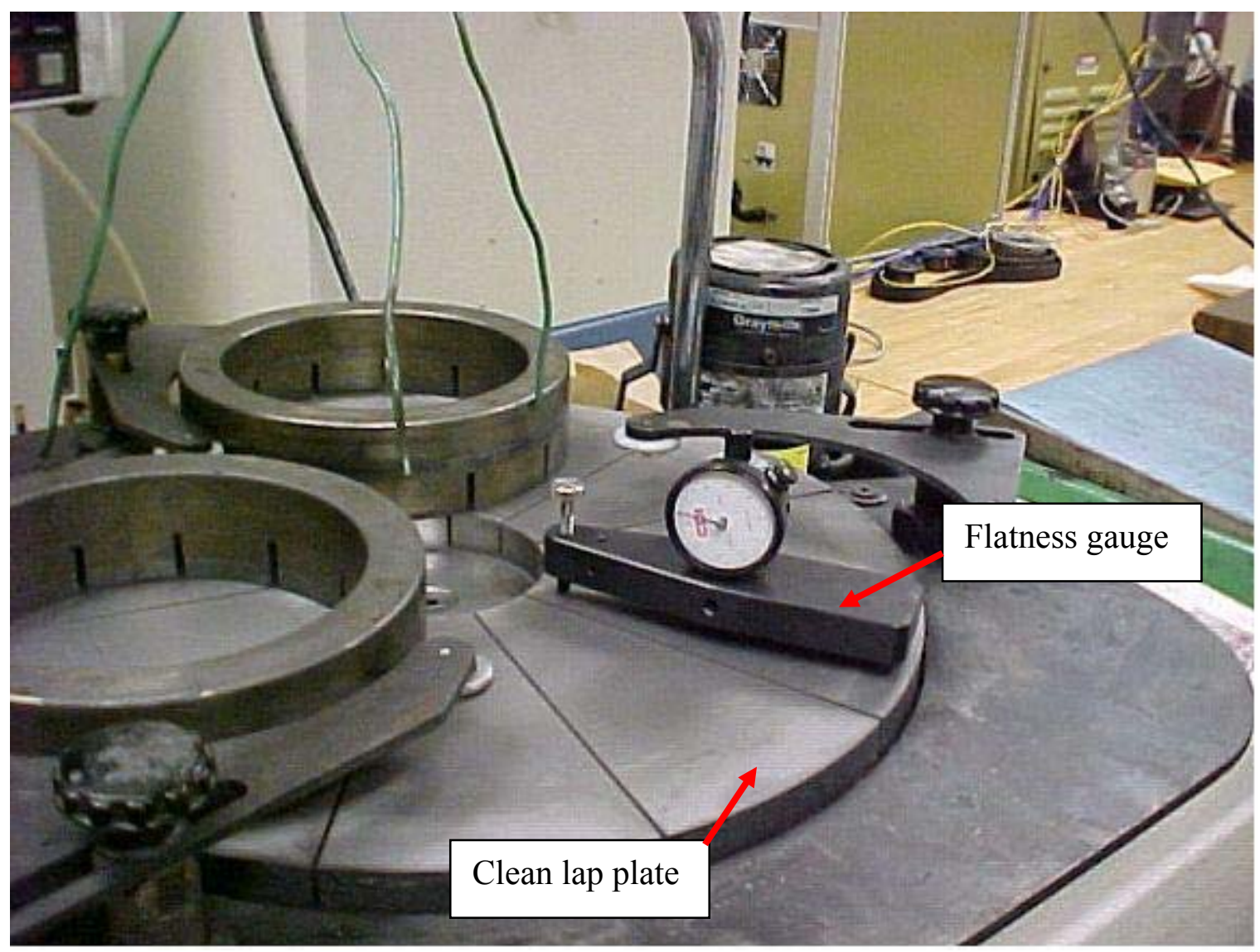

Figure 2-5 Checking lap plate flatness

The flatness gauge is calibrated by placing it on a master flat and zeroing the dial indicator reading so that the master flat provides a flat reference surface. Figure 2-5 illustrates the placement of the flatness gauge on the lap plate to check for lap plate flatness. The dial reading on the gauge is noted. The pointer will show a positive, negative or zero readout. A positive readout indicates that the lap plate has an out of flat profile that is convex. A negative reading indicates concavity and zero readout indicates perfect flatness with respect to the reference. The gauge is placed both in the radial and tangential direction on the lap plate and dial readings are noted. An out of flat lap plate has to be 'conditioned' or adjusted for flatness before lapping. A convex lap plate is conditioned by slightly moving the conditioning rings towards the ID of the lap plate and 
running the machine with abrasive flow so as to preferentially wear the lap plate. Similarly for a concave lap plate is conditioned by moving the conditioning rings outwards. The time of conditioning depends upon the degree of concavity or convexity of the plate. After conditioning for some time, the lap plate is again checked for flatness and lapping should not be started till the flatness gauge dial reads close to zero.

Once the lap plate is properly conditioned, it is ready for flat lapping samples. The conditioning ring is filled with dummy rings and the SS substrate as shown in fig 2-6. Note that the conditioning ring has to be filled with parts of almost same thickness in order to apply uniform and predictable pressure during the lapping process. After mounting the substrate on the lap plate, appropriate weights are applied on the sample so as to apply uniform pressure on the specimens.

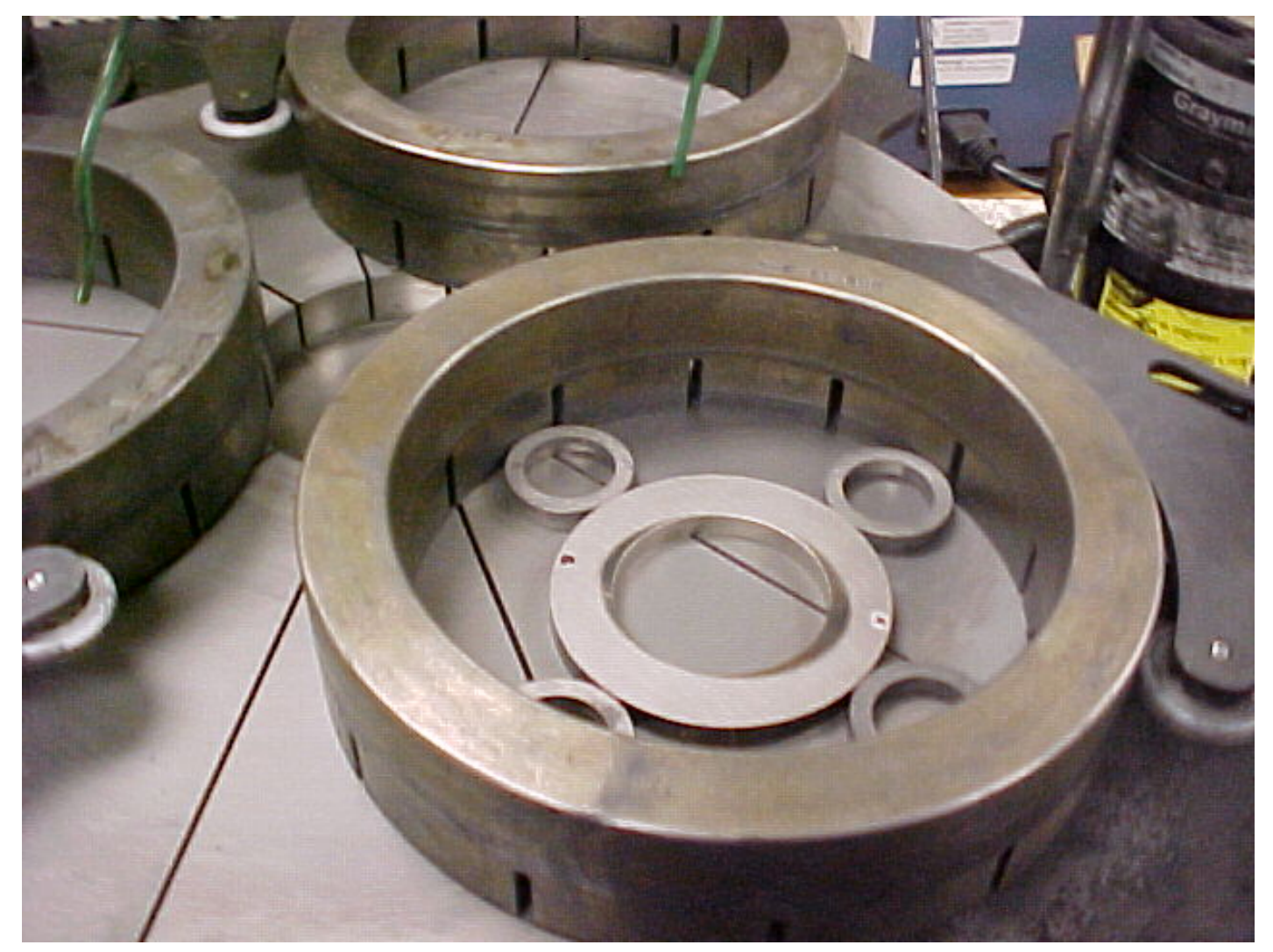

Figure 2-6 Mounting substrate in conditioning ring 
The lapping machine is started and uniform slurry is made to drip on the lap plate through the slurry outlet ports. The sample is lapped for 10 minutes and the flatness is checked. The lap plate flatness is also checked from time to time as the plate experiences uneven wear during the course of the lapping cycles. Note that lapping a part for a long time does not make it flat but worsens its flatness so if the flatness of a sample is not improving, the flatness of the lap plate has to be checked before further lapping.

\subsubsection{Measurement of flatness using optical flat}

The term commonly used to specify flatness of a surface is 'light band'. Light bands are commonly measured using a monochromatic light source (helium) and an optical flat. The wavelength of helium light is 23.2 millionths of an inch and one light band is equal to half this value i.e. 11.6 millionths of an inch. So a flatness of one light band means that the total deviation from a perfectly flat surface is 11.6 millionth of an inch or $0.29 \mu \mathrm{m}$.

The part being inspected is cleaned and polished to adequate reflectivity on a polishing pad. It is then placed under the monochromatic light source and the optical flat is positioned on the surface to be checked. Alternate light and dark light bands shown in fig 2-7 are seen when the surface is viewed through the optical flat. The width of the bands depends on the thickness of the air wedge between the part surface and the optical flat. The width of the bands or number of bands does not change the surface measurement. The surface shown in the figure is flat to within 2 light bands. The curvature of these bands indicates the measure of flatness of the surface. A perfectly flat surface would exhibit straight parallel light bands. Any curvature in the light bands indicates that the surface has deviated from absolute flatness. An in-depth reference for measuring flatness and interpreting light bands is found in [16]. 


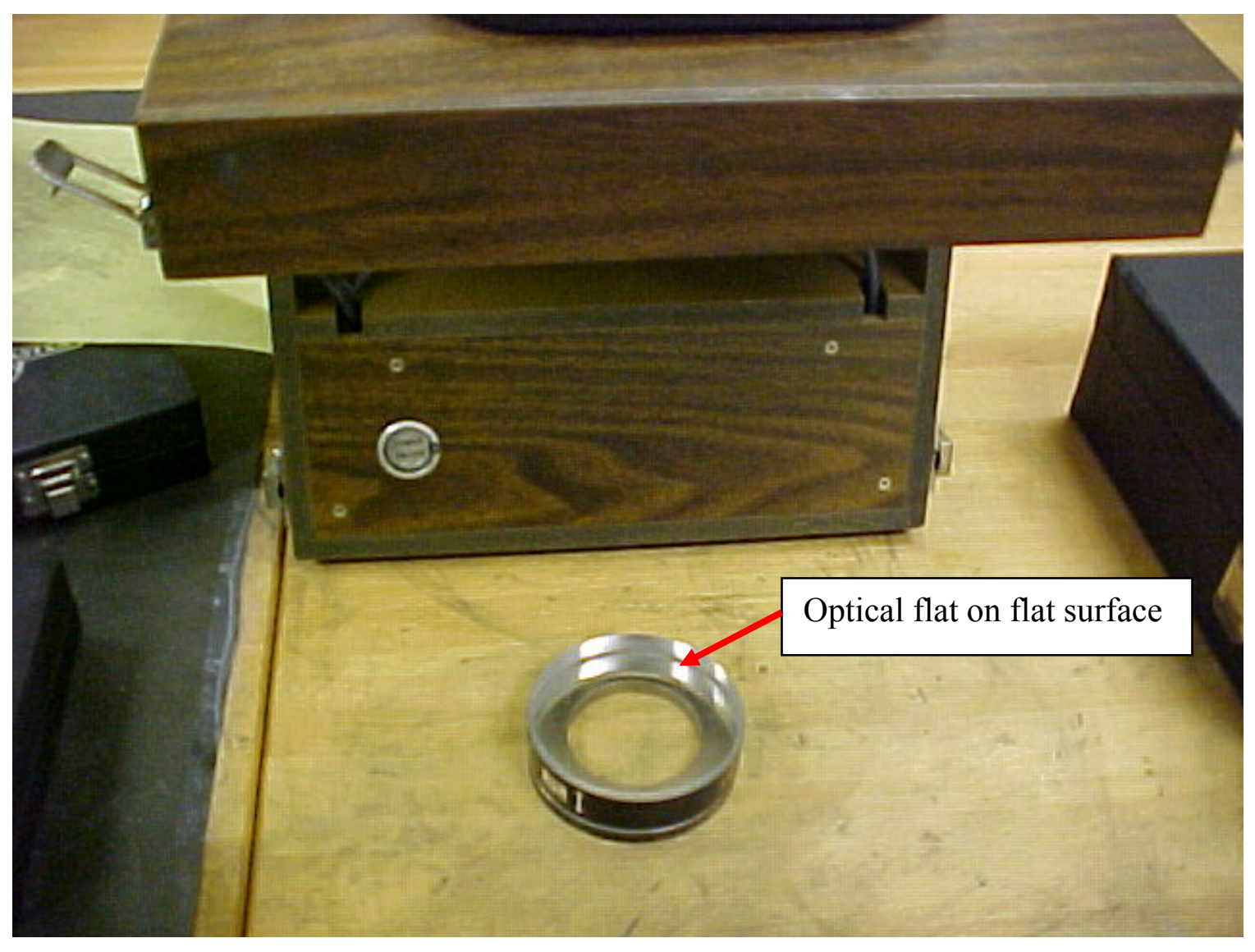

Figure 2-7 Light bands on a surface

\subsection{Polishing}

The surface of the substrate after lapping has a scratch free dull matte finish with low reflectivity. Also the random surface roughness is limited by the size of abrasive used to around $0.1 \mu \mathrm{m}$. But it is of interest to minimize the random surface roughness to practically as low as possible preferably to the atomic scale. Chemical Mechanical Polishing (CMP) is one technique used to polish the substrate surface to smooth mirror finish and roughness values in the range of $10 \mathrm{~nm}$. A refurbished STRAUSBAUGH ${ }^{\circledR} 6 \mathrm{CA}$ CMP machine is used to polish the substrate to a smooth finish. The abrasive slurry used is colloidal silica having an average particle size of $15 \mathrm{~nm}$. Due to high pressures during 
the CMP process and a combined action of chemical and mechanical polishing, the substrate surface gets a smooth mirror finish and ultra low roughness.

The substrate is polished in the CMP machine for 15 minutes and the substrate surface is ultrasonically cleaned to remove traces of colloidal silica from the substrate surface.

\subsection{UV Photolithography}

The UV photolithography process is a widely used technology for effective pattern transfer in integrated circuit (IC) fabrication [18]. In this process, small features of submicron dimensions are fabricated by patterning a photo sensitive polymer called the photoresist. The photoresist is a material that is sensitive to ultra violet or any other high energy low wavelength radiation like X-rays and gamma rays. The minimum feature size is limited by the wavelength of the exposure source $(365 \mathrm{~nm}$ in the case of normal UV radiation). The principle concept of a photolithography process is based on the fact that the properties of a photoresist are chemically altered when exposed to high energy radiation. Hence, when the photoresist layer is exposed to these radiations in the presence of a patterned photomask, the patterns on the photomask are transferred on to the photoresist layer after exposure and subsequent processing. The subsequent processes usually are photoresist developing, metal deposition and photoresist liftoff.

Two types of photoresist exists namely positive photoresist and negative photoresist. The main difference between the two is the chemical changes that take place within the photoresist when exposed to UV radiation. Exposed positive resists tends to become weaker due to the breakage of molecular bonds within them and exposed negative resists become stronger due to chemical cross-linking. The resists used in this Thesis are 
Shipley 1813 positive photoresist from ROHM and HAAS ${ }^{\circledR}$ Electronic Materials, to fabricate positive asperities and

NANO $^{\text {TM }}$ SU-8 10 negative photoresist from MICROCHEM ${ }^{\circledR}$ Corporation, to fabricate negative asperities.

The deterministic surface texture pattern is first crated using AutoCAD ${ }^{\circledR}$ drafting package and this pattern is transferred on to a ultra low expansion glass surface that acts the photomask. Figure 2-8 shows optical micrographs of small cross sections from a typical photomask. The dark triangles in the figure are transparent sections through which UV radiation passes.

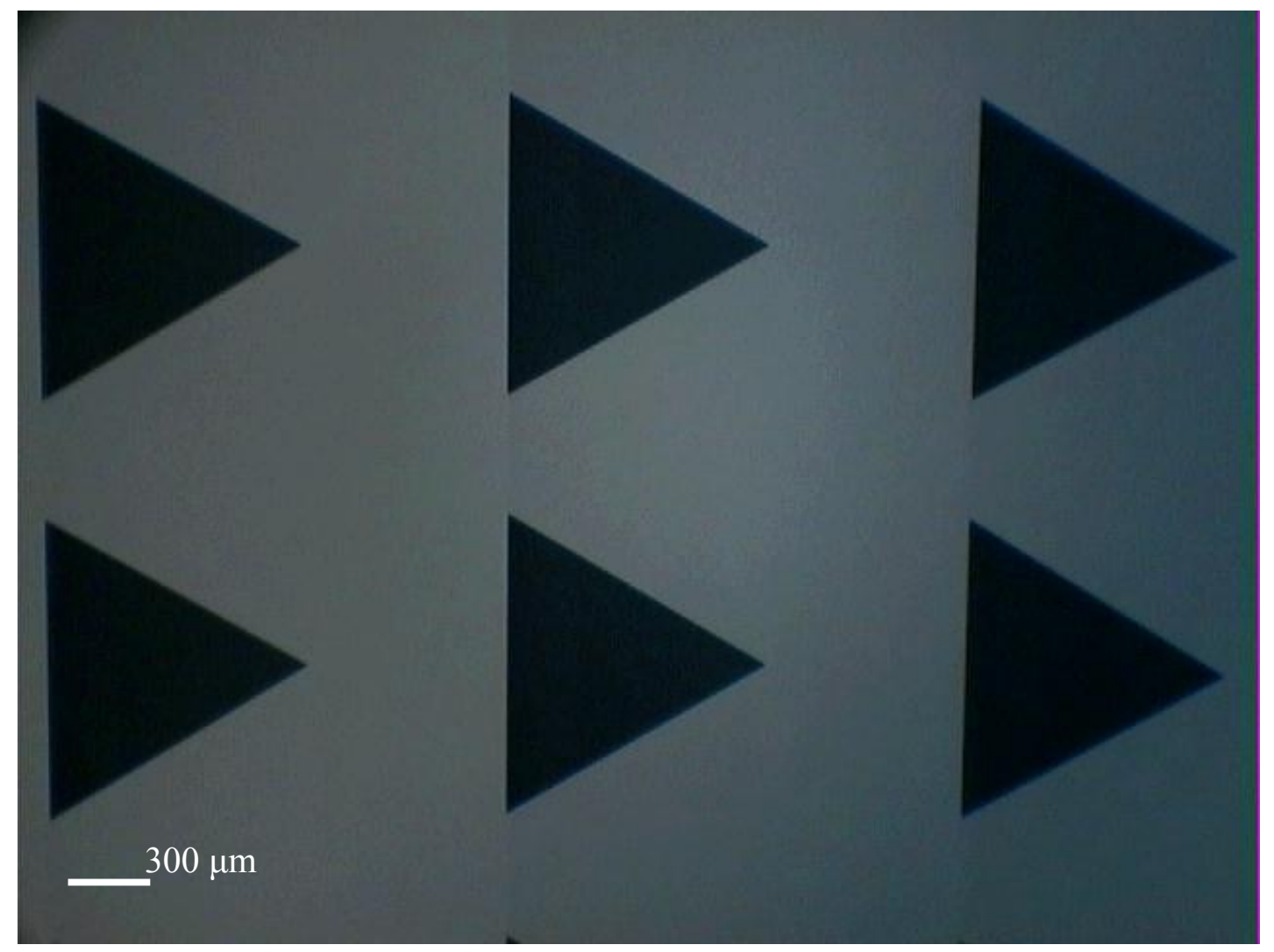

Figure 2-8 Photomask of triangle pattern, $\delta^{2}=0.2$ 


\subsubsection{Spin Coating and baking of photoresist}

The SS substrate surface is cleaned thoroughly using isopropyl alcohol (IPA) and acetone, rinsed with de-ionized (DI) water and dried by blowing a stream of compressed air or nitrogen gas. The photoresist layer is coated onto the substrate by a spin coating process where a known volume of resist is dispensed on the substrate surface and the substrate is spun on a spin coater at a specific speed. A uniform layer of the resist results due to centrifugal forces during spinning. The thickness of this layer largely depends on the spin speed and viscosity of the photoresist. The spin speeds and properties of the resists used to fabricate surface textures are outlined later in this Chapter.

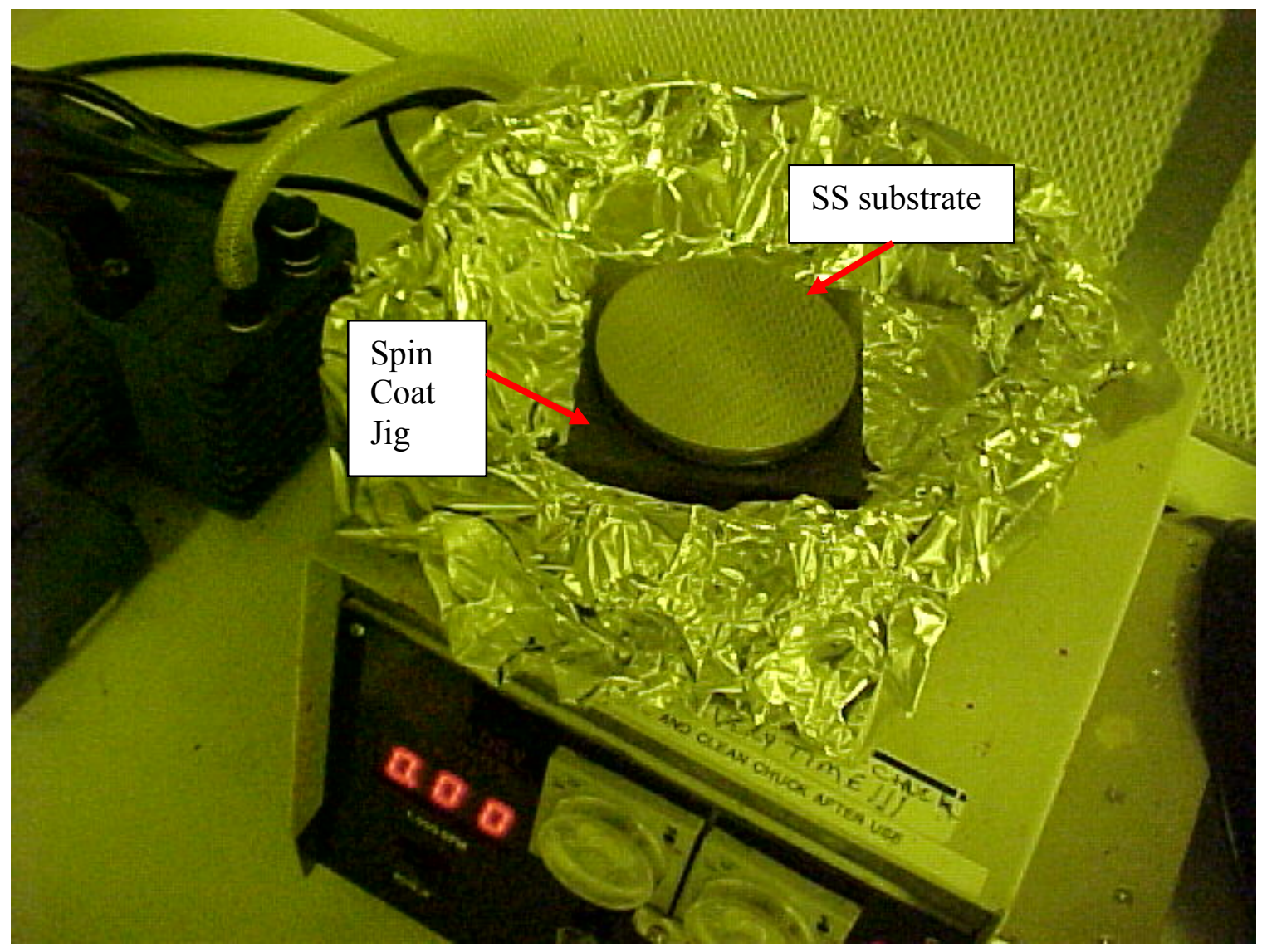

Figure 2-9 Mounting the substrate on spin coater 
Figure 2-9 illustrates the sample mounted on the spin coater. The spin coater is held on the rotating vacuum chuck by means of suction pressure between the vacuum chuck grooves and the substrate. The spin coater jig is used to center the round substrate on the vacuum chuck so that the center of the substrate coincides with the axis of rotation of the vacuum chuck. The desired spin speed is set and $1 \mathrm{ml}$ of resist for every inch of substrate diameter is dispensed onto the substrate surface. The spin coater top is covered and the spinner is set to rotate to complete the spin coat cycle.

After spin coating, the resist needs to be baked on a conventional level top hot plate. Any photoresist consists of three components namely polymer, solvent and sensitizers [18]. The polymeric phase is used to change the structure of the resist when exposed to UV radiation. The solvent allows for spin coating applications and the sensitizers control chemical reaction in a polymeric phase. The baking step is done to drive away the solvent phase from the photoresist. Baking times and temperatures are indicated later in the Chapter.

\subsubsection{UV Exposure}

Exposure of the baked resist layer is done on a mask aligner. The mask aligner has the capability of both UV exposure and accurately aligning the photomask to the substrate. Figure 2-10 shows a picture of a KARL SUSS $^{\circledR}$ MJB 3 mask aligner. The main components of the mask aligner are UV lamp, power supply unit for the lamp, control panel to set exposure properties, a microscope, mask holder and $\mathrm{X}-\mathrm{Y}-\theta$ stage for substrate-mask alignment. The photomask is held in vacuum contact on the mask holder and the substrate is fixtured on the $\mathrm{X}-\mathrm{Y}$ table by a substrate holder. The distance between the mask and the sample is adjusted so that there is absolute contact between them. 


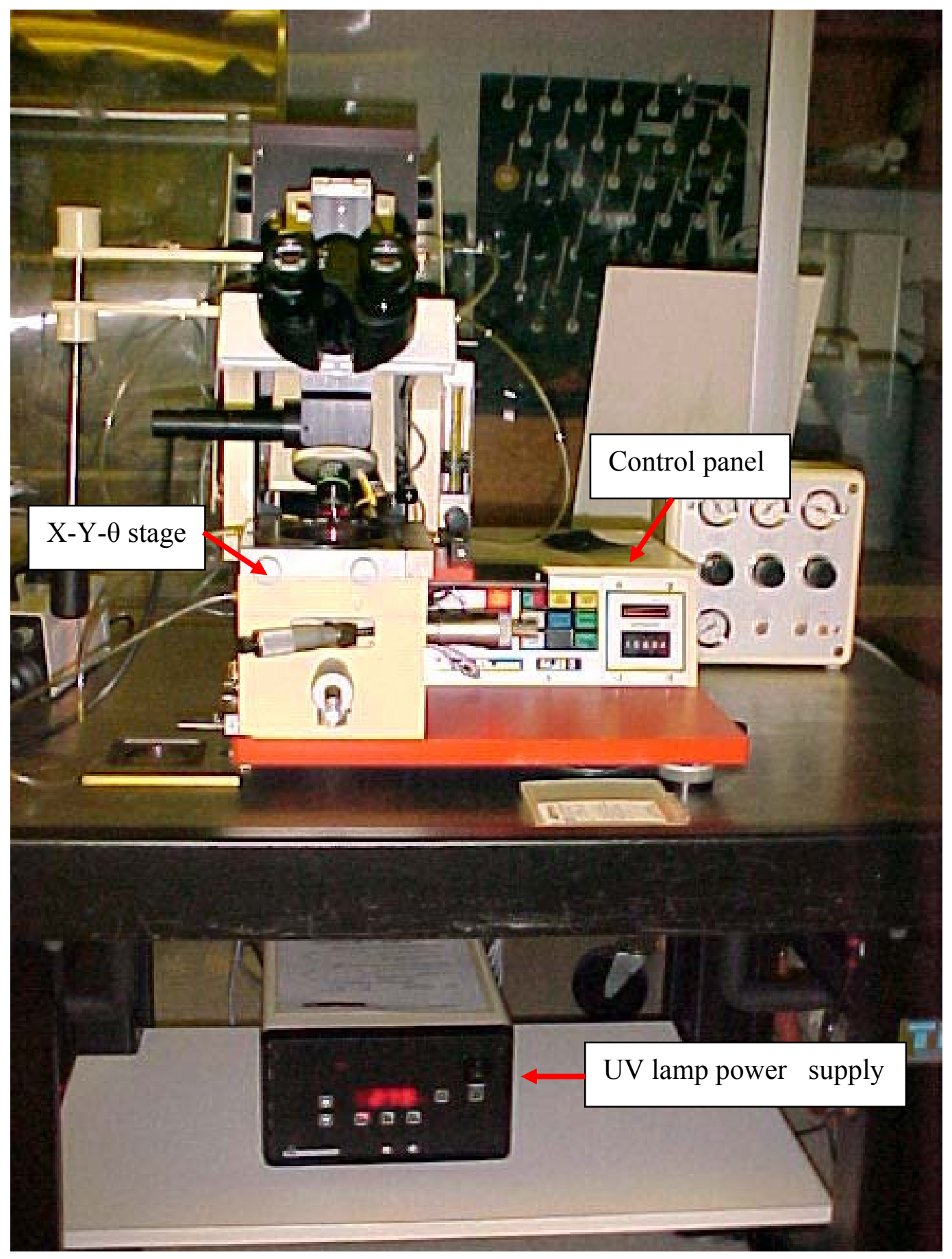

Figure 2-10 KARL SUSS MJB3 mask aligner

The exposure time is calculated based on the exposure energy of the UV radiation. The intensity of UV light (in $\mathrm{mW} / \mathrm{cm}^{2}$ ) multiplied by the time of exposure (sec) gives the total radiation energy (in $\left.\mathrm{mJ} / \mathrm{cm}^{2}\right)$ [18]. 


\subsubsection{Photoresist developing}

After exposure, the exposed photoresist will have undergone chemical changes and the unnecessary regions on the resist need to be etched away. A proprietary developer solution is used to dissolve unexposed/exposed resist depending on the type of photoresist. As stated earlier, for a positive resist, the exposed portion is dissolved after developing and vice versa for a negative photoresist. Also, a post exposure bake step is necessary in the case of a negative photoresist to initiate complete cross-linking of the exposed polymeric phase. After the developing step, a polymeric mold is created on which nickel is electrodeposited to yield nickel microasperities.

\subsection{Nickel Electroplating}

The next step after fabricating the polymeric mold is to electro deposit metal on regions of the mold where the substrate surface is exposed. It is of interest in this research to get nickel microasperities hence nickel is deposited by electroplating. Electroplating is a deposition process based on the principle that when a metal is immersed in a solution of its ions, it attains a specific electrical potential which is characteristic of that particular metal and the concentration of the metal ion [19]. When direct current is made to flow between two electrodes immersed in a conductive aqueous solution of the metal salt, causes one of the electrode to dissolve (anode) and the other electrode to become coved with the metal (cathode). In nickel electroplating, the conductive electroplating solution is nickel sulfamate solution. Nickel pallets or rounds are made the anode and the substrate is made cathode. Cleanliness of the substrate surface is vital for the electroplating process. The surface must be free of dust, oil and oxidation layers that passivates the surface and does not allow nickel ions from the anode to be deposited. 
The nickel electroplating is a three step process namely $\mathrm{C}-12$ activation, Nickel strike in Wood's nickel bath and the actual nickel plating in nickel sulfamate solution. Note that this three step procedure is used for electroplating nickel on stainless steel. For electroplating nickel on an older plated nickel layer, only C-12 activation and nickel electroplating need to be done.

\subsubsection{C-12 Activation}

Figure 2-11 shows a schematic of the circuit used to perform the $\mathrm{C}-12$ cleaning. The activation process is done to remove oxidation layer on the metal substrate. The C-12 solution is prepared by mixing C-12 activator from Puma Chemical ${ }^{\circledR}$ with dilute

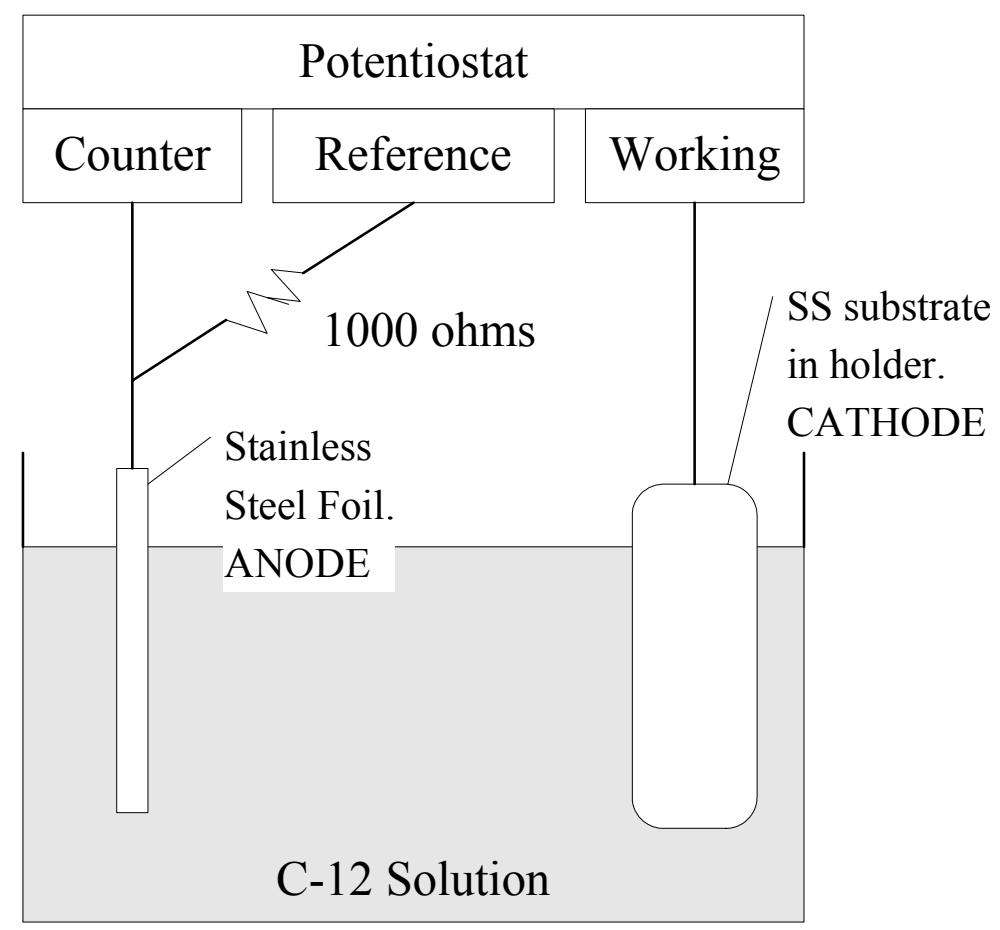

Figure 2-11 C-12 Activation 
sulphuric acid and DI water until the $\mathrm{pH}$ of the solution is 1.5 [20]. Stainless Steel foil is used as anode and the stainless steel substrate is held in a polycarbonate holder that is the cathode. A negative potential of $2 \mathrm{~V}$ is applied between the counter (anode) and working(cathode) electrodes through a potentiostat. A $1000 \mathrm{ohm}$ resistor is included between the counter and reference electrode based on the potentiostat manufacturer's recommendation. The purpose of the resistor is to limit the current applied between the reference electrode and simultaneously maintain a constant voltage between the anode and cathode. The activation is done for 1 minute with strong agitation in the solution.

\subsubsection{Nickel strike in Wood's solution}

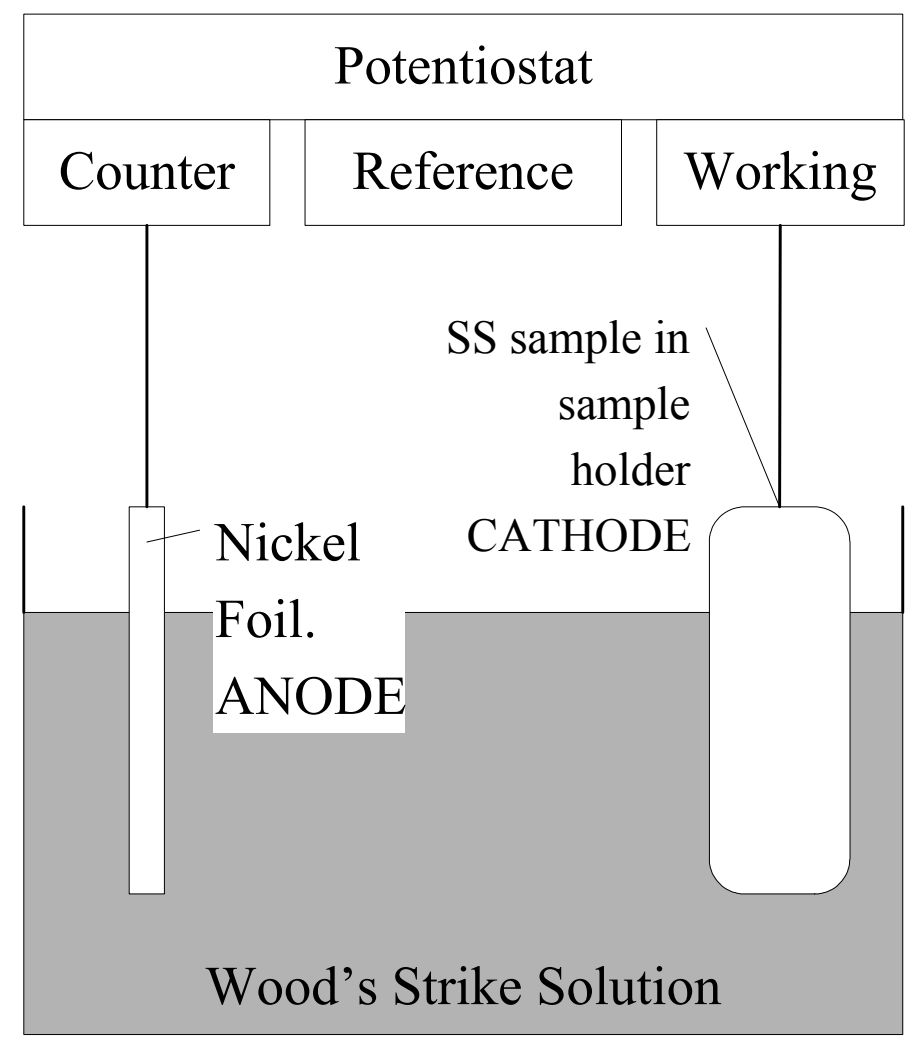

Figure 2-12 Nickel strike in Wood's strike solution 
The next step is nickel strike in Wood's solution which is a standard practice in nickel electroplating [21]. Wood's strike solution is an acidic solution of nickel chloride and hydrochloric acid. This process deposits a thin layer of nickel on the substrate surface. Figure 2-12 illustrates a schematic of the electrical circuit for the wood strike process.

During the wood's strike process a current density of $50 \mathrm{~mW} / \mathrm{cm}^{2}$ is desired. Hence appropriate current value that is to flow through the circuit is calculated. The desired coating thickness in typical electroplating applications is calculated using the formulae from [19],

$$
s=\frac{m}{d^{*} A} \ldots \ldots \ldots \ldots \ldots \ldots \ldots
$$

Where, $\mathrm{s}=$ Thickness of electrodeposited Nickel $(\mu \mathrm{m})$

$\mathrm{m}=$ Amount of Nickel deposited at cathode (grams)

$\mathrm{d}=$ Density of Nickel $\left(8.907 \mathrm{~g} / \mathrm{cm}^{2}\right)$

$A=$ Surface area to be electroplated $\left(\mathrm{cm}^{2}\right)$

This formula is further simplified to include the current density term as

$$
s=\frac{1.095 * a * I * t}{d * A} \ldots \ldots \ldots \ldots . . . . .
$$

Where $\mathrm{a}=$ current efficiency ratio

$\mathrm{I}=$ current flowing through the plating tank (Amperes)

$\mathrm{t}=$ Time of plating/time that current flows (hours)

(1.095) is a proportionality constant equal to $\mathrm{M} / \mathrm{nF}$, where $\mathrm{M}$ is the atomic weight of Nickel (58.69), $\mathrm{n}$ is the number of electrons in the electrochemical reaction (2) and $\mathrm{F}$ is Faraday's constant, equal to 26.799 ampere-hours (more commonly given as 96500 coulombs) [19]. I/A is the current density in usually expressed in $\mathrm{mA} / \mathrm{cm}^{2}$ for 
electroplating applications. The anode efficiency for nickel dissolution is almost always $100 \%$ under practical electroplating conditions, i.e. $\mathrm{a}=1$ when estimating anode weight loss.

An expression for average coating thickness, $\mathrm{s}$ in $\mu \mathrm{m}$ is hence derived from (2.1) and (2.2) and is of the form, $s=\frac{1229 * I * t}{A}$, where (I/A) is the current density in $\mathrm{mA} / \mathrm{cm}^{2}$ and $t$ is the time of electroplating in hours. Having set a value for current density, say $20 \mathrm{~mA} / \mathrm{cm}^{2}$, the current flowing through the plating tank is calculated if the surface area to be plated is known.

\subsubsection{Nickel Electroplating in sulfamate bath}

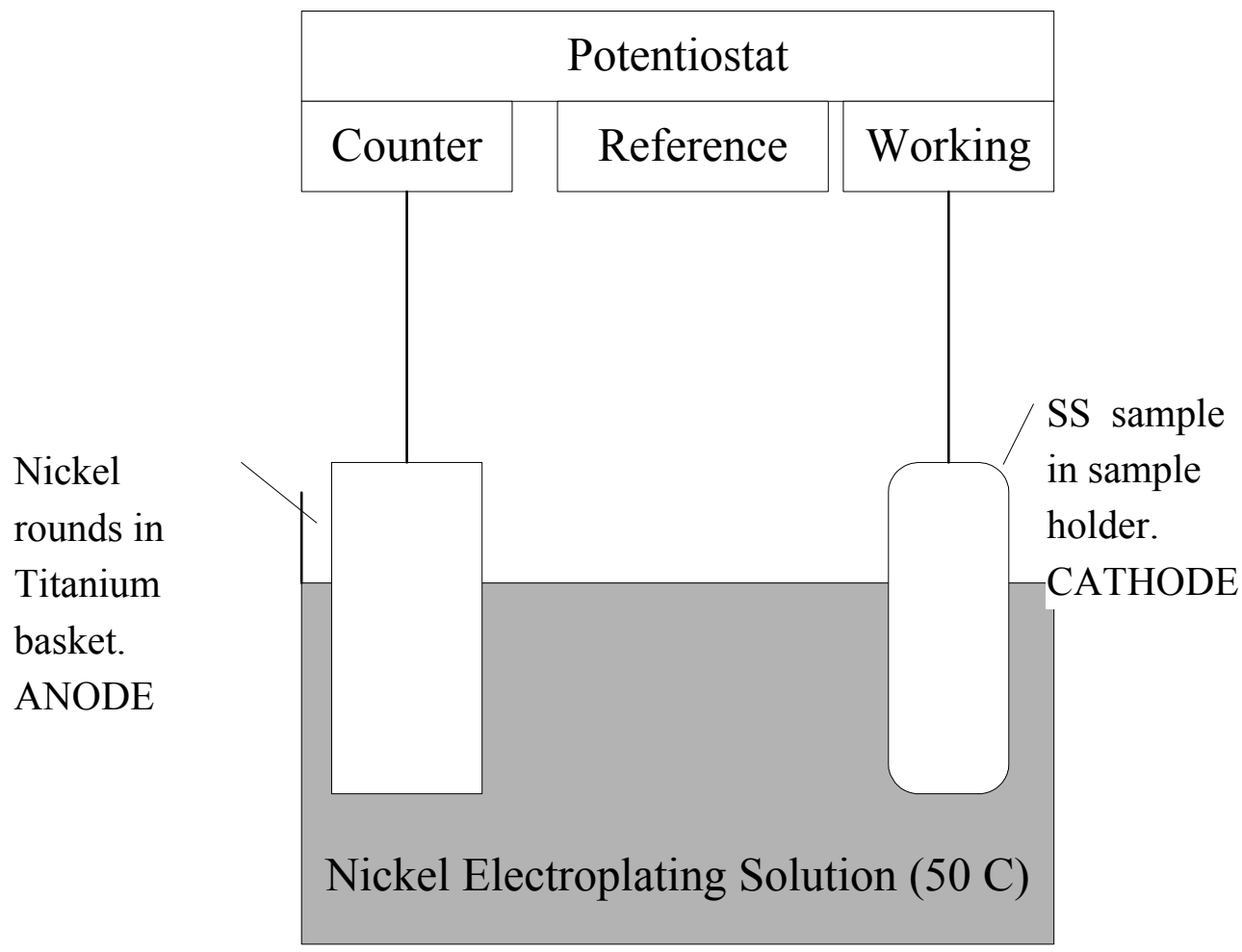

Figure 2-13 Nickel Electroplating 
After the activation and wood's strike processes, the substrate is immersed in nickel sulfamate solution and the circuit connections are made as shown in figure 2-13. The electroplating process is done at $55^{\circ} \mathrm{C}$ with strong agitation. The thickness of the deposition layer depends on the time of electroplating. The time of electroplating is calculated based on the surface area to be plated and the desired metal film thickness.

\subsection{Photoresist liftoff}

After electroplating, the remaining photoresist on the substrate has to be removed. The Shipley 1813 positive photoresist is removed by immersing the substrate in acetone and slightly stirring the solution followed by DI water rinse. This will completely remove any trace of photoresist. The SU-8 negative resist is completely removed by immersing the substrate in REMOVER PG solution (from Microchem Corp.) at $80^{\circ} \mathrm{C}$.

Tables 2-3 and 2-4 summarize the fabrication parameters used in this research to fabricate positive and negative asperities.

Table 2-3 Fabrication parameters for Positive asperities

\begin{tabular}{|c|c|}
\hline Parameter & Value or attribute \\
\hline Lapping time/ flatness & $\begin{array}{c}10 \mathrm{~min} / 2 \text { light } \\
\text { bands }\end{array}$ \\
\hline Polishing time & $20 \mathrm{~min}$ \\
\hline Photoresist used & Shipley 1813 \\
\hline Spin coat cycle & $\begin{array}{c}50 \mathrm{rpm} \text { for } 5 \mathrm{sec} \\
1500 \mathrm{rmm} \text { for } 25 \mathrm{sec}\end{array}$ \\
\hline Baking temperature/time & $115^{\circ} \mathrm{C}$ for $1 \mathrm{~min}$ \\
\hline Exposure time & $35 \mathrm{sec}$ \\
\hline Exposure intensity & $25 \mathrm{~mW} / \mathrm{cm}^{2}$ \\
\hline Post exposure bake & - \\
\hline Developing time & $1 \mathrm{~min}$ \\
\hline $\begin{array}{c}\text { Current Density during } \\
\text { nickel plating }\end{array}$ & $20 \mathrm{~mW} / \mathrm{cm}^{2}$ \\
\hline Resist liftoff & $\begin{array}{c}\text { Immerse in acetone } \\
\text { for } 2 \text { min }\end{array}$ \\
\hline
\end{tabular}


Table 2-4 Fabrication parameters for Negative asperities

\begin{tabular}{|c|c|}
\hline Parameter & Value or attribute \\
\hline Lapping time/ flatness & $10 \mathrm{~min} / 2$ light bands \\
\hline Polishing time & $20 \mathrm{~min}$ \\
\hline Photoresist used & SU-8 10 \\
\hline Spin coat cycle & $\begin{array}{c}50 \mathrm{rpm} \text { for } 5 \mathrm{sec} \\
2500 \mathrm{rpm} \text { for } 25 \mathrm{sec}\end{array}$ \\
\hline Baking temperature/time & $\begin{array}{l}65^{\circ} \mathrm{C} \text { for } 2 \mathrm{~min} \\
95^{\circ} \mathrm{C} \text { for } 5 \mathrm{~min}\end{array}$ \\
\hline Exposure time & $15 \mathrm{sec}$ \\
\hline Exposure intensity & $25 \mathrm{~mW} / \mathrm{cm}^{2}$ \\
\hline Post exposure bake & $\begin{array}{l}65^{\circ} \mathrm{C} \text { for } 1 \mathrm{~min} \\
95^{\circ} \mathrm{C} \text { for } 3 \mathrm{~min} \\
\end{array}$ \\
\hline Developing time & $2 \mathrm{~min}$ \\
\hline $\begin{array}{c}\text { Current Density during } \\
\text { nickel plating }\end{array}$ & $20 \mathrm{~mW} / \mathrm{cm}^{2}$ \\
\hline Resist liftoff & $\begin{array}{l}\text { Immerse in Remover } \\
\text { PG solution @ } 80^{\circ} \mathrm{C} \text { for } \\
10 \mathrm{~min}\end{array}$ \\
\hline
\end{tabular}

Copyright $($ C Sriram Venkatesan, 2005 


\section{CHAPTER 3 - SURFACE CHARACTERIZATION}

\subsection{Overview of surface characterization techniques}

A surface, by definition is an interface, a marked discontinuity from one material to another [22]. Any real surface has a finite depth and in characterizing a surface one must at some point consider what this depth is. In the case of deterministic surface texture, the height/depth of the asperities are of interest as have an impact on film thickness and hence the load carrying capacity of the surface. In addition to these asperities, the solid surface is itself covered with thin contaminant layer of atomic dimensions ( $\sim \mathrm{nm}$ thick). These contaminant layers are unavoidably present on every surface of any solid matter that has been exposed to air. Knowledge of contaminant layers is of great interest to materials engineers and scientist in surface modifications, thin film and coatings. The structure and geometry of the deterministic surface texture is of importance to tribologists interested in surface texture modification for improved performance.

A wide range of physical and chemical surface analysis techniques are available. Most techniques involve electrons, photons (light), x-rays etc. Many mechanical techniques are also available for assessing surface roughness and micro-mechanical properties of material surfaces. One of the most widely used mechanical probing technique for surface roughness characterization is the stylus profilometer in which a pointed stylus is made to drag along the surface under inspection, the vertical and horizontal motion of the stylus is picked up effectively replicates the surface topography. Table 3-1 outlines some of the popular characterizations tools available for characterizing various surfaces. 
Table 3-1 Techniques for surface characterization [22]

\begin{tabular}{|c|c|c|c|}
\hline Technique & Main information & Vertical resolution & $\begin{array}{l}\text { Types of } \\
\text { specimen }\end{array}$ \\
\hline Optical profiler & $\begin{array}{c}\text { 3D and 2D imaging } \\
\text { Morphology } \\
\text { Profilometry } \\
\text { Wear volume } \\
\text { Film thickness } \\
\text { Defects }\end{array}$ & $\sim 0.1 \mathrm{~nm}$ & All \\
\hline Light Microscopy & $\begin{array}{c}\text { Imaging } \\
\text { Morphology } \\
\text { Defects } \\
\text { Damages } \\
\end{array}$ & $\begin{array}{c}\text { From few } \mathrm{nm} \text { to few } \\
\mu \mathrm{m}\end{array}$ & All \\
\hline Stylus Profilometry & $\begin{array}{l}\text { Profilometry } \\
\text { Morphology } \\
\text { Topographic tracing } \\
\text { Film thickness } \\
\text { Wear volume } \\
\text { Scar and crater depth }\end{array}$ & $0.5 \mathrm{~nm}$ & $\begin{array}{l}\text { Almost all; } \\
\text { Flat smooth } \\
\text { films }\end{array}$ \\
\hline $\begin{array}{l}\text { Scanning Tunneling } \\
\text { Microscopy (STM) }\end{array}$ & $\begin{array}{c}\text { Topographic imaging } \\
\text { Morphology } \\
\text { Profilometry } \\
\text { Film Thickness } \\
\text { Spectroscopy } \\
\text { Defects } \\
\end{array}$ & $<0.03$ to $0.05 \mathrm{~nm}$ & Conductors \\
\hline $\begin{array}{c}\text { Atomic Force } \\
\text { Microscopy (AFM) }\end{array}$ & $\begin{array}{c}\text { Topographic imaging } \\
\text { Friction force mapping } \\
\text { Morphology } \\
\text { Profilometry } \\
\text { Defects } \\
\text { Structure }\end{array}$ & $<0.03$ to $0.05 \mathrm{~nm}$ & All \\
\hline $\begin{array}{l}\text { Scanning Electron } \\
\text { Microscopy (SEM) }\end{array}$ & $\begin{array}{c}\text { Imaging } \\
\text { Morphology } \\
\text { Elemental compositions } \\
\text { Defects } \\
\text { Crystallography } \\
\text { Grain Structure } \\
\end{array}$ & $\begin{array}{l}\text { From few } \mathrm{nm} \text { to few } \\
\mu \mathrm{m}\end{array}$ & $\begin{array}{c}\text { Conductors } \\
\text { and coated } \\
\text { insulators }\end{array}$ \\
\hline $\begin{array}{c}\text { Micrometer and } \\
\text { nanometer scratch } \\
\text { hardness } \\
\text { measurement }\end{array}$ & $\begin{array}{l}\text { Adhesion failure of thin } \\
\text { films and coatings } \\
\text { Abrasion resistance } \\
\text { Scratch hardness } \\
\text { Deformation } \\
\text { Friction } \\
\text { Anisotropy } \\
\end{array}$ & $0.3 \mathrm{~nm}$ & All \\
\hline
\end{tabular}


The techniques employed in this Thesis to characterize deterministic surface features are optical microscopy, optical profilometry and scanning electron microscopy (SEM).

\subsection{Surface Metrology Parameters}

Dimensional metrology is the science of measurement. Any manufacturing process produces parts that are checked for accuracy and precision using instruments, gauges and other techniques. A perfectly smooth surface is impossible to manufacture and all surfaces are rough at least at the atomic level.

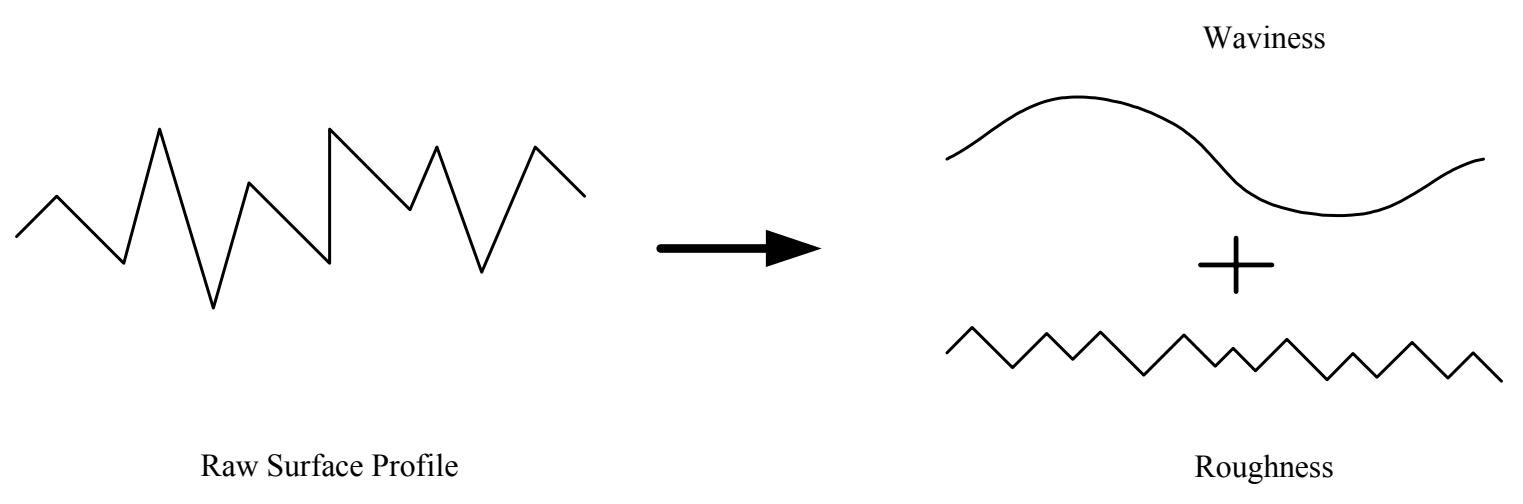

Figure 3-1 Components of a surface profile

A surface profile consists of two main components as shown in fig 3-1. The raw surface profile consists of the longer wavelength (low frequency) waviness component and the shorter wavelength (high frequency) roughness component. Any larger wavelength deviation is also classified as form error and has much larger wavelength than the waviness and defines the overall form of the surface. Likewise, any small wavelength is classified as noise but it is essentially the roughness component having really low wavelength in the nanometer scale. The raw profile of the surface has to be filter using appropriate filter cut-off frequencies and wavelength to separate the waviness and the 
roughness components. After separating the surface into its components, the roughness and waviness are quantifiably assessed using commonly known terms in dimensional metrology. Some typical terms that define the roughness/waviness of any surface are Average roughness $\left(R_{a}\right)$, Root Mean Square roughness $\left(R_{q}\right)$, Peak value of surface profile $(\mathrm{PV})$, Average Waviness $\left(\mathrm{W}_{\mathrm{a}}\right)$, Root Mean Square Waviness $\left(\mathrm{W}_{\mathrm{q}}\right)$, Skewness $\left(\mathrm{R}_{\mathrm{sk}}\right)$ and Kurtosis $\left(\mathrm{R}_{\mathrm{ku}}\right)$. These terms are defined below from [23],

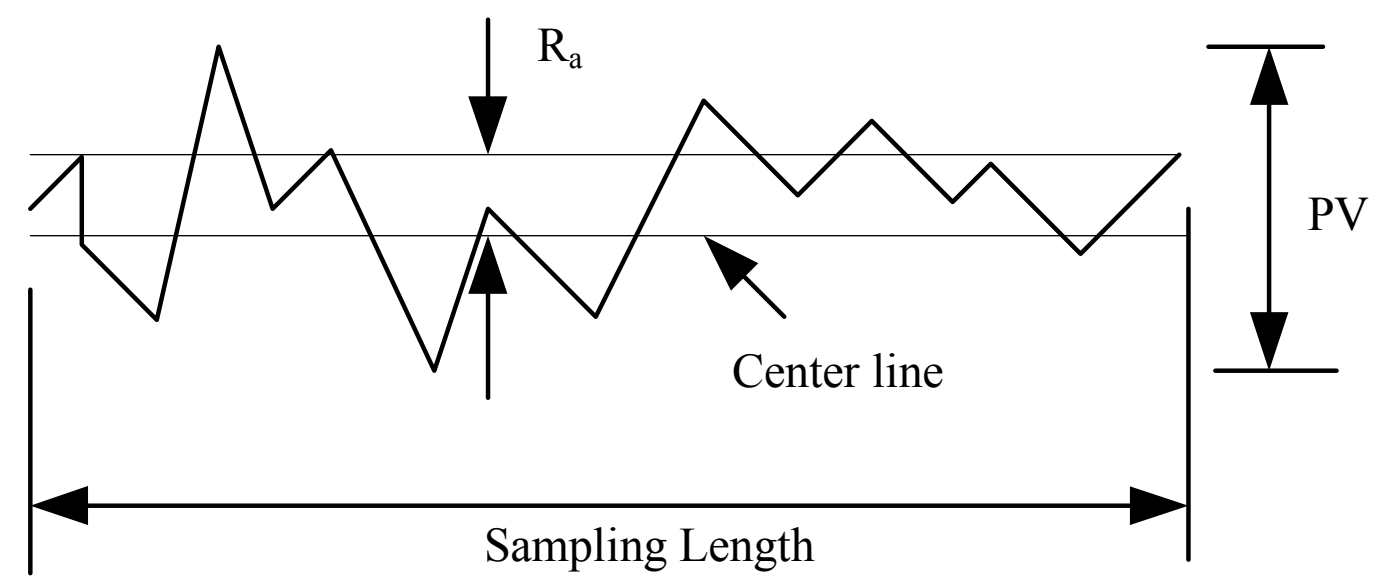

Figure 3-2 Average Roughness

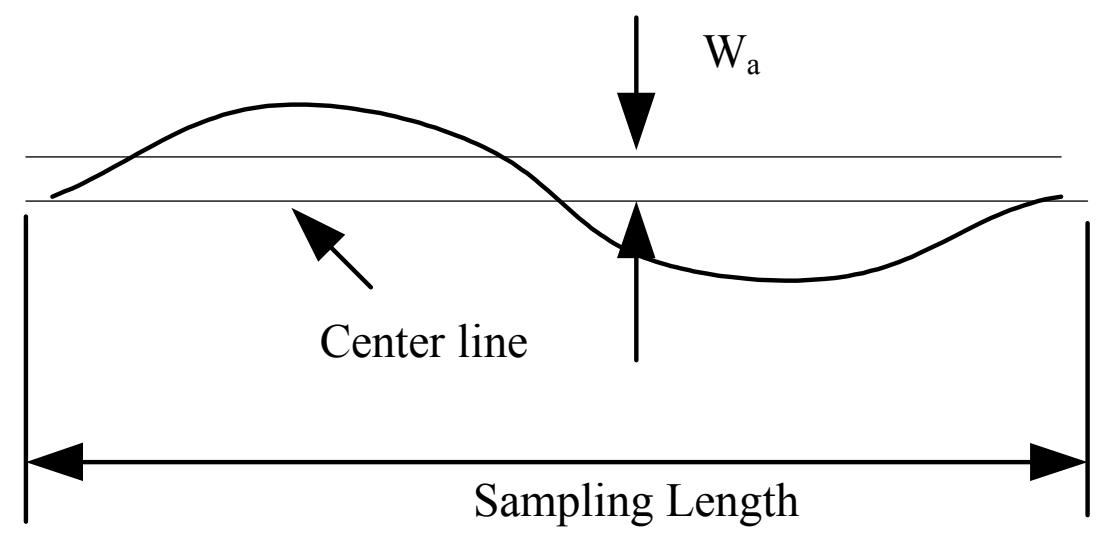

Figure 3-3 Average Waviness 
$R_{a}$ - The average surface roughness or the average deviation of all points from a plane fit to the test surface. In fig 3-2, the center line is the plane fit to the three-dimensional surface. $\mathrm{R}_{\mathrm{a}}$ is expressed as, $R a=\frac{Y 1+Y 2+Y 3+\ldots+Y n}{n}$

$\mathrm{R}_{\mathrm{q}^{-}}$is the root mean square (RMS) average of the measured height deviations taken within the evaluation length or area and measured from the mean linear surface. $\mathrm{R}_{\mathrm{q}}$ represents the standard deviation of profile heights. It is expressed as, $R q=\sqrt{\frac{1}{L} \int_{0}^{L} y(x) d x}$, where $\mathrm{L}$ is the evaluation/sampling length.

PV- The peak value represents the maximum peak to valley height over the sample. $\mathrm{W}_{\mathrm{a}^{-}}$The average waviness is the average surface height or deviation of all points from a plane fit to the waviness data as shown in fig 3-3. $W a=\frac{Y 1+Y 2+Y 3+\ldots+Y n}{n}$ $\mathrm{W}_{\mathrm{q}^{-}}$the RMS of all points from a plane fit to the waviness data. $W q=\sqrt{\frac{1}{L} \int_{0}^{L} y^{2}(x) d x}$ $\mathrm{R}_{s k^{-}}$is a measure of the symmetry of the profile about the mean line. Negative skew indicates a predominance of valleys, while a positive skew indicates peaky surface. Bearing surfaces should have negative skew. $R s k=\frac{1}{n(R q)^{3}} \sum_{i=1}^{n}(Y i)^{3}$ $\mathrm{R}_{\mathrm{ku}}$ - is a measure of the randomness of the profile heights and of the sharpness of the surface. Kurtosis values ranges from 0 to 8 . A perfectly random surface has a value of 3 . The farther the result is from 3, the less random and more repetitive the surface is. Spiky surfaces have a high value; bumpy surfaces have a low value. $R k u=\frac{1}{n(R q)^{4}} \sum_{i=1}^{n}(Y i)^{4}$ 


\subsection{Characterization of Deterministic Surface Texture}

This section outlines the characterization procedure used to evaluate the effectiveness of the manufacturing process used to fabricate the deterministic surface textures. The deterministic surface texture on the stainless steel substrate is in the form of both positive and negative asperities. In all there are 4680 asperities on the surface and these are radially arranged. The unit cell of each asperity is assumed to be rectangular since the average radius of the thrust ring is 6 orders of magnitude greater than the radial width of the cavity within the unit cell. The manufacturing process for fabricating such asperities was discussed in the previous sections. The asperities that are fabricated using these steps are prone to fabrication errors during the manufacturing steps. These errors reflect as irregularities in the manufacturing process. The sources of these errors are identified and their effects on the asperity geometry are minimized. Of particular interest is to use the resulting error distribution to assess the overall accuracy and repeatability of the manufacturing process. This will result in engineered surface textures that impact lubrication performance per design with minimum effect from fabrication errors.

The photoresist mold structure is one of the important in determining the quality of the micro asperities. Figure 3-4 shows an SEM micrograph of a SU-8 structure corner. In this figure, the corner a perfect true corner but there is some rounding at the corner. Since, the nickel asperity is electroplated around the SU-8 structures; the profile around the corner will also be rounded. This is identified as a fabrication error. The corner rounding is measured by observing the asperity corner under the microscope and measuring the rounding using an $\mathrm{x}-\mathrm{y}$ positioning stage. 


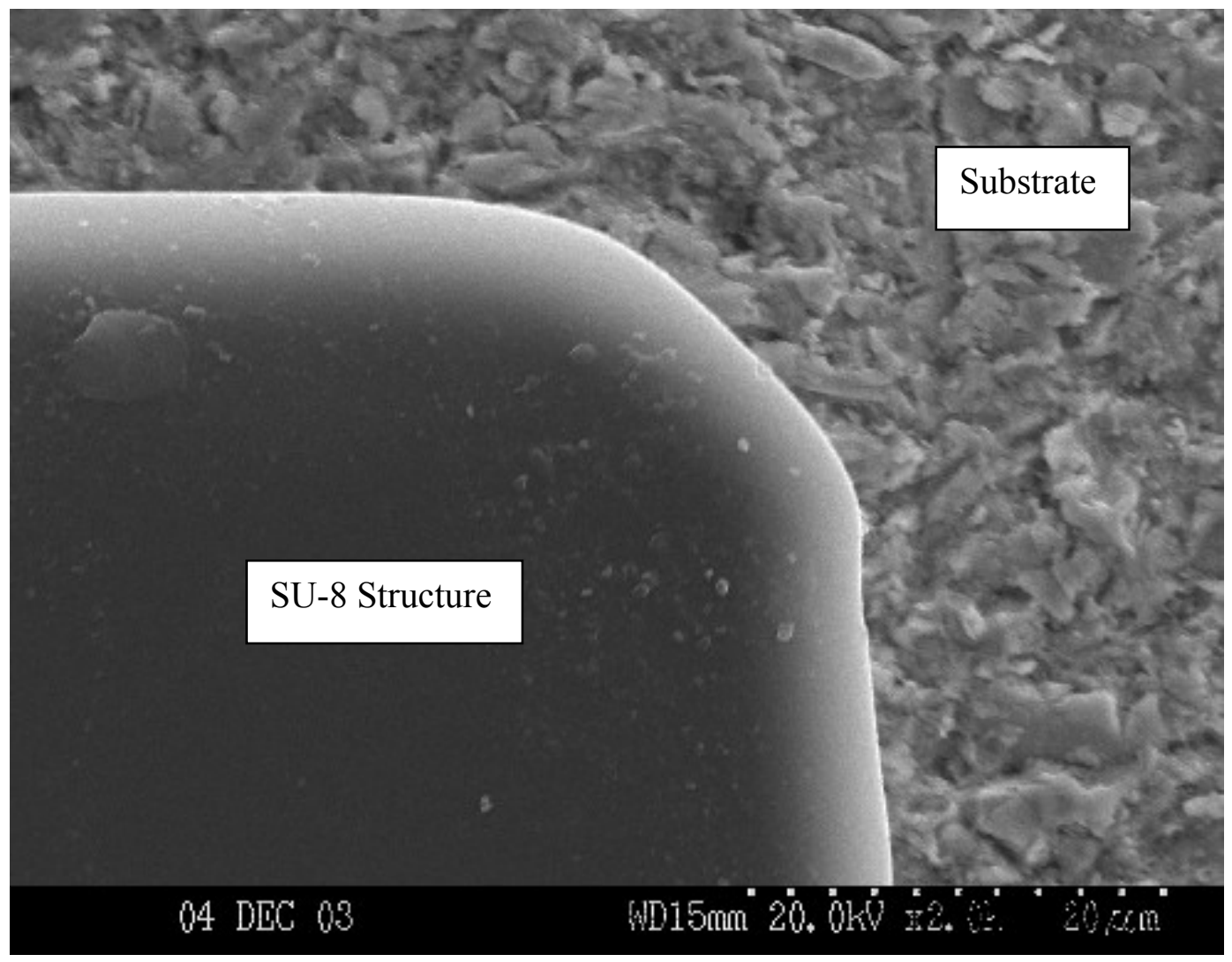

Figure 3-4 SEM micrograph of an SU-8 Structure Corner

The asperity corner rounding is one the sources of deviation of the asperity geometry from ideal. The rounding in the SU-8 structure is only of the order of a few microns but nevertheless a quantifiable error in asperity form. This rounding is caused due to overexposure of the photoresist layer to UV light. Figure 3-5 is an SEM micrograph of an array of SU-8 structures on the substrate. The figure shows a slight inclination of the sidewalls of the rectangular structures. This type of a sidewall profile is called a negative sidewall profile and is a characteristic of the negative photoresists. This type of sidewall profile would translate to an inclined sidewall for the electrodeposited nickel. Hence, the sidewall of the manufactured asperity is not perfectly straight but is inclined. The sidewall profile is quantified using an optical profiler. 


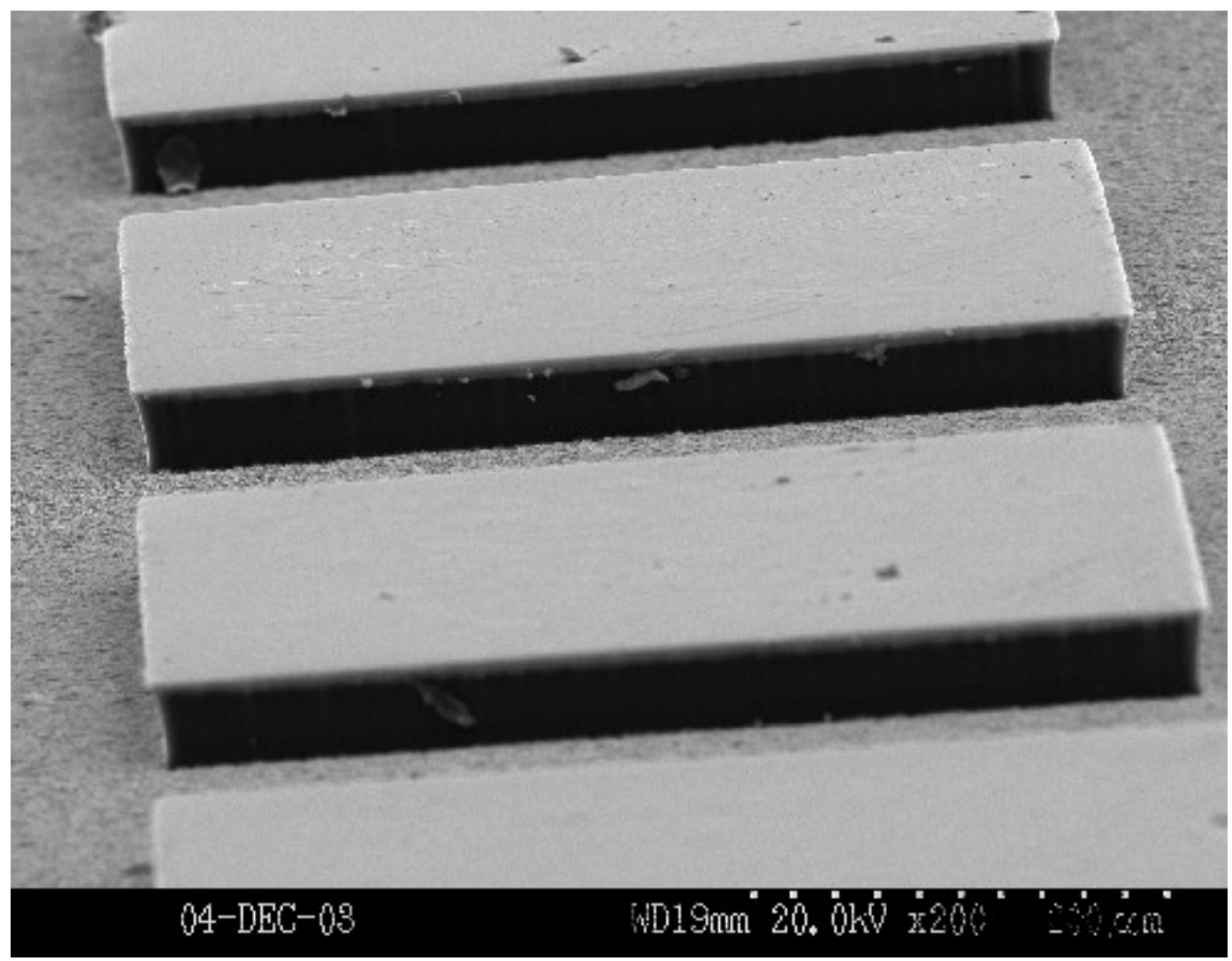

Figure 3-5 SEM Micrograph of an array of rectangular SU-8 structures

Some of the other fabrication errors include error in asperity lateral dimensions, error in surface form (waviness), asperity top tilt, and surface roughness between and on/inside asperities. Figure 3-6 shows an optical micrograph image of triangular negative asperities. The triangular cavities have a depth of $5 \mu \mathrm{m}$ and the surface between asperities and inside cavities are smooth and have a mirror finish. The side length of the triangles deviates slightly from the length of the triangles on the mask due to thermal expansion effects during the manufacturing process. These deviations are also measured and quantified. The highly polished surface inside and in-between cavities also have a roughness albeit in the atomic scale. This deviation is measured using an optical profiler. The next section details all fabrication errors identified in both positive and negative asperity geometries. 


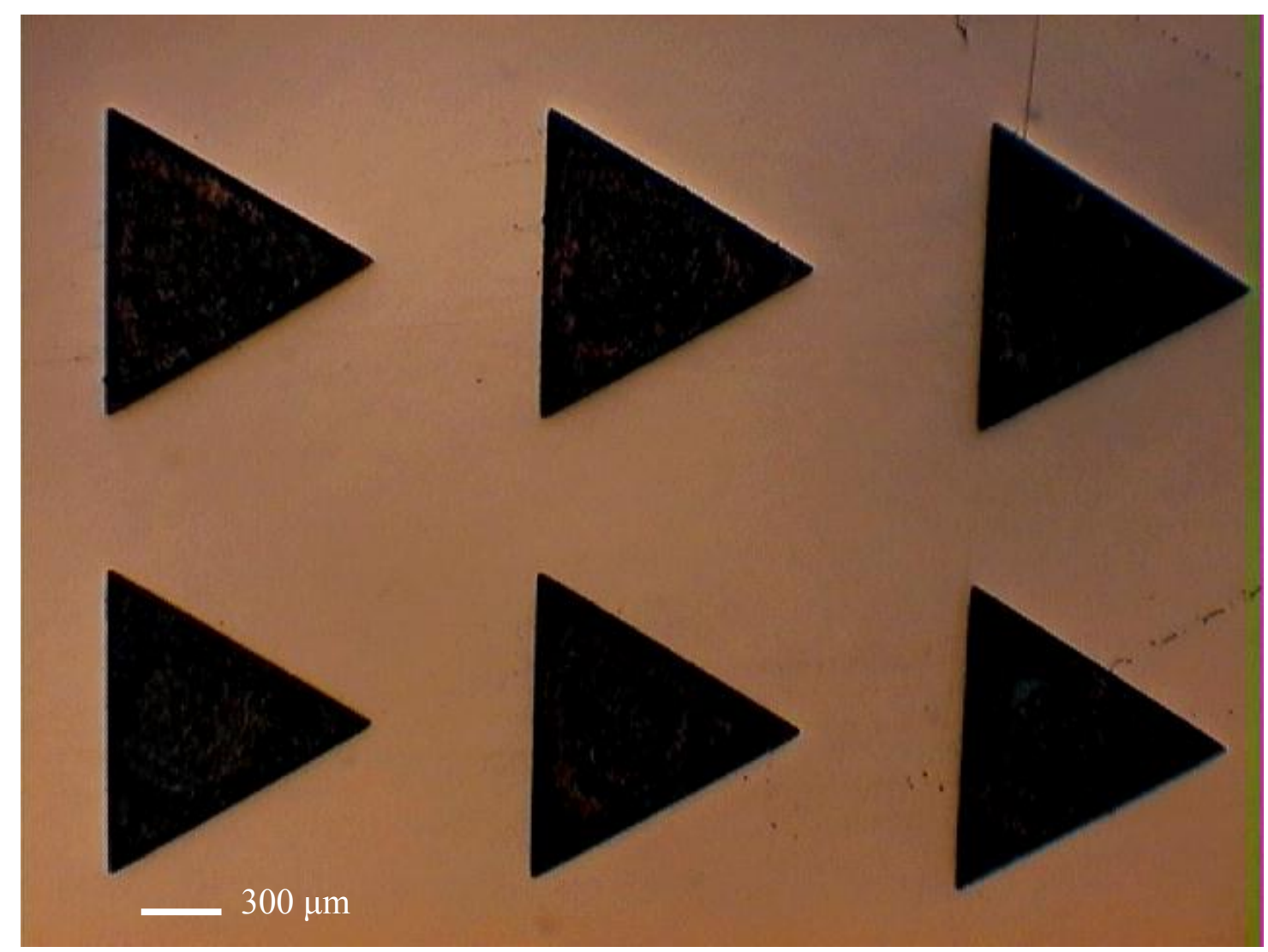

Figure 3-6 Optical micrograph of triangular negative asperities $\boldsymbol{\delta}^{\mathbf{2}}=\mathbf{0 . 2}$

Figure 3-7 shows the cross sectional profile of the array of triangular positive asperities as measured using the optical profiler. The dotted lines shown in the figure are called cross-hairs and are used to measure the distance between any two points on the profile. The cross-hairs are effectively used to measure accurately the lateral and vertical distances on the profile thereby yielding useful information on the profile geometry. The geometry of the actual profile is quantifiably assessed in terms of deviation from the 'ideal' profile. The fabrication errors that are readily measured using this technique are the changes in lateral dimensions of the asperity, height/depth of the asperity and sidewall verticality. The optical profiler also readily gives information on the roughness inbetween and on asperities. 


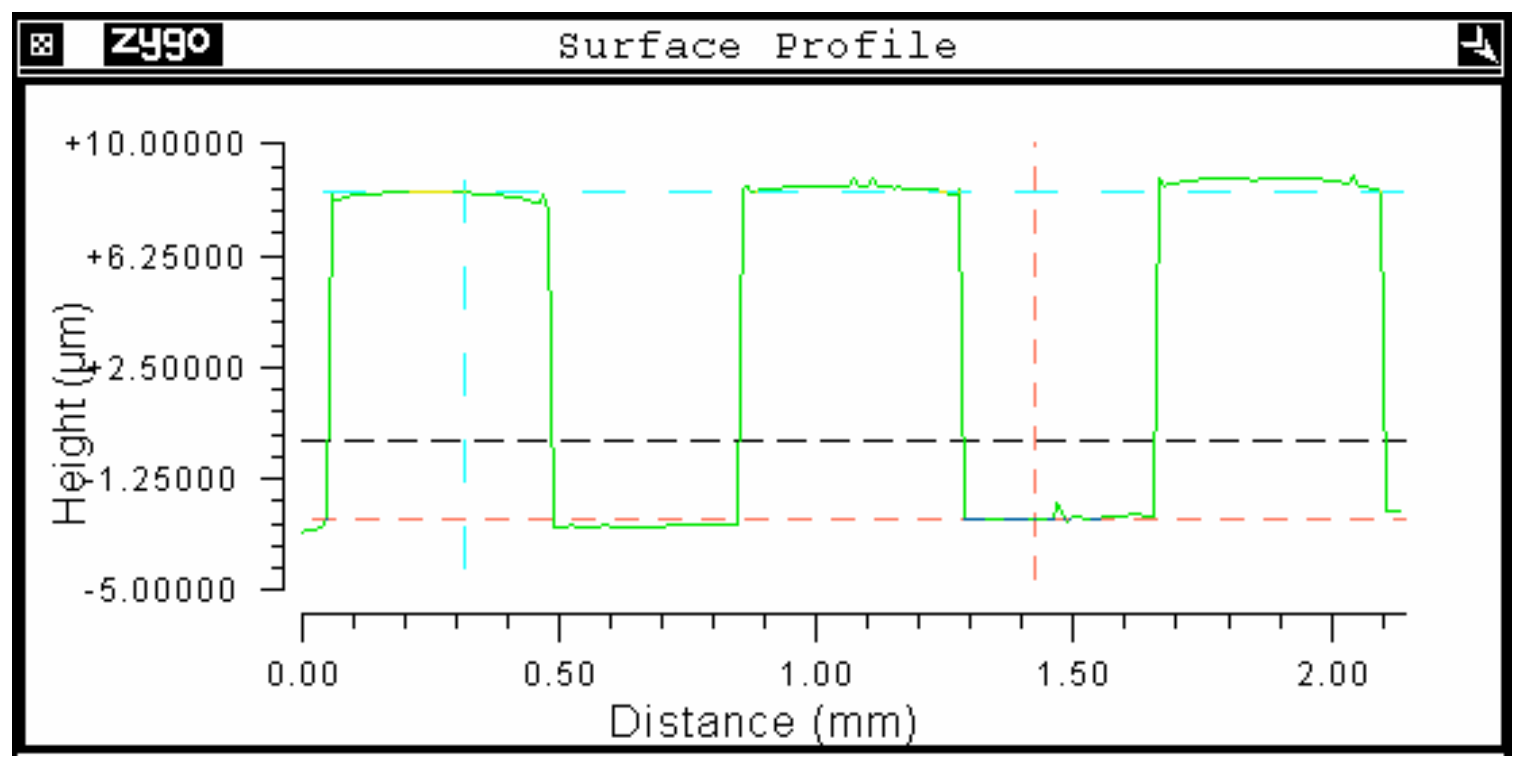

Figure 3-7 Profile of positive asperities

\subsection{Fabrication errors in surface texture features}

The fabricated deterministic asperities are prone to processing errors and these errors may impact the performance of the textured surface. Asperities on the thrust surface is primarily of some definable geometry viz. square, triangle, hexagon or circle. Figure 3-8 (a) shows a schematic of a single rectangular asperity in its unit cell. The other views in the figure show the cross-section of a negative and positive asperity respectively. The figure shows the dimensions of the asperity and an exaggerated illustration of the fabrication errors in asperity geometry. The rectangle is centered within its unit cell. The asperities are on a thrust surface and ' $U$ ' denotes the direction of the slider. Eight processing errors in the asperity geometry are identified for both positive and negative asperity geometries. These errors are indicative of the process capability of the asperity manufacturing process. These errors are listed below and in the next chapter; a statistical analysis of the fabrication errors is presented. 


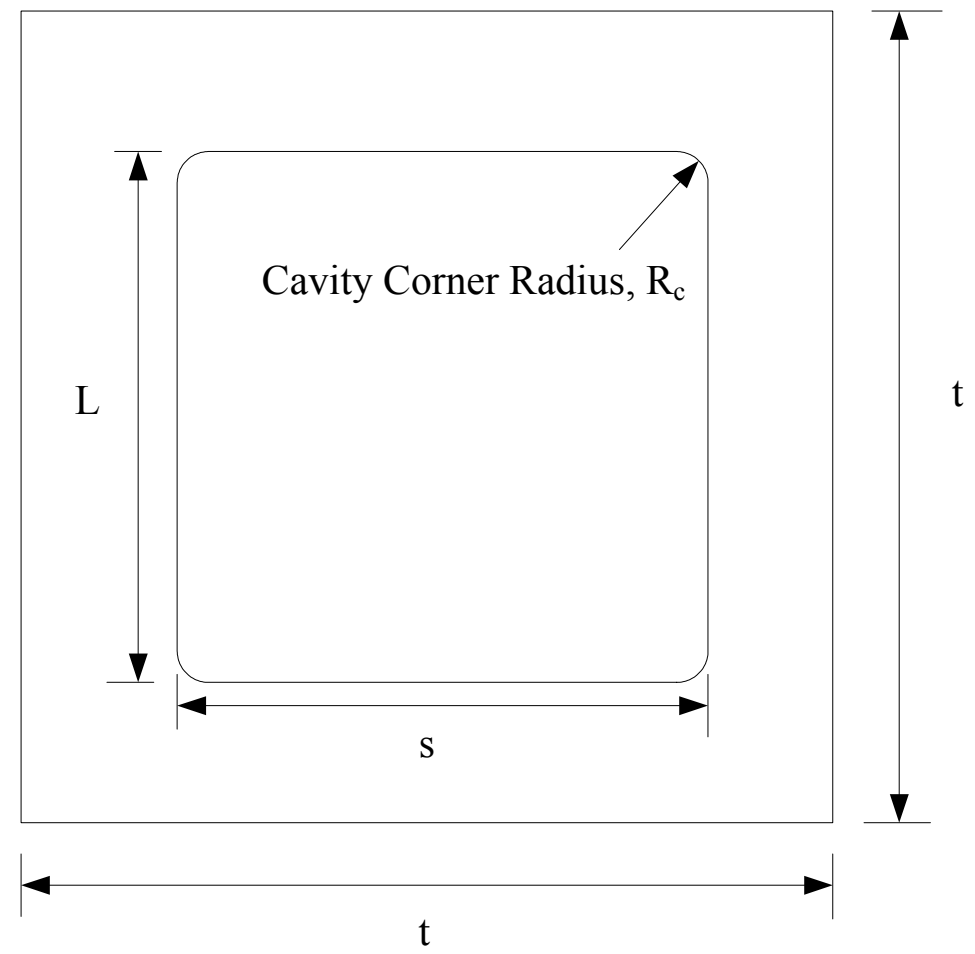

(a) Rectangular asperity in unit cell

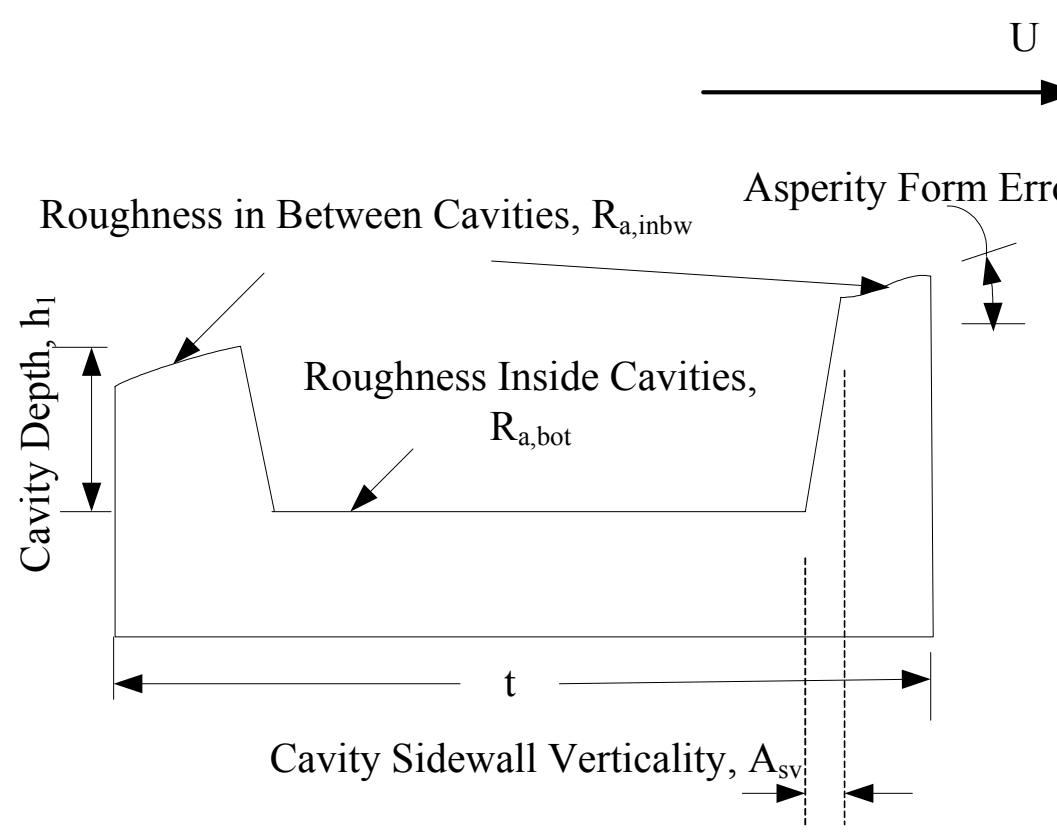

(b) Cross-section of negative asperity 


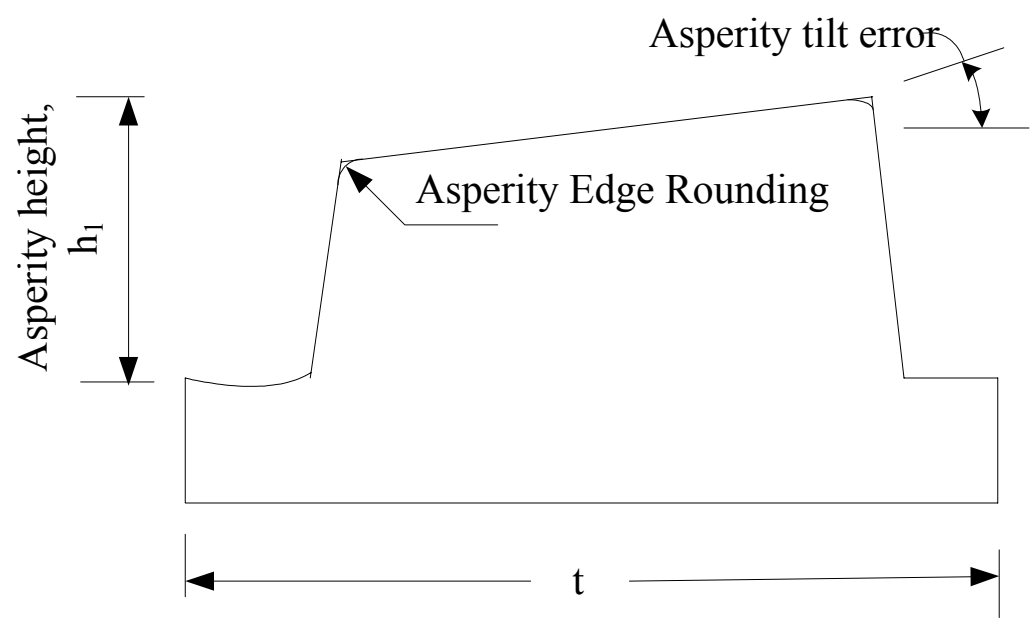

(c) Cross-section of positive asperity

Figure 3-8 Errors in asperity geometry

For a negative asperity the fabrication errors are,

1) Cavity corner radius, $R_{c, \text { neg- }}$ A small rounding at the cavity corners.

2) Cavity Sidewall Verticality, $A_{\mathrm{sv}, \text { neg- }}$ - An inward tilt in the cavity sidewall, which should be perfectly vertical.

3) Asperity form error, $\theta_{\text {asp,neg- }}$ this is the deviation in the form of the asperity surface due to overall surface waviness.

4) Error in cavity depth, $\Delta \mathrm{h}_{1, \text { neg- }}$ - is the difference between the desired depth of the cavity to its measured depth.

5) Error in cavity length, $\Delta \mathrm{s}_{\text {neg }}$ - is the difference between the desired length of the cavity to its measured length.

6) Cavity Edge rounding (not shown for negative asperity) - This is the rounding in the asperity edge due to polishing or lapping pressure.

7) Average random roughness between cavities, $R_{a, \text { inbw }}$.

8) Average random roughness inside cavities, $R_{a, b o t}$. 
For a positive asperity, errors (1), (2), (5), (6) and the average random roughness components exists and errors (3) and (4) may be designated as,

9) Asperity Tilt, $\theta_{\text {asp,pos- }}$ a small tilt on asperity tops that may be caused due to processing errors or may be intentionally manufactured.

10) Error in asperity height, $\Delta \mathrm{h}_{1, \text { neg- }}$ is the difference between the desired height of the asperity to its measured height.

The errors identified above are unique for the asperity manufacturing process detailed in this Thesis and may not be the same for surface textures fabricated using other manufacturing processes.

Copyright $\odot$ Sriram Venkatesan, 2005 


\section{CHAPTER 4 - STATISTICAL ANALYSIS OF FABRICATION ERRORS}

\subsection{Magnitude of fabrication errors}

The fabrication errors identified in the earlier chapter are measured using optical microscope and a Zygo ${ }^{\circledR}$ Newview optical profiler. Table 4-1 [24] summarizes the magnitudes of some of the fabrication errors that are measured on cavities having three different sizes. The sample size for all measurements is 30 and table 4-1 gives the mean standard deviation and $99 \%$ confidence intervals for the measured values of errors. The average cavity corner radius for the cavity having $\delta^{2}=0.1$ is $12.1 \mu \mathrm{m}$ compared to a perfect corner radius of zero. The magnitude of this error is higher for cavities having $\delta^{2}$ values of 0.4 and 0.7 . The asperity sidewall verticality is the total inward run-out in the cavity sidewall profile as compared to an ideal run-out of zero. The low confidence intervals for this error indicate a high probability of this value to lie close to its mean value. The asperity form error is approximated by an angle for convenience of measurement and modeling. This error is also negative for negative slope in the surface form. The maximum error in cavity depth is for the cavity with $\delta^{2}=0.4$. Errors in cavity length have acceptable values in terms of percentage error for all cavity sizes. The maximum percentage error in cavity width is $11.9 \%$ for the cavity having a $\delta^{2}=0.4$ and the average of all the percentage errors is $6.5 \%$. The surface roughness in-between and inside cavities are quantified as an average roughness parameter. All the samples, having different $\delta^{2}$, are lapped and polished for same time and hence there is only one common value of mean, standard deviation and confidence intervals (CI) each for roughness inbetween and inside cavity, with a sample size of 30 . The magnitude of average roughness in- 
Table 4-1 Summary of error results

\begin{tabular}{|c|c|c|c|c|c|c|c|c|c|}
\hline \multirow{2}{*}{$\delta^{2}$} & \multicolumn{3}{|c|}{0.1} & \multicolumn{3}{|c|}{0.4} & \multicolumn{3}{|c|}{0.7} \\
\hline & Mean & SD & $99 \% \mathrm{CI}$ & Mean & SD & $99 \% \mathrm{CI}$ & Mean & SD & $99 \% \mathrm{CI}$ \\
\hline $\begin{array}{l}\text { Average } \\
\text { Cavity } \\
\text { Corner } \\
\text { Radius, } R_{c} \\
(\mu \mathrm{m})\end{array}$ & 12.2 & 2.6 & $\begin{array}{l}10.9- \\
13.3\end{array}$ & 21.8 & 4.3 & $\begin{array}{l}19.8- \\
23.8\end{array}$ & 18.5 & 3.2 & $16.9-20$ \\
\hline $\begin{array}{l}\text { Average } \\
\text { Cavity } \\
\text { Sidewall } \\
\text { Verticality, } \\
\mathrm{A}_{\mathrm{sv}},(\mu \mathrm{m})\end{array}$ & 6.6 & 2.2 & $5.5-7.6$ & 9.2 & 3.1 & $7.7-10.6$ & 10.3 & 3.1 & 8.9-11.9 \\
\hline $\begin{array}{l}\text { Average } \\
\text { Asperity } \\
\text { Form } \\
\text { Error, } \theta_{\text {asp }} \\
\text { (degrees) }\end{array}$ & 0.00063 & 0.006 & $\begin{array}{l}-0.002- \\
0.003\end{array}$ & 0.0028 & 0.0197 & $\begin{array}{l}-0.006- \\
0.01\end{array}$ & 0.001 & 0.034 & $\begin{array}{c}-0.009- \\
0.011\end{array}$ \\
\hline $\begin{array}{l}\text { Error } \\
\text { Cavity } \\
\text { Depth, } \\
\Delta \mathrm{h}_{1},(\mu \mathrm{m})\end{array}$ & 0.03 & 2.1 & $-0.9-1$ & 1.7 & 2.4 & $0.5-2.8$ & 0.4 & 2.2 & $-0.6-1.5$ \\
\hline $\begin{array}{l}\text { \%age } \\
\text { Error in } \\
\text { Cavity } \\
\text { Depth }\end{array}$ & \multicolumn{3}{|c|}{$0.2 \%$} & \multicolumn{3}{|c|}{$11.1 \%$} & \multicolumn{3}{|c|}{$2.8 \%$} \\
\hline $\begin{array}{l}\text { Error in } \\
\text { Cavity } \\
\text { length, } \Delta \mathrm{s}, \\
(\mu \mathrm{m})\end{array}$ & 5 & 4 & $3.2-7$ & 21.8 & 6.7 & $18.7-25$ & 6.3 & 4.4 & $4.3-8.3$ \\
\hline $\begin{array}{l}\text { \%age } \\
\text { Error in } \\
\text { Cavity } \\
\text { length }\end{array}$ & \multicolumn{3}{|c|}{$1.4 \%$} & \multicolumn{3}{|c|}{$4.4 \%$} & \multicolumn{3}{|c|}{$0.98 \%$} \\
\hline $\begin{array}{l}\text { Error in } \\
\text { Cavity } \\
\text { width, } \Delta \mathrm{L} \\
(\mu \mathrm{m})\end{array}$ & 20.3 & 3.6 & $18.5-22$ & 17.7 & 8. & $\begin{array}{l}13.7- \\
21.7\end{array}$ & 19.7 & 7.5 & $16.2-23.2$ \\
\hline $\begin{array}{l}\text { \%age } \\
\text { Error in } \\
\text { Cavity } \\
\text { Width }\end{array}$ & \multicolumn{3}{|c|}{$11.9 \%$} & \multicolumn{3}{|c|}{$3.7 \%$} & \multicolumn{3}{|c|}{$3 \%$} \\
\hline \multicolumn{6}{|c|}{ Average Roughness in- between cavities, $R_{a, \text { inbw }},(\mu \mathrm{m})$} & \multicolumn{4}{|c|}{$0^{\mu .08}{ }^{\mu=0.07 ; \sigma=0.04 ; C I=0.06-}$} \\
\hline \multicolumn{6}{|c|}{ Average Roughness inside cavities, $\mathrm{R}_{\mathrm{a}, \mathrm{bot}},(\mu \mathrm{m})$} & \multicolumn{4}{|c|}{$\mu=0.3 ; \sigma=0.02 ; \mathrm{CI}=0.3-0.4$} \\
\hline
\end{tabular}

between cavities and asperity form error are very small but are nevertheless deviations from a perfectly smooth surface. 
The asperity edge error is not reported in table $4-1$ as this error or irregularity occurs only after lapping/polishing the textured sample and description of this error is considered in later sections. The next section describes the distributions of these errors based on the measurements.

\subsection{Statistical distribution of fabrication errors}

From the surface characterization data, all the errors in asperity geometry are statistically quantified through histograms. A sample size of $\mathrm{N}=30$ is selected to statistically determine the variations in the error parameters. The sample size for each

value of $\delta^{2}$ is selected from three patterned SS substrates. Error magnitude is measured for the patterned rings having different values of $\delta^{2}$ and histograms of sample distribution are plotted for all the error parameters except the random roughness in-between and inside the cavities. Figures 4-1 to 4-6 show the histograms of cavity corner radius, cavity sidewall verticality, asperity form error, error in cavity depth, error in cavity length and width respectively. A bell shaped curve having the same mean and variance as the histograms is superimposed on the histograms. This gives the first indication of the type of distribution of the population of the error parameters. In order to evaluate the normality of the error distribution, a goodness of fit test is performed.

\subsection{1 $\chi^{2}$ (Chi-squared) test for the goodness of fit}

This test is performed to corroborate the distribution of a particular measurement variable [25]. This test is based on the quantity, $\chi^{2}$ that is given as, $\chi^{2}=\sum_{i=1}^{k} \frac{(O i-E i)^{2}}{E i}$, where Oi is the observed frequency of the $i$ th class interval or bin, Ei is the expected frequency of the $i$ th class interval based on the hypothesized theoretical distribution 
(Gaussian/normal in this case), $k$ is the number of class intervals and $\chi^{2}$ is the value of a random variable whose sampling distribution is approximated very closely by the chisquared distribution with $v=k-1$ degrees of freedom. The values for $\chi^{2}$ at every $v$ are found from statistical tables for chi-squared distribution [25]. Ei is evaluated by finding the probability that a value lies between the boundaries of a particular class interval, multiplied by the total number of samples $(\mathrm{N})$ in the measurement. Note here that Oi's are integers while Ei's may not be. For all the error parameters, a normal distribution, having a mean and standard deviation of the respective error parameters is hypothesized. A small value of $\chi^{2}$ indicates a good fit and this leads to the acceptance of the assumed hypothesis that Oi's are drawn from a population represented by Ei's. A large value of $\chi^{2}$ leads to the rejection of the above hypothesis. The values of $\chi^{2}$ for the discrete distributions of error parameters are shown below the respective histograms along with the degrees of freedom of the chi-squared distribution for the particular case. Further, to validate the normality claim on the evaluated distribution of errors, the respective $\chi^{2}$ values are compared to $\chi_{\alpha}^{2}$, the value of a chi-squared distribution at $\alpha(=0.05)$ level of statistical significance and at the number of degrees of freedom, $v$. This value is taken from the statistical table of critical values for $\chi^{2}$. If $\chi^{2}<\chi_{\alpha}^{2}$, then the error parameter is acceptable assumed to be normally distributed. Referring to the histograms in fig 4-1 to 4-6, all the error parameters are normally distributed except the cavity sidewall verticality for $\delta^{2}=0.4$ case. In this case, the value of $\chi^{2}$ is high as the peak of the histogram is skewed towards the left. However, this is a special case and the normality hypothesis for this error parameter has to be verified in this case using a larger sample size. Overall, 
from the goodness of fit test results of the distribution of error parameters, a normal distribution for the error parameters measured is a good approximation.

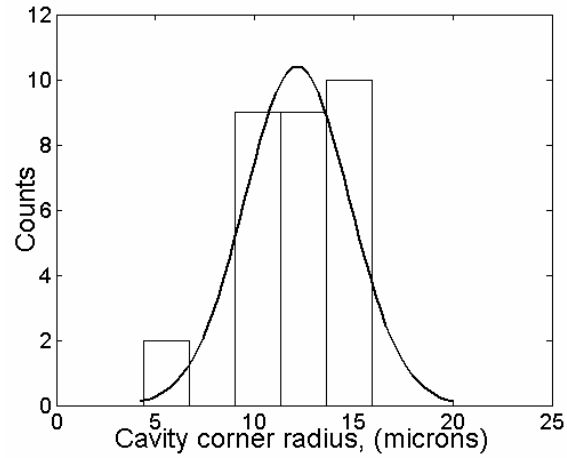

(a) $\delta^{2}=0.1 ; \chi^{2}=1.11 ; v=2$

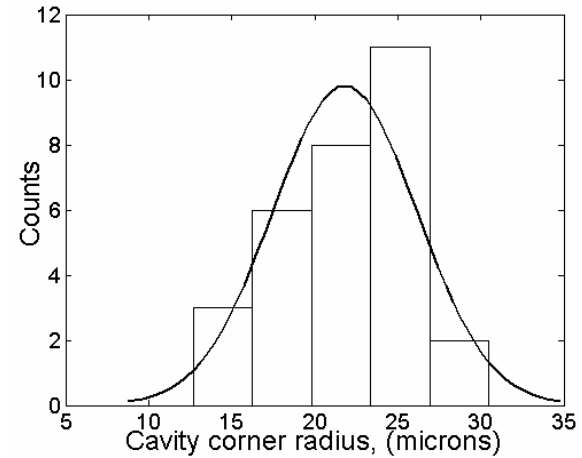

(b) $\delta^{2}=0.4 ; \chi^{2}=1.47 ; v=2$

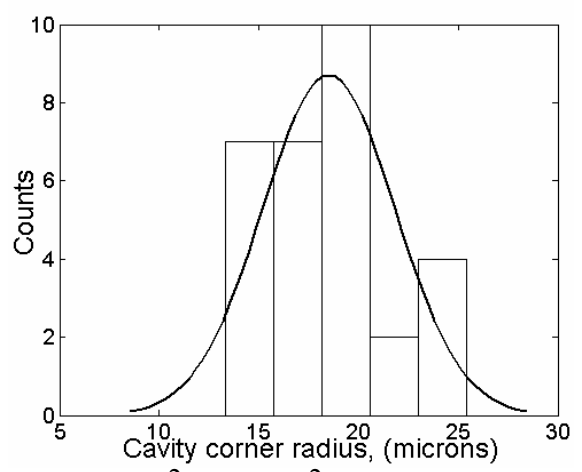

(c) $\delta^{2}=0.7 ; \chi^{2}=2.87 ; v=2$

Figure 4-1 Histograms of cavity corner radius

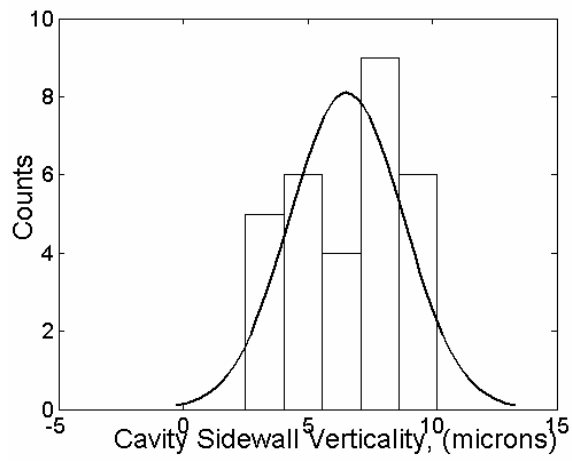

(a) $\delta^{2}=0.1 ; \chi^{2}=0.57 ; v=1$

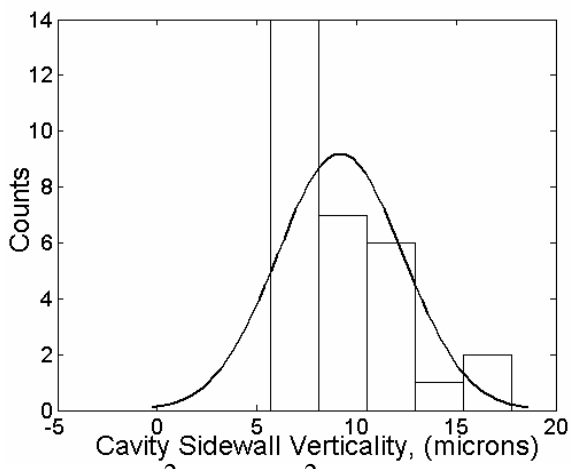

(b) $\delta^{2}=0.4 ; \chi^{2}=10.25 ; v=1$ 


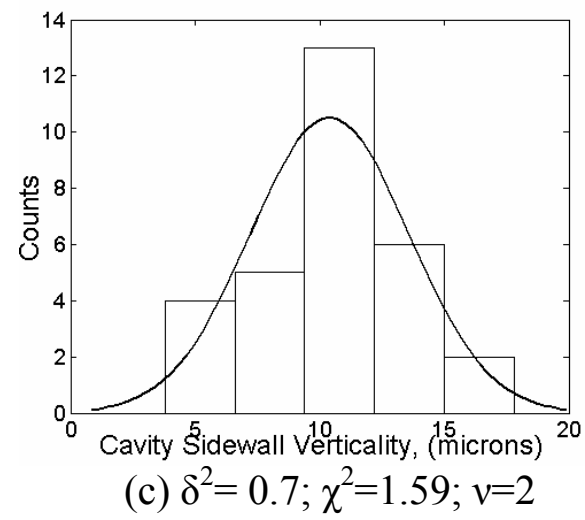

Figure 4-2 Histogram of cavity sidewall verticality

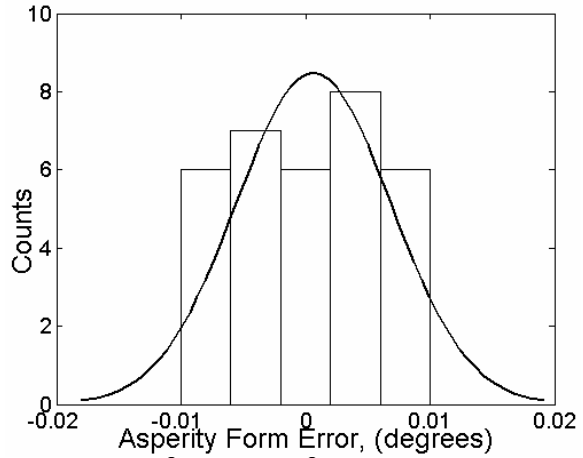

(a) $\delta^{2}=0.1 ; \chi^{2}=0.97 ; v=2$

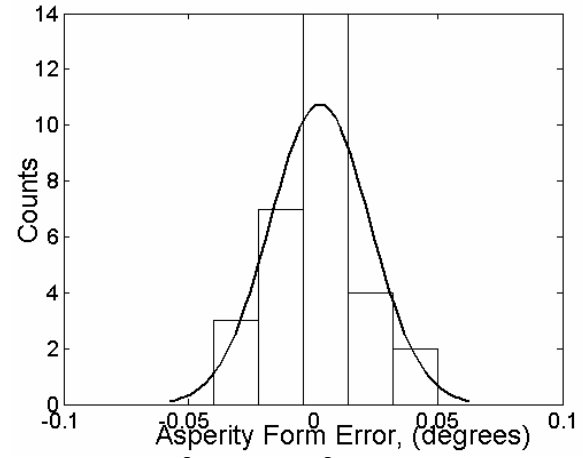

(b) $\delta^{2}=0.4 ; \chi^{2}=0.99 ; v=1$

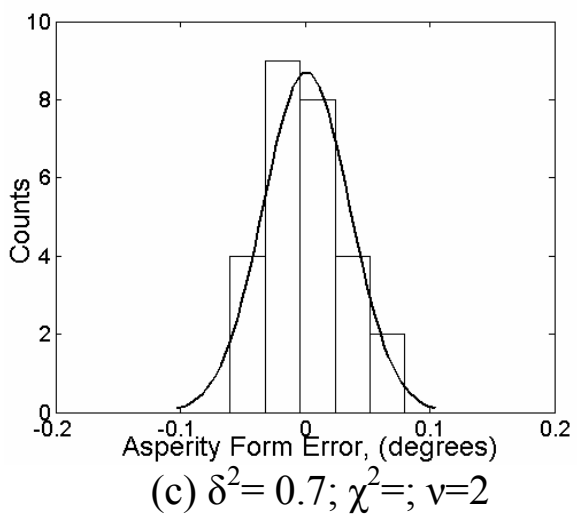

Figure 4-3 Histogram of asperity form error 


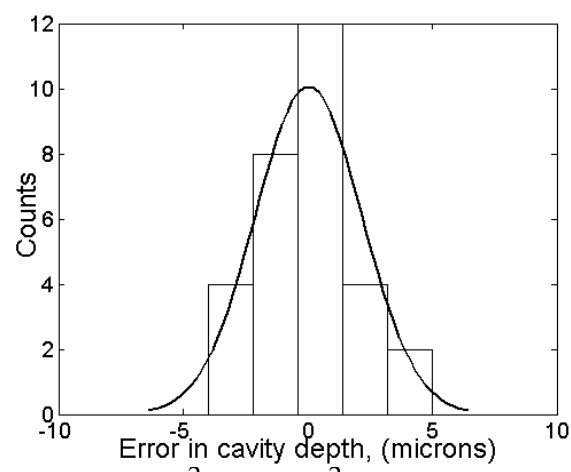

(a) $\delta^{2}=0.1 ; \chi^{2}=0.8 ; v=1$

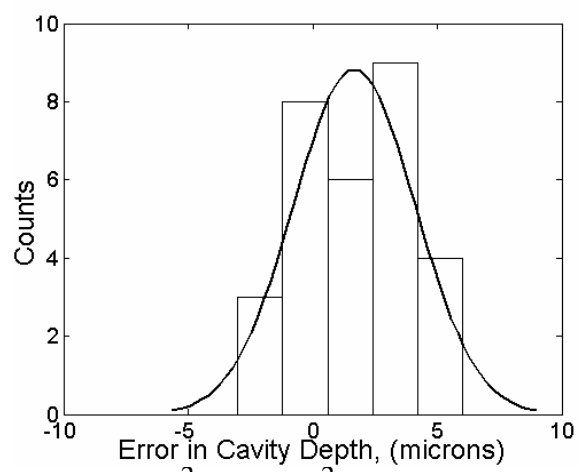

(b) $\delta^{2}=0.4 ; \chi^{2}=1.8 ; v=1$

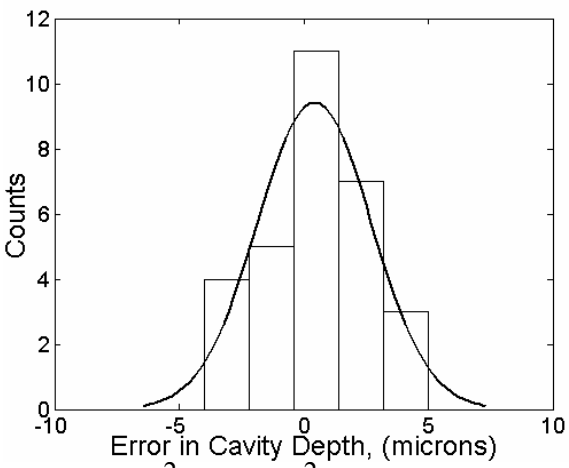

(c) $\delta^{2}=0.7 ; \chi^{2}=0.72 ; v=2$

Figure 4-4 Histogram of error in cavity depth

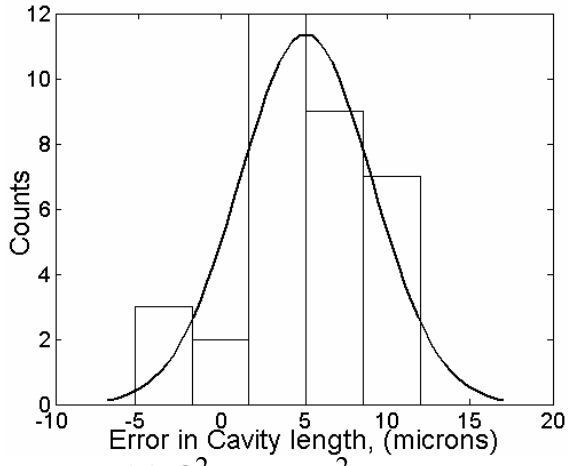

(a) $\delta^{2}=0.1 ; \chi^{2}=0.5 ; v=1$

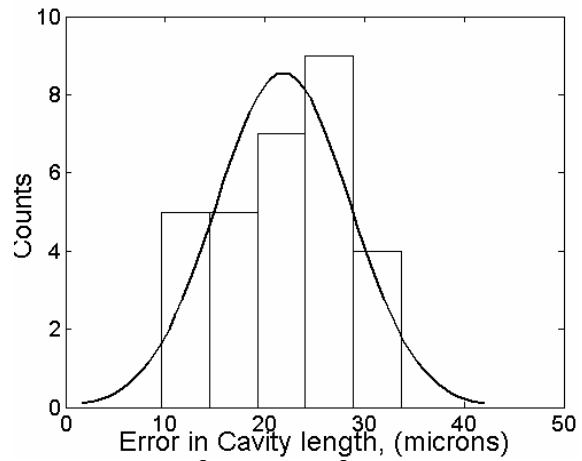

(b) $\delta^{2}=0.4 ; \chi^{2}=1.30 ; v=2$ 


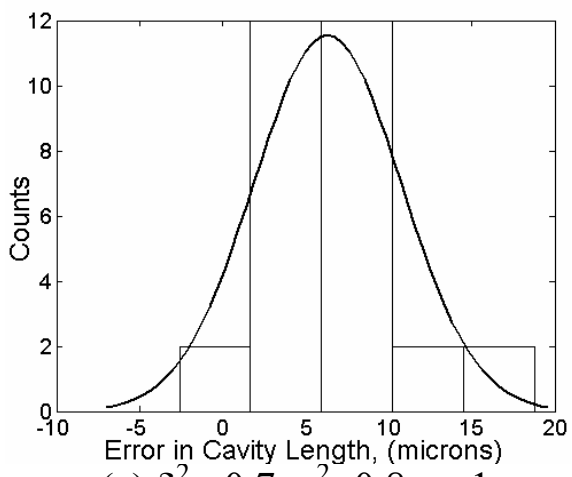

(c) $\delta^{2}=0.7 ; \chi^{2}=0.8 ; v=1$

Figure 4-5 Histograms of error in cavity length

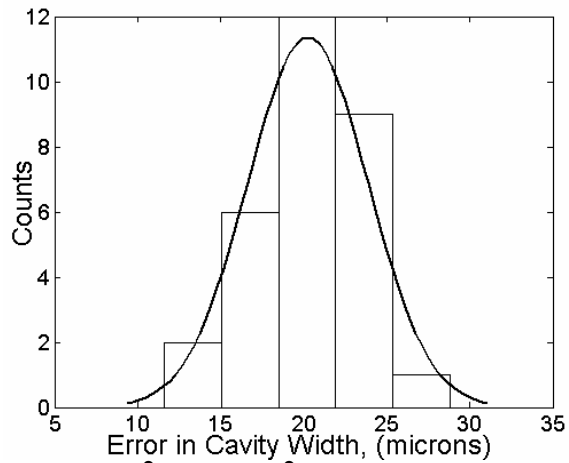

(a) $\delta^{2}=0.1 ; \chi^{2}=0.76 ; v=2$

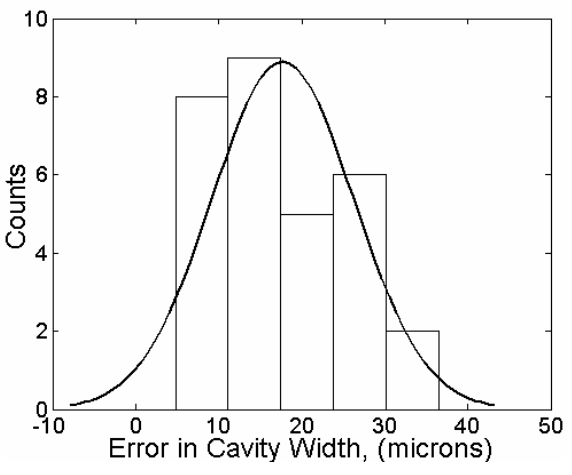

(b) $\delta^{2}=0.4 ; \chi^{2}=2.575 ; v=3$

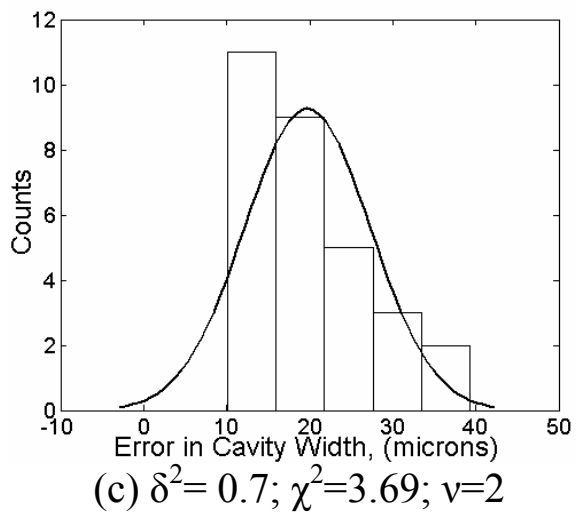

Figure 4-6 Histograms of error in cavity width 


\subsection{Waviness of Stainless steel ring}

In the previous section, the errors in asperity geometry were statistically quantified and the error distributions were normal or Gaussian. These errors were errors in asperity geometry or were deviations from perfectly accurate asperity geometry. In this section, the error in substrate form is considered. This is better known as the waviness of the substrate. Due to the waviness, the fabricated asperities are placed along hills and valleys as opposed to a perfectly flat surface. The waviness on the substrate is classified as radial waviness and circumferential waviness.

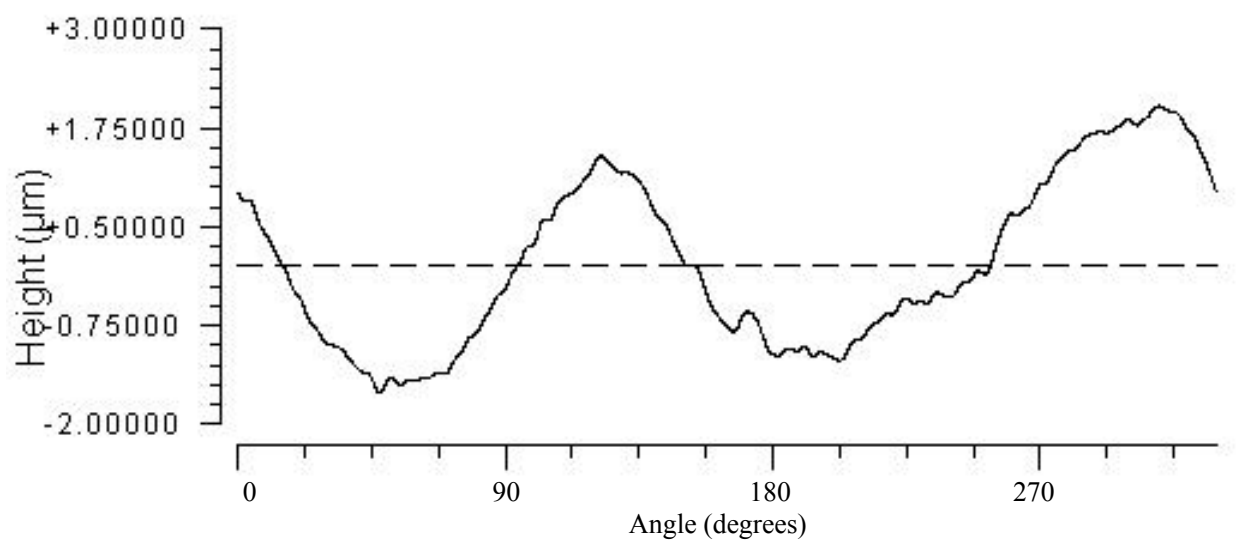

Figure 4-7 Substrate waviness before lapping

The circumferential waviness is found to be approximately sinusoidal as will be discussed below. The amplitude of this sinusoidal wave largely depends on the processing of the substrate. Figure 4-7 shows an optical interferometer profile of the circumferential waviness of the substrate surface before lapping. The profile is sinusoidal with amplitude of $2 \mu \mathrm{m}$. This waviness profile is likely the result of the processing of the substrate. The disc substrate is cut from a stainless steel bar stock and then face-turned on a lathe to the desired thickness. 


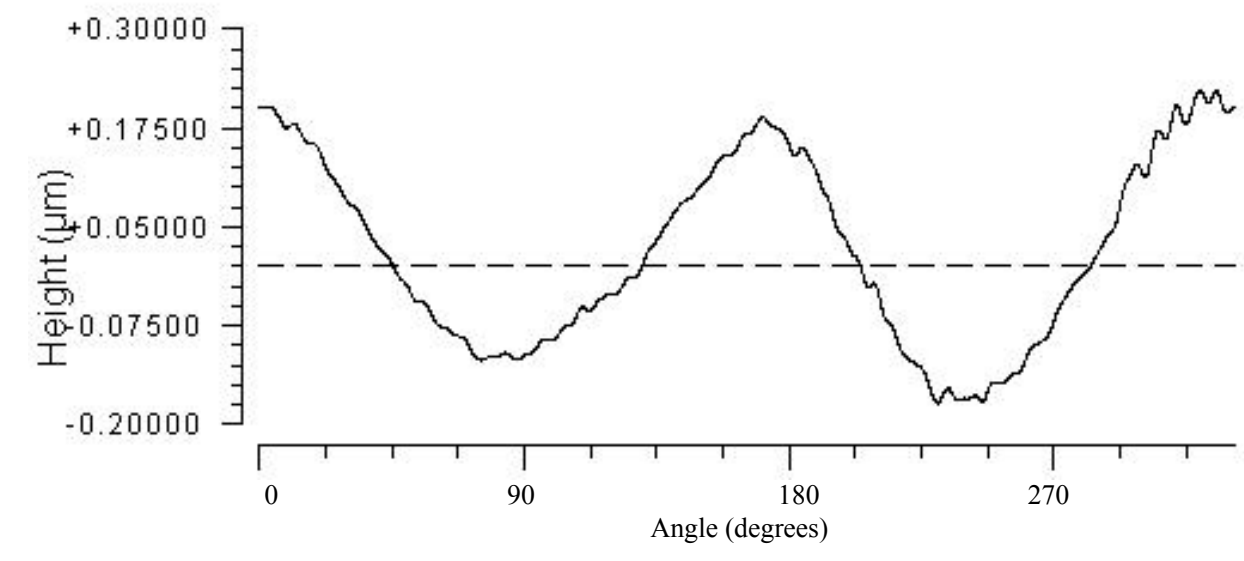

Figure 4-8 Substrate waviness after lapping and polishing

The clamping and tool forces during the machining process are a likely source for the circumferential waviness profile. The amplitude of this profile is minimized after lapping and polishing the substrate. Figure 4-8 shows the waviness profile of the lapped substrate. The amplitude of this wave is only $0.22 \mu \mathrm{m}$ but the profile is still sinusoidal. The substrate face may further distort due to the non uniform thermal cycles it may endure during operation.

\subsection{Asperity edge rounding error}

During the fabrication of asperities, it is often required to control asperity heights/depths by some material removal process mainly lapping and polishing. An important criterion to consider during this type of height control is to control the asperity edge rounding. Figure 4-9 shows an optical interferometer profile of positive asperities. Only an array of 3 asperities is shown in the figure. The sharp corners in the profile show the asperity profile to be near perfect. The height of the asperities shown is $11 \mu \mathrm{m}$. Figure 4-10 shows the profile of the asperities after polishing the surface at a pressure of $0.06 \mathrm{MPa}$ (10psi) for 10 minutes. 


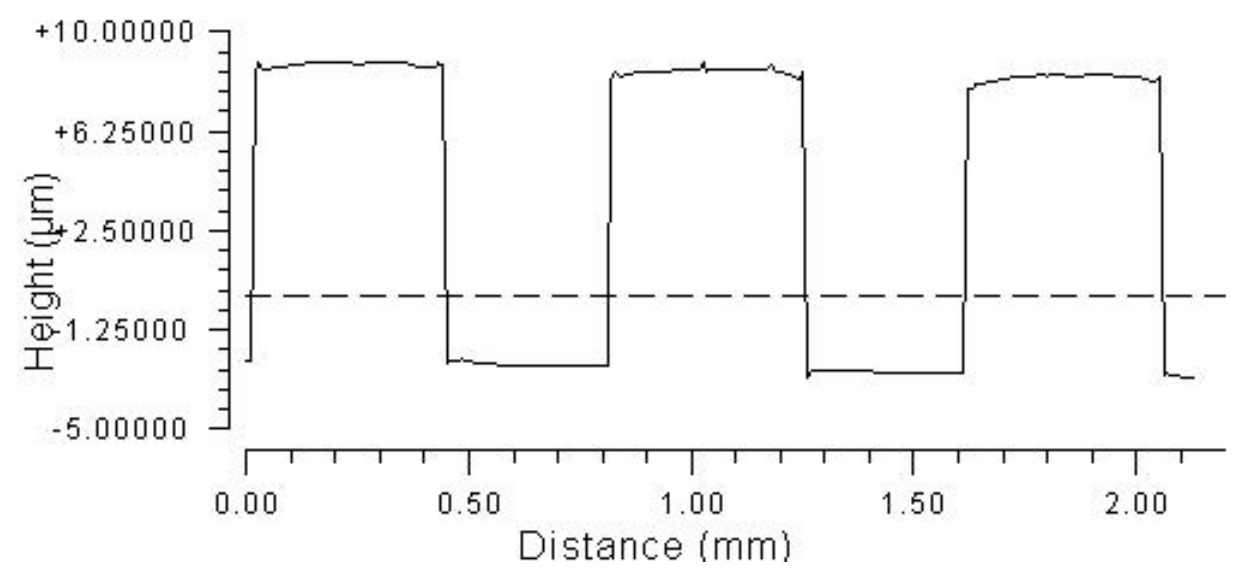

Figure 4-9 Profile of positive asperities

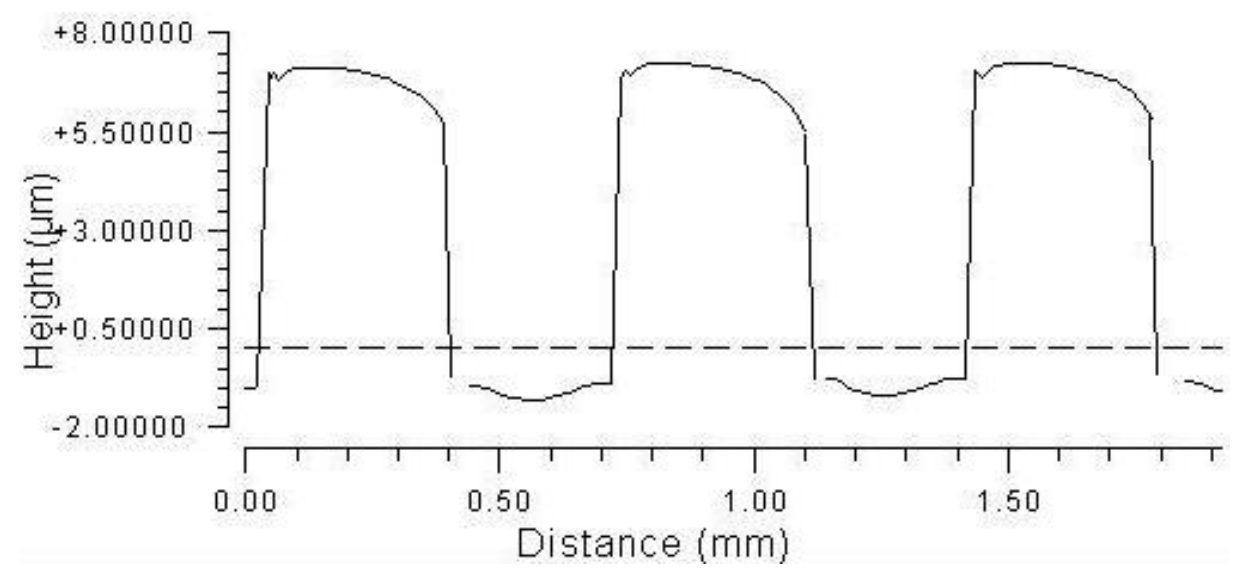

Figure 4-10 Profile of positive asperities after polishing

The asperity top edges are rounded by about $10 \%$ of the side length of the asperity. The rounded asperity tops itself acts as converging/diverging wedges when the textured face is running against another surface and this may induce additional load support.

Copyright $\odot$ Sriram Venkatesan, 2005 


\section{CHAPTER 5 - SENSITIVITY ANALYSIS OF FABRICATION ERRORS}

\subsection{Introduction and modeling}

In the previous chapters, errors in asperity geometry were identified and quantified. The surface texture design for any thrust surface is based on the assumption of a perfect geometry of the texture itself. But the ideal surface texture is never attained using any manufacturing process. The errors in surface feature geometries may be sensitive to the lubrication performance of the textured surface. Hence, having known the magnitude of these errors in the previous sections, it is desired to model the effect of these errors to analyze their effects on hydrodynamic lubrication.

A two-dimensional lubrication model for a surface texture design was developed in [14]. A similar model is developed in this chapter to analyze the sensitivity of some of the errors in micro asperity geometry and the corresponding trends are studied.

\subsubsection{Lubrication model}

Four asperity geometries are considered in this study namely, square, circle, triangle and hexagon. The desired asperity height and cavity depth are fixed at $15 \mu \mathrm{m}$. Table 5-1 summarizes the values of constants used in this study. An asperity density, $\mathrm{N}=1.71 / \mathrm{mm}^{2}$ in a square unit cell is chosen with a unit cell size $t=754 \mu \mathrm{m}$. The slider speed is held constant at $\mathrm{U}=3.5 \mathrm{~m} / \mathrm{s}$. These values are selected as they reflect typical values of surfaces that have been fabricated and tested by authors in $[13,26]$. The lubrication model is similar to the model in [14] but here the model is improved by incorporating some of the errors in asperity geometry. 
Table 5-1 Values of constants

\begin{tabular}{|c|c|c|}
\hline $\begin{array}{c}\text { Parameter } \\
\text { Symbol }\end{array}$ & Units & Value \\
\hline $\mathrm{N}$ & $\mathrm{asp} / \mathrm{mm}^{2}$ & 1.71 \\
\hline $\mathrm{t}$ & $\mu \mathrm{m}$ & 754 \\
\hline $\mathrm{U}$ & $\mathrm{m} / \mathrm{s}$ & 3.5 \\
\hline $\mathrm{Ro}$ & $\mathrm{mm}$ & 38.1 \\
\hline $\mathrm{Ri}$ & $\mathrm{mm}$ & 24.9 \\
\hline $\mathrm{h} 1$ & $\mu \mathrm{m}$ & 15 \\
\hline$\mu$ & $\mathrm{N}-\mathrm{s} / \mathrm{m}^{2}$ & 0.2 \\
\hline $\mathrm{W}_{\text {des }}$ & $\mathrm{N} / \mathrm{mm}^{2}$ & $10^{5}$ \\
\hline
\end{tabular}

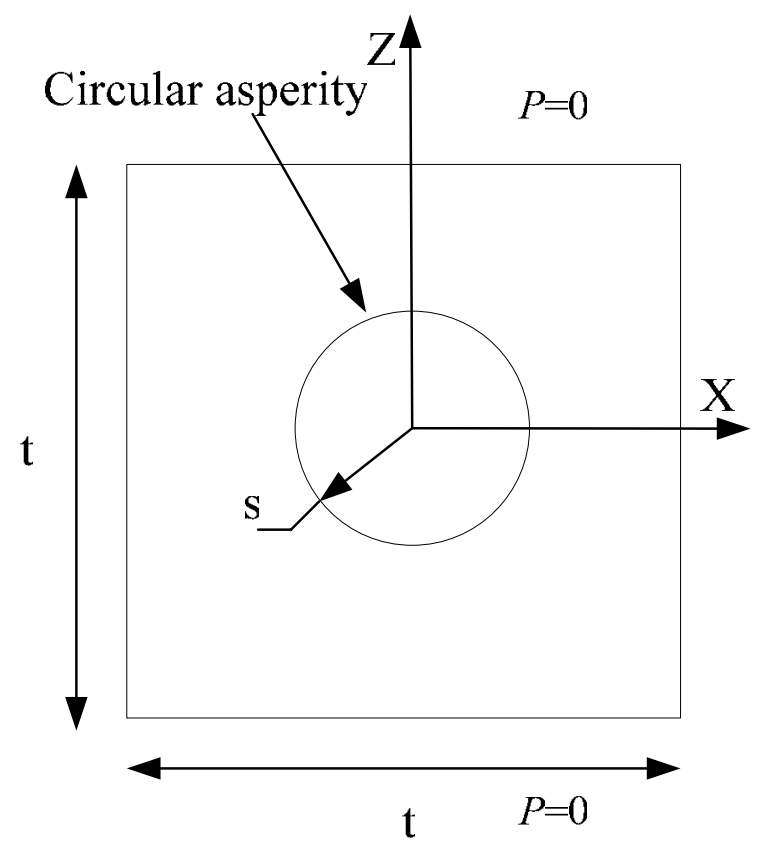

\section{Figure 5-1 Circular asperity within unit cell}

The modeling approach taken here is to consider a single unit cell with periodic boundary conditions that account for asperity interactions in the tangential direction (x). It is assumed that the effects of radial interactions are negligible by comparison [14]. Figures 5-1 and 5-3 show cross sections of an ideal positive and negative asperity respectively. 


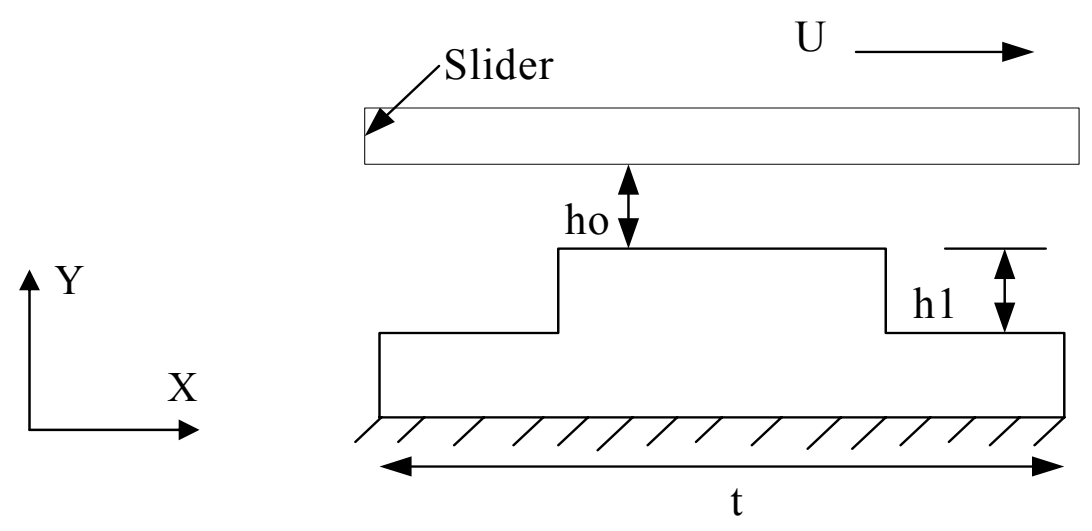

Figure 5-2 Side view of a positive asperity

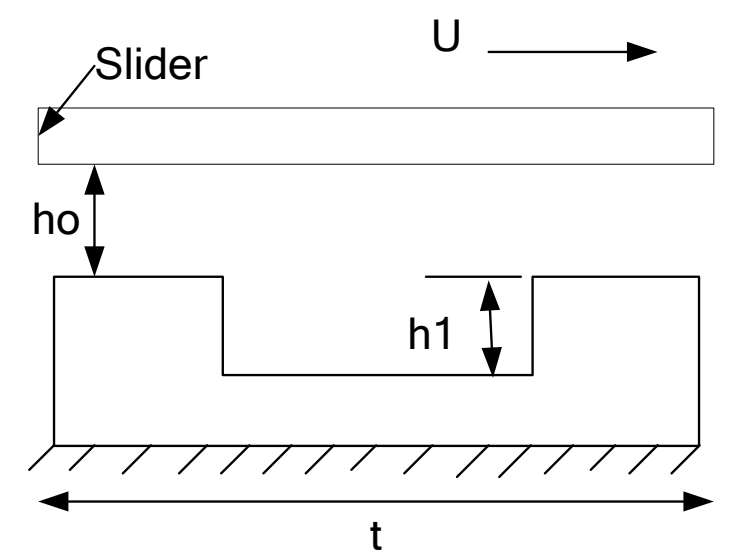

Figure 5-3 Side view of negative asperity

The asperity height/depth is denoted by $\mathrm{h} 1$ and ho is the film thickness above the asperities. The slider velocity $\mathrm{U}$ is in the $\mathrm{x}$-direction. The film thickness for all geometries is given by,

$$
\begin{aligned}
& h(x, y)=\left\{\begin{array}{cc}
h o, & \text { above positive asperities } \\
h o+h 1, & \text { between positive asperities }
\end{array}\right. \\
& h(x, y)=\left\{\begin{array}{cc}
h o+h 1, & \text { above negative asperities } \\
h o, & \text { between negative asperities }
\end{array}\right.
\end{aligned}
$$


Assuming a thin Newtonian lubricant film undergoing laminar, incompressible flow and neglecting temperature and inertial effects, the pressure $p(\mathrm{x}, \mathrm{z})$, is governed by the Reynolds equation,

$$
\frac{\partial}{\partial x}\left(h^{3} \frac{\partial p}{\partial x}\right)+\frac{\partial}{\partial z}\left(h^{3} \frac{\partial p}{\partial z}\right)=6 \mu U \frac{\partial h}{\partial x} .
$$

Where $\mu$ is the fluid viscosity (assumed constant) and squeeze film effects neglected. The enforced boundary conditions at the unit cell boundaries are given by,

$$
\begin{aligned}
& p(x, t / 2)=0 \ldots \ldots \ldots \ldots \ldots \\
& p(x,-t / 2)=0 \ldots \ldots \ldots \ldots \ldots \\
& p(-t / 2, z)=p(t / 2, z) \ldots \ldots \\
& \frac{\partial p}{\partial x}(-t / 2, z)=\frac{\partial p}{\partial x}(t / 2, z)
\end{aligned}
$$

Equations (5.4) and (5.5) are periodic boundary conditions in the tangential direction. The Reynolds cavitation condition is approximated using the Swift-Steiber conditions at the vapor region in the film and is given by [14],

$$
p=p_{c a v}=0, \text { if } p<0
$$

Equation (5.3) is solved using a finite difference numerical scheme. The finite difference equation is solved iteratively using Gauss-Siedel method with a square staggered grid. The errors in asperity geometry are modeled assuming a constant set of running conditions. This requires an iterative solution to Eqs (5.3)- (5.8), which is accomplished using an optimization routine that minimizes the difference between the desired load capacity, $\mathrm{W}_{\mathrm{des}}$ and the computed load capacity, $\mathrm{W}_{\text {comp. }}$ Using the pressure results, the average load capacity of one unit cell is given by, 


$$
W_{\text {comp }}=\frac{1}{t^{2}} \int_{-t / 2}^{t / 2} \int_{-t / 2}^{t / 2} p(x, z) d x d z \ldots \ldots \ldots \ldots \ldots \ldots \ldots \ldots \ldots \ldots
$$

The friction coefficient is computed as done in [14].

\subsection{Sensitivity Analysis}

A lubrication model to solve the hydrodynamic problem for a single asperity was presented in the previous section. The errors in the asperity geometry is incorporated into this model such the profiles of the asperity shapes is slightly distorted based on the error studied i.e. the asperity tilt error would be modeled as an inclination on the asperity tops etc. The lubrication problem is solved numerically over a staggered grid. The errors independent of grid spacing are cavity form error, asperity tilt error, variation in asperity height and variation in cavity depth. The errors dependant on the grid spacing is percentage change in asperity/cavity major dimension and asperity/cavity corner radius.

The errors that are independent on grid spacing are the ones that are analyzed by varying the film thickness profiles over the top the respective asperities. Here the film thickness is varied according to the magnitude of the respective error.

The asperity/cavity corner radius is not directly introduced into the model. The asperity corner radius in effect reduces the net surface area of the asperities as compared to the area of a perfect geometric shape (squares, triangles) due to the rounded corners. Due to this reduction is area, the asperity area fraction $\delta^{2}$ is reduced. This reduction in $\delta^{2}$ is plotted against load capacity to ascertain the sensitivity of the asperity/ cavity corner radius error. In other words, a reduced $\delta^{2}$ value is calculated for each value of asperity/cavity corner radius and is plotted against load capacity. 
The percentage change in asperity and cavity major dimensions also produce the same effect of a reduction in the net surface area of the asperities and are hence analyzed in a similar way as discussed in the previous paragraph.

\subsection{Sensitivity of tilt angle}

The two-dimensional lubrication model discussed in the previous section is the base model on which modifications are made to include the effects of some of the errors in asperity geometry. The errors modeled for a positive asperity are asperity tilt error, variation in asperity height, errors in asperity major dimension and asperity corner radius. For a negative asperity, asperity form error, variation in cavity depth, error in cavity major dimension and cavity corner radius are modeled. The asperity major dimension is the critical dimension of an asperity geometry namely, side length in the case of square, triangle and hexagon, radius in the case of a circle. The numerical solution for the lubrication model was benchmarked based on the method discussed in [14] so that the numerical model produces desired results. Figures 5-4 and 5-5 show the sensitivity of tilt angle with respect to load capacity and friction coefficient respectively. The errors in asperity geometry that are dependent directly on the film thickness ho are the tilt angle, error in asperity height in the case of a positive asperity and asperity form error, error in cavity depth in the case of a negative asperity. The asperity shape considered in these figures is a circular asperity having $\delta^{2}=0.4$. In analyzing the sensitivities of the above mentioned errors in asperity geometry, the error sensitivity is almost independent of asperity shape i.e. the sensitivity of errors is almost the same for a square or any other geometry of the same size. Hence, only circular asperities are considered in this study. From fig $5-4$, it is seen that small tilts on asperity tops have a considerable effect only 


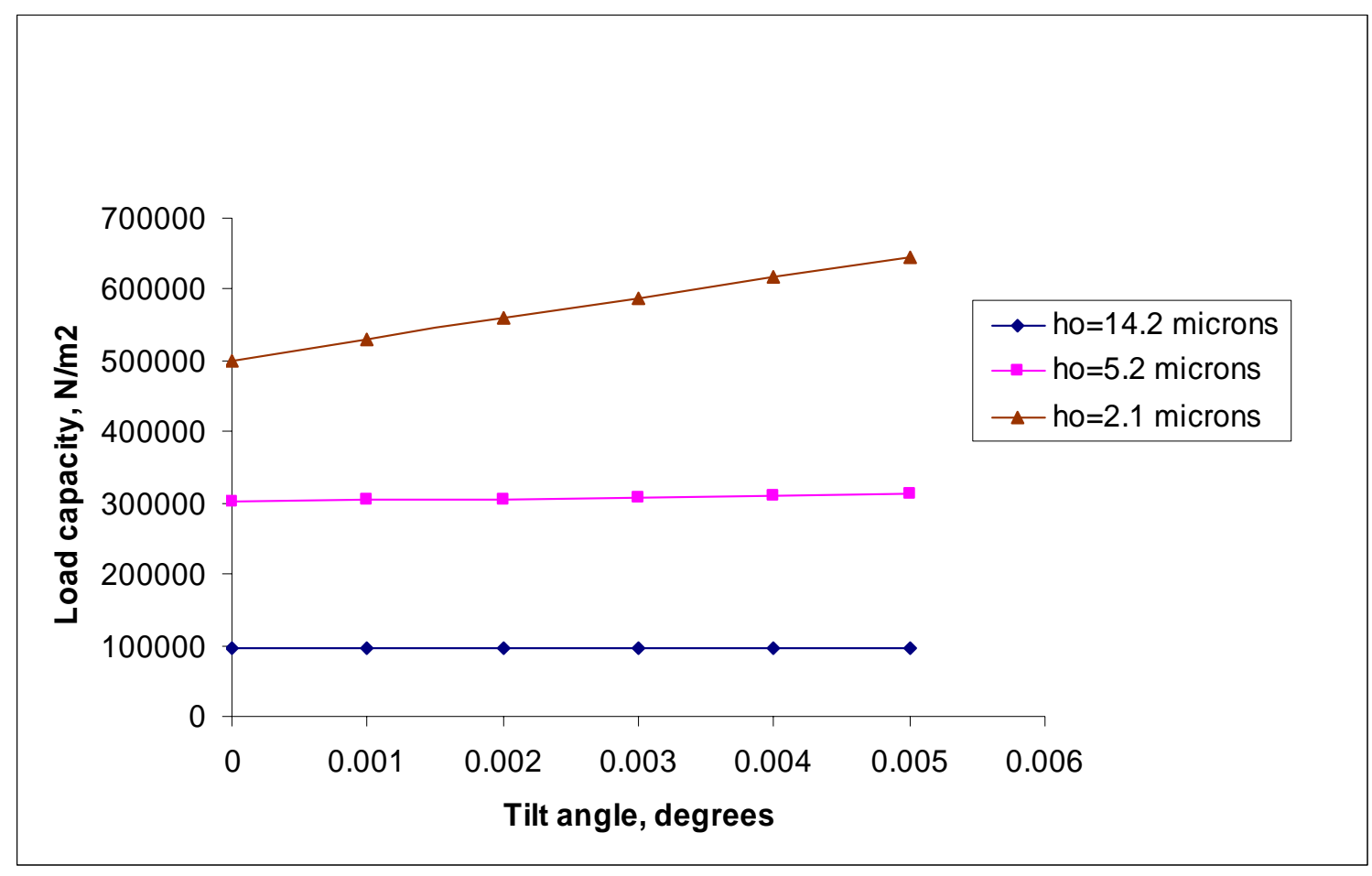

Figure 5-4 Sensitivity of tilt angle, vs load capacity (circle positive asperity)

when the film thickness is small as is the case with the curve for ho= 2.1 microns. The magnitude of this error is in the range assumed by the authors in [8].

This error is sensitive to load capacity only when the surface supports high loads. This conforms to the results in [8]. In the case of larger film thicknesses, the asperity tilt error does not impact lubrication performance given their magnitude. From fig 5-5 it is evident that the friction coefficient does not change appreciable within the range of the error magnitudes, the maximum change being that for ho= 2.1 microns. This again confirms the conclusion that the above two errors in asperity geometry are sensitive to lubrication performance if the film thickness is small. From the above figures, and from other sensitivity results, it was confirmed that the friction coefficient was not vary with 
respect to the errors in asperity geometry, hence only sensitivity with respect to load capacity will be considered hereafter.

\subsection{Sensitivity of error in asperity height}

Figure 5-6 shows the sensitivity plot of the sensitivity of error in asperity height for a circle positive asperity of $\delta^{2}=0.4$. Here again the maximum change in load capacity is seen when ho is small. For ho $=2.1$ microns, a maximum of $32 \%$ change in film thickness is seen over the range of magnitude of the error considered.

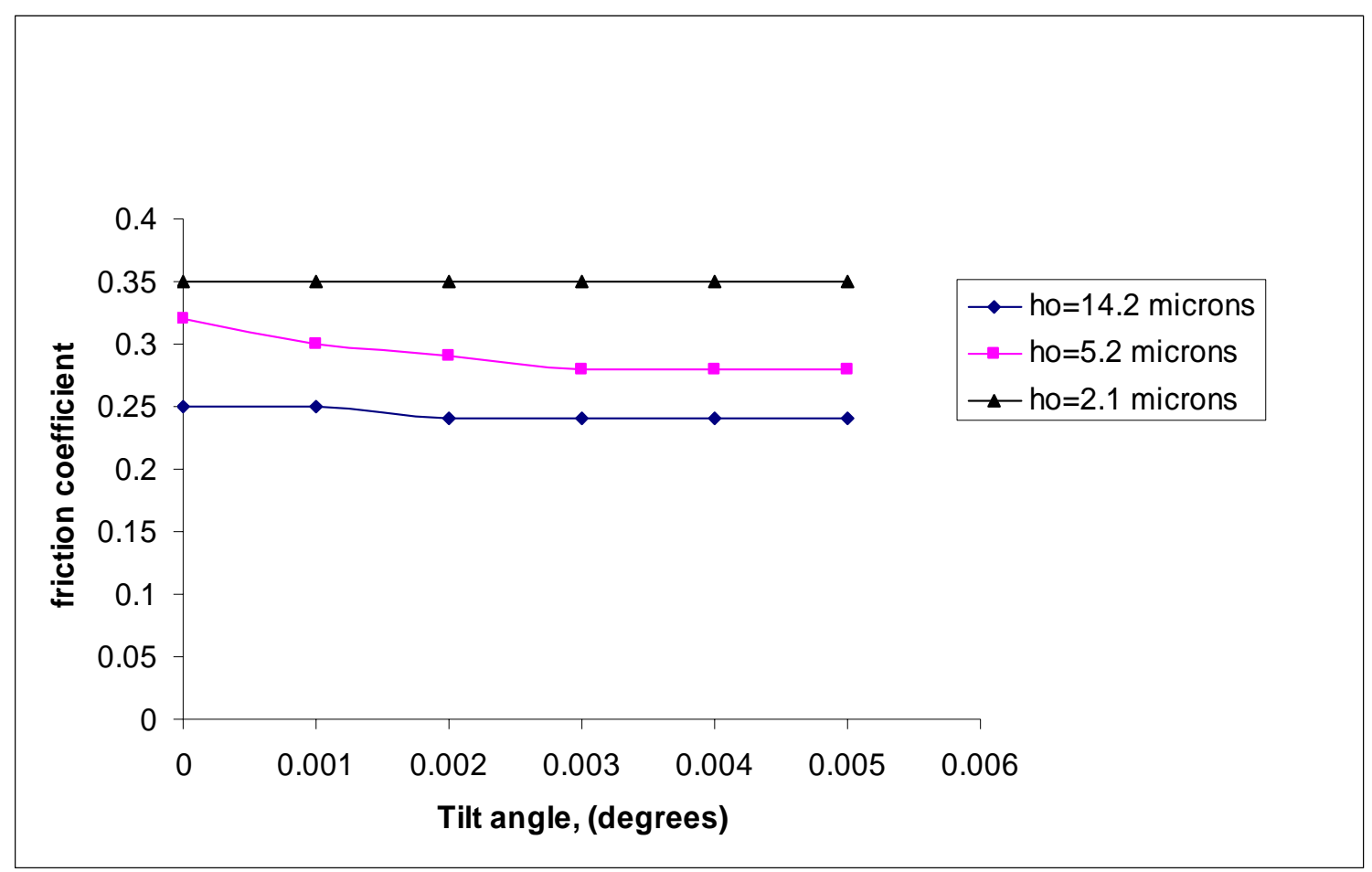

Figure 5-5 Sensitivity of tilt angle, vs coefficient of friction (circle positive asperity) 


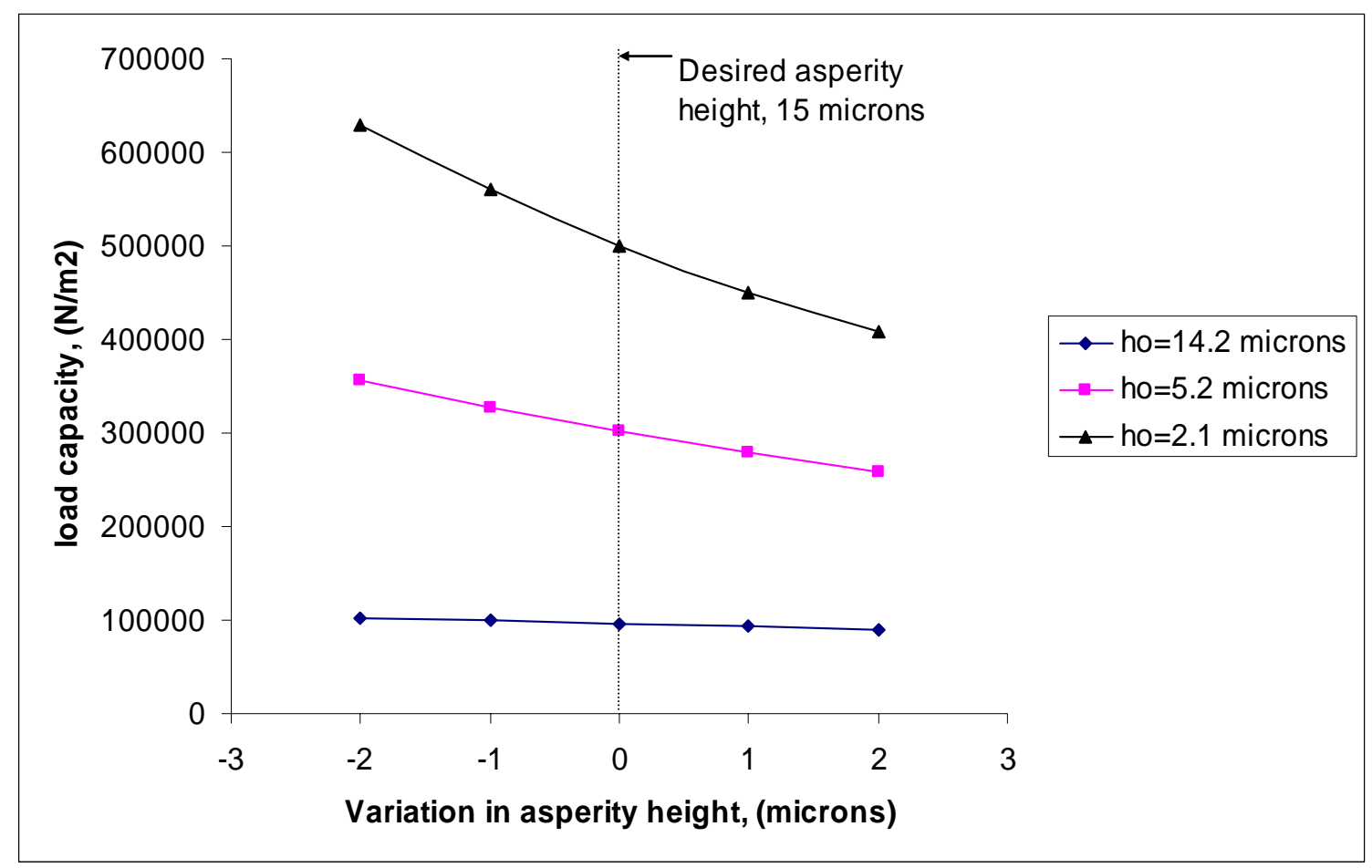

Figure 5-6 Sensitivity of error in asperity height (circle positive asperity)

\subsection{Sensitivity of asperity form error}

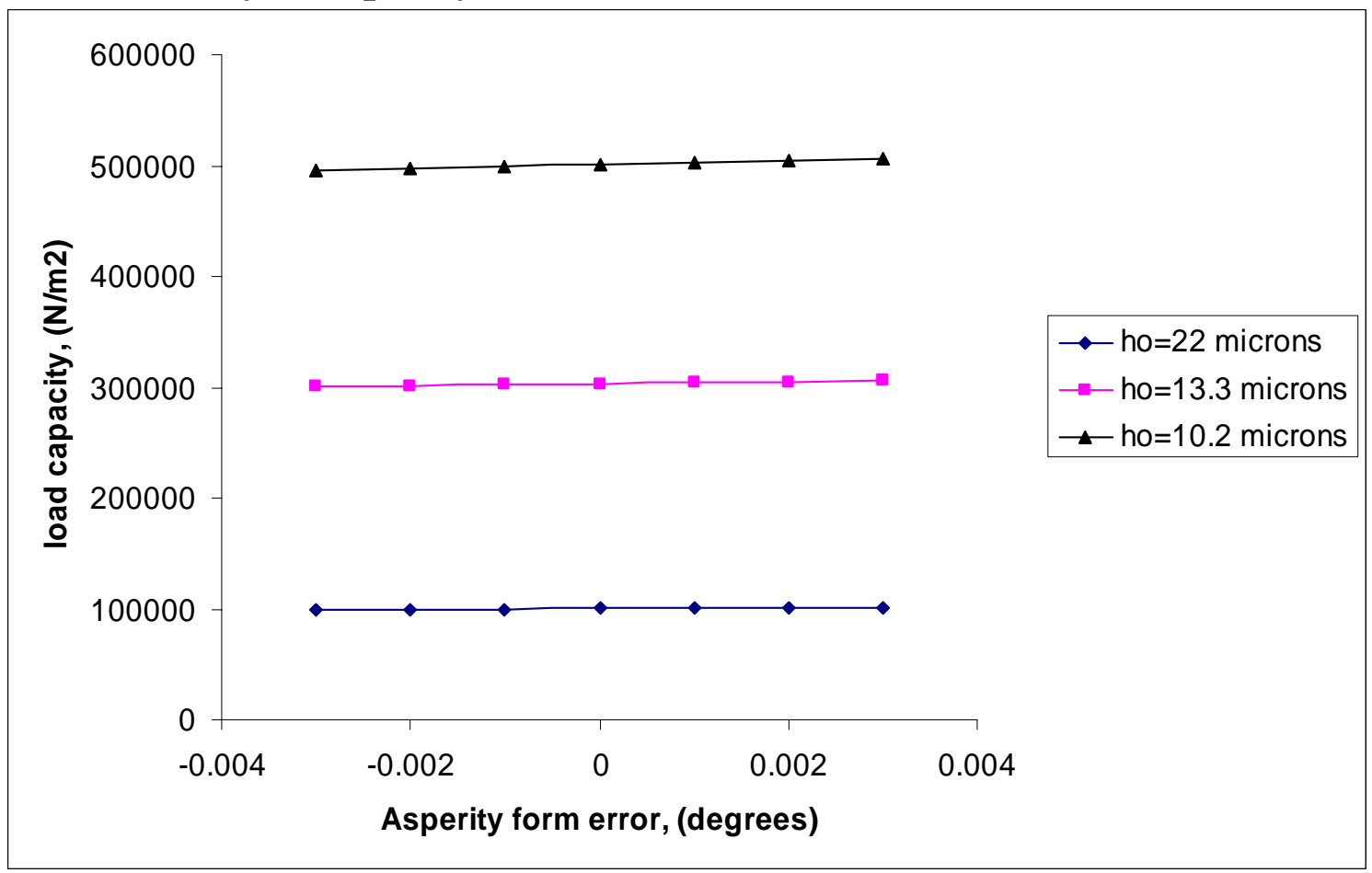

Figure 5-7 Sensitivity of asperity form error (circle negative asperity) 
Figure 5-7 is the sensitivity plot of asperity form error of a circular negative asperity of $\delta^{2}=0.4$. The near parallel lines on the plot indicate that this error is not very sensitive to lubrication performance in the range of the error magnitude considered.

\subsection{Sensitivity of error in cavity depth}

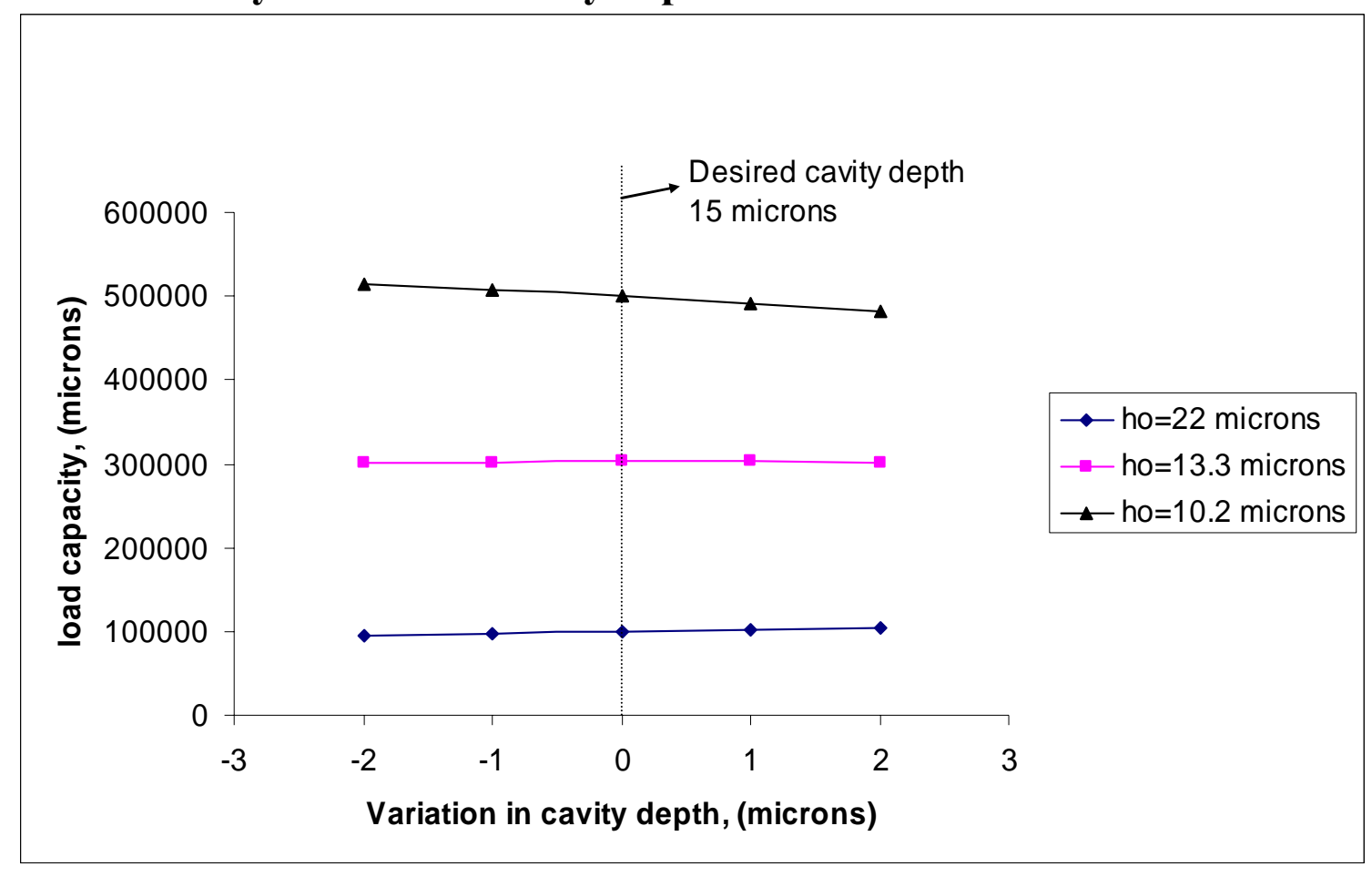

Figure 5-8 Sensitivity of error in cavity depth (circular negative asperity)

Figure 5-8 is the sensitivity plot of error in cavity depth with respect to load capacity. Here again this error is not very sensitive to lubrication in the range of errors considered. In the case of a negative asperity, relatively larger film thickness results as compared to positive asperities. Hence due to a larger film thickness, the errors in asperity geometry do not have a considerable effect. The other errors in asperity geometry considered in this study are asperity major dimension and asperity corner radius for both positive and 
negative asperities. For the sensitivity plots of these errors, a constant film thickness that will support a desired load of $10^{5} \mathrm{~N} / \mathrm{m}^{2}$ is assumed.

\subsection{Sensitivity of error in asperity/cavity major dimension}

Figures 5-9 and 5-10 show the sensitivity plots of error in asperity and cavity major dimension respectively.

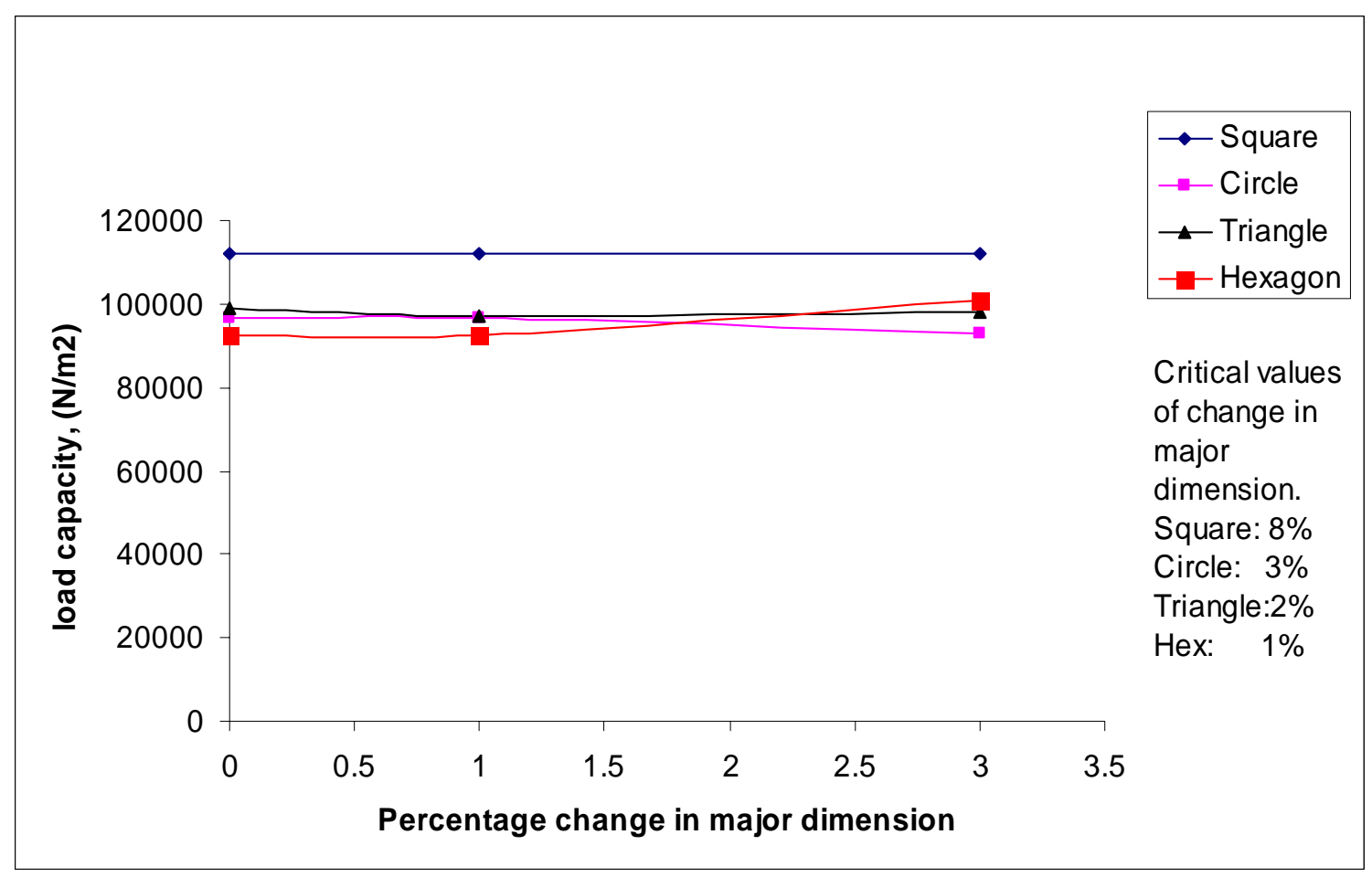

Figure 5-9 Sensitivity of asperity major dimension (Positive asperities)

From these graphs, this error is insensitive to lubrication up to a certain critical value and when the magnitude of this error is larger than this critical value, and then the error has a considerable effect on performance. Note here that based on the surface characterization of the errors presented in the previous chapter, the magnitude of these errors seldom exceed the critical values indicated in figures 5-9 and 5-10. Hence, the conclusion that the errors are insensitive to lubrication performance is valid. The critical values of error in 
asperity major dimension for a positive square, circle, triangle and hexagon are $8 \%, 3 \%$, $1 \%$ and $2 \%$ respectively. From fig $5-10$, for a negative asperity, the critical values are $7 \%, 2 \%, 1 \%$ and $1 \%$ respectively. From the surface characterization results in [24], the average errors in asperity major dimension is less than the critical value of the error in the case of a square negative asperity and the same is hypothesized for other asperity shapes hence this error is also insensitive to lubrication performance given its magnitude.

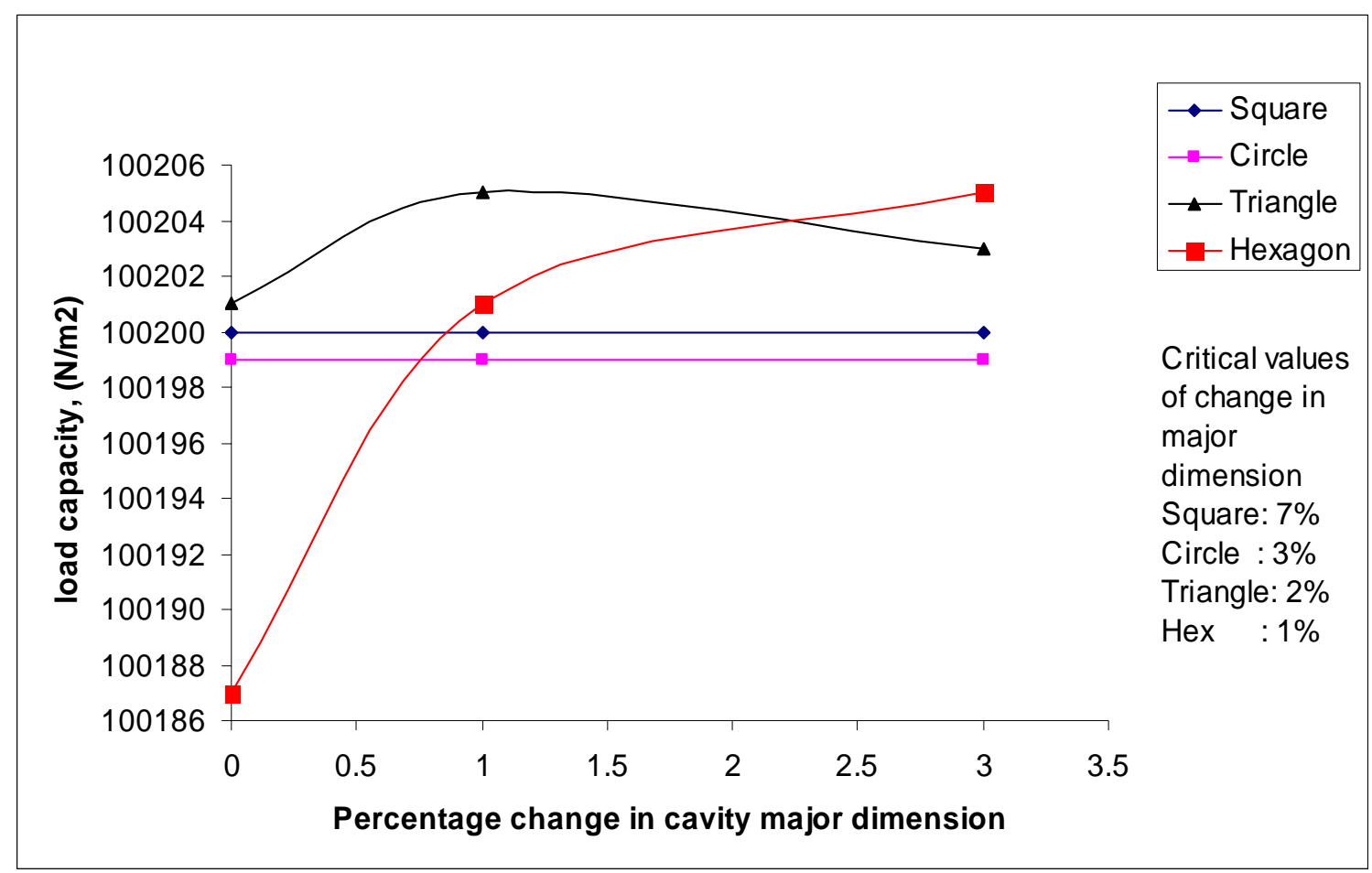

Figure 5-10 Sensitivity of cavity major dimension (Negative asperities)

\subsection{Sensitivity of cavity corner radius}

Figures 5-11 and 5-12 are the sensitivity plots of the corner radius error in both positive and negative asperities respectively. Parallel straight lines from these plots indicate that this error is insensitive to performance of the textured surface and the critical error values are larger than the actual value of measured errors in [24]. Hence this error does not impact performance of the textured surface. 


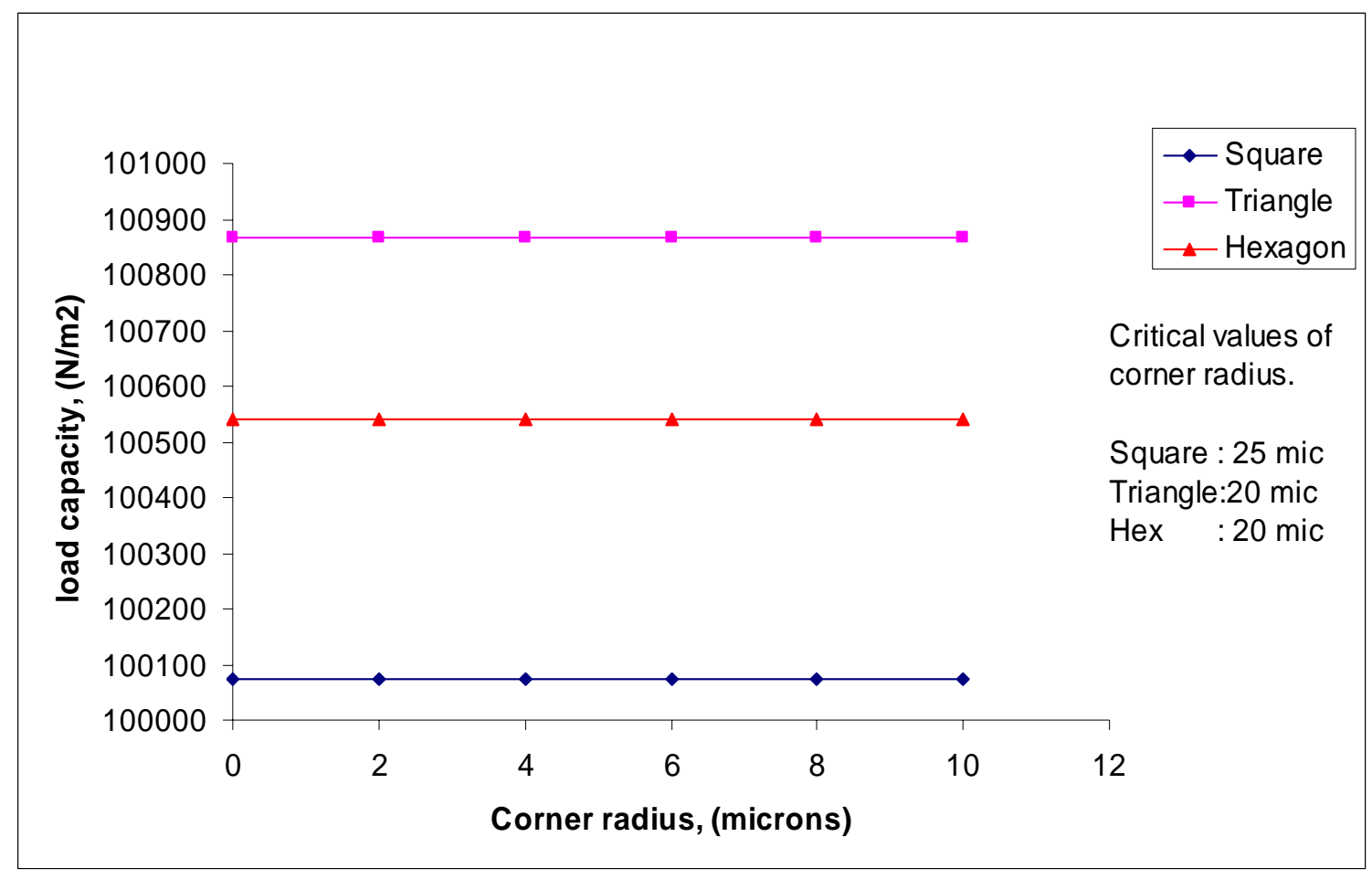

Figure 5-11 Sensitivity of corner radius, positive asperities

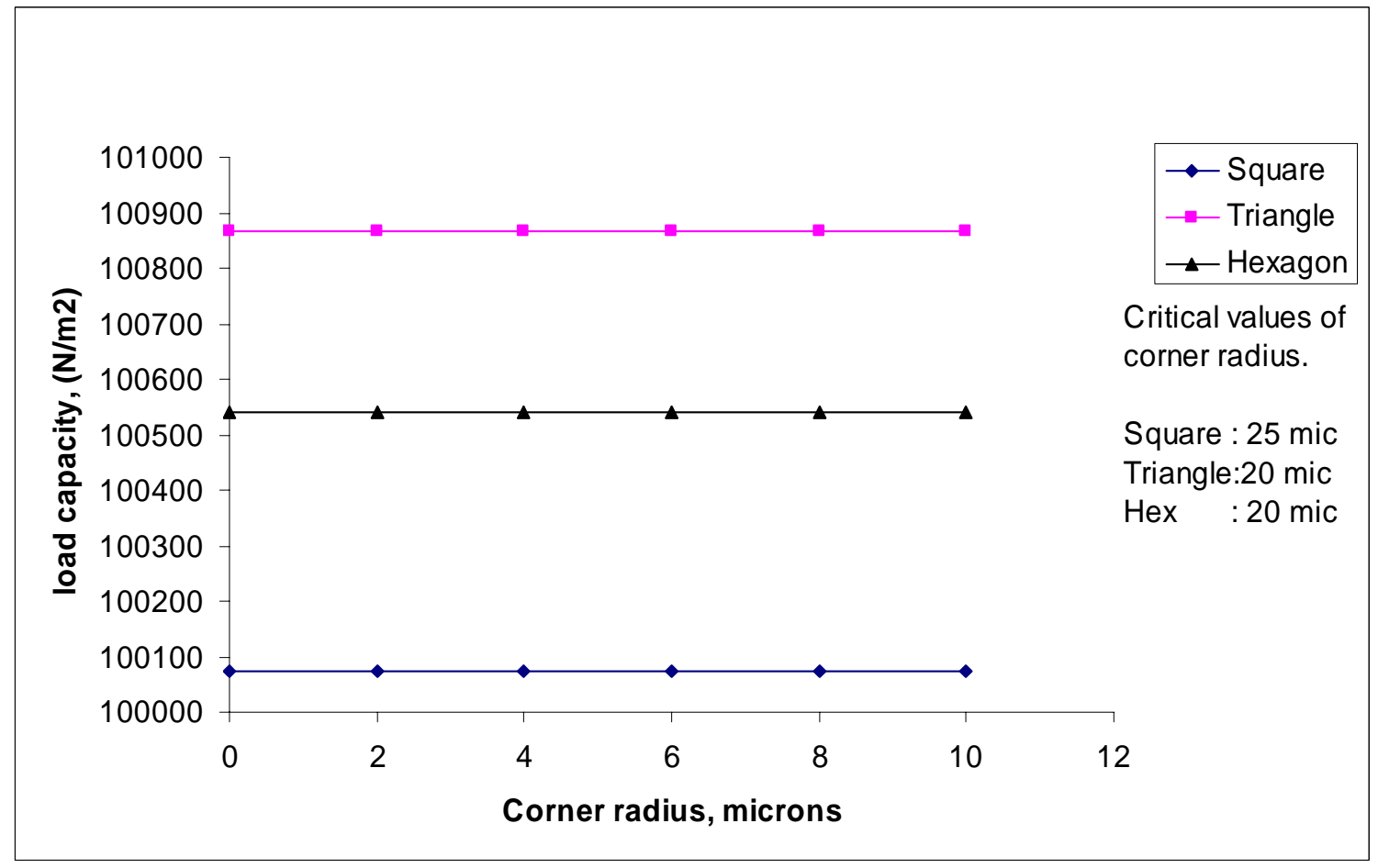

Figure 5-12 Sensitivity of corner radius, negative asperities

Copyright $(C)$ Sriram Venkatesan, 2005 


\section{CHAPTER 6- CONCLUSIONS AND FUTURE WORK}

\subsection{Conclusions}

This research work details a manufacturing process to fabricate a specific deterministic surface texture on flat stainless steel surfaces. Surface characterization of this fabricated surface texture revealed some errors of form in both the surface and the deterministic features. These errors were identified and statistically quantified. A sensitivity analysis of these errors was performed to ascertain their impact on hydrodynamic lubrication. The highlights and conclusions of this Thesis are as follows,

- A detailed surface texture fabrication process is presented outlining all process parameters and procedures required to successfully duplicate the process.

- The use of the LIGA/UV photolithography process is shown to be favorable for fabricating metallic surface features on flat thrust rings.

- Surface characterization of the fabricated surface features revealed some errors of form in both the surface and the deterministic features.

- Statistical quantification of these errors shows that the errors follow a Gaussian distribution.

- The accuracy of the manufacturing process was found to lie within $6.5 \%$ over all the errors studied and the random surface roughness was 1 to 3 orders of magnitude less than the deterministic feature size.

- The "flat" substrate surface had a two wave circumferential waviness with amplitude of $0.22 \mu \mathrm{m}$. This waviness may be formed during clamping operation of the substrate. 
- To ascertain the impact of fabrication errors in the deterministic features, a sensitivity analysis of the errors was performed on a lubrication model of these surface textures.

- Sensitivity analysis results showed minimum/negligible effect of fabrication errors on hydrodynamic lubrication given the magnitude of the errors when the film thickness (ho) was greater than $5.2 \mu \mathrm{m}$.

- For smaller film thickness of the order of $2.1 \mu \mathrm{m}$, the asperity tilt error and the error in asperity height/depth have a considerable effect, hence these errors have to be taken into account when smaller film thicknesses are found in experiments.

- The results from the sensitivity analyses also prove that the outlined surface texture fabrication process is ideal for experimental testing with minimum effects from manufacturing process variations.

\subsection{Future work}

The results presented in this Thesis provide some useful insights for future research mainly in the area of surface textures for enhanced lubrication. These are as follows,

- The manufacturing process may be improvized sufficiently so as to fabricate deterministic surface textures on non-planar surfaces such as on the outer diameter of a shaft.

- Fabrication of the surface textures on surfaces of different materials, as per their requirements, has to be studied.

- Although the fabrication process discussed in this Thesis produces accurate and repeatable micro patterns, the capital cost of fabrication equipment is high resulting in higher cost per piece for a textured thrust ring. So the fabrication 
process has to be improvized to suit mass production needs. A suggested cheaper alternative for mass production needs may be to use the surface textured ring as a master die and use some sort of an embossing technique to rapidly and repeatably manufacture surface textures. This is foreseen by the author to produce optimum results.

Copyright $\odot$ Sriram Venkatesan, 2005 


\section{APPENDIX}

\section{A.1 MATLAB ${ }^{\circledR}$ script to solve general 2D lubrication problem for deterministic microasperities patterned onto a surface in a square array}

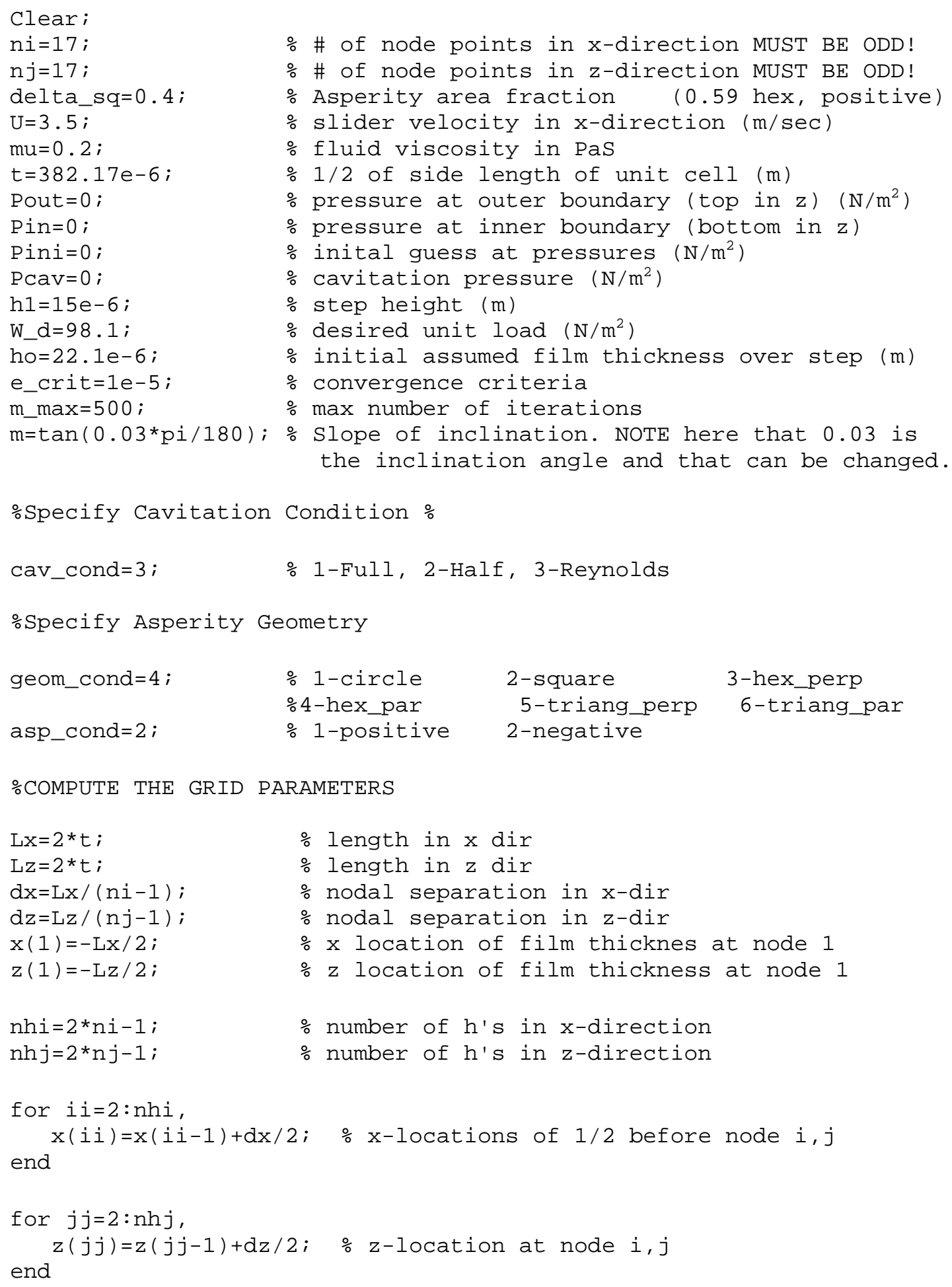




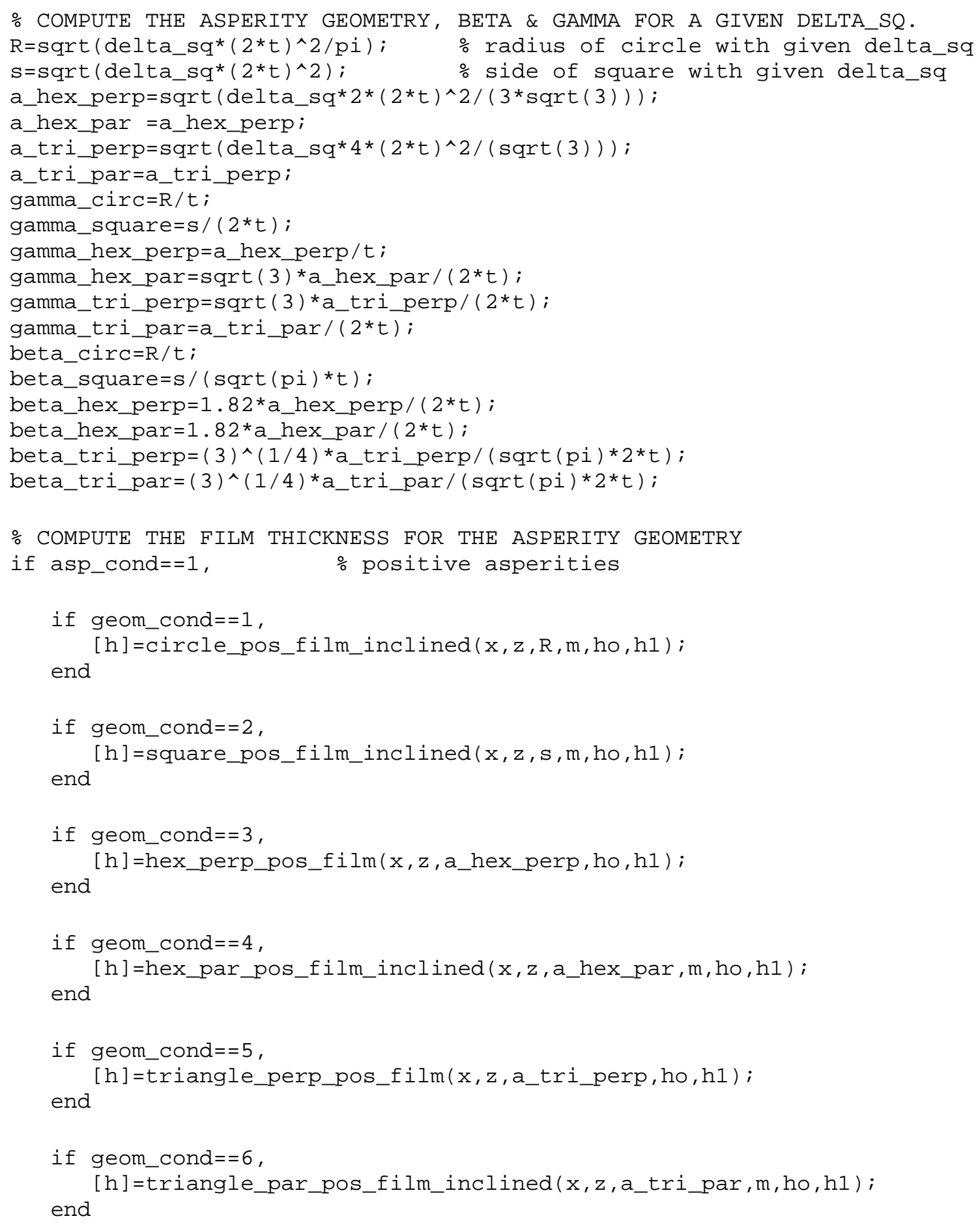

end

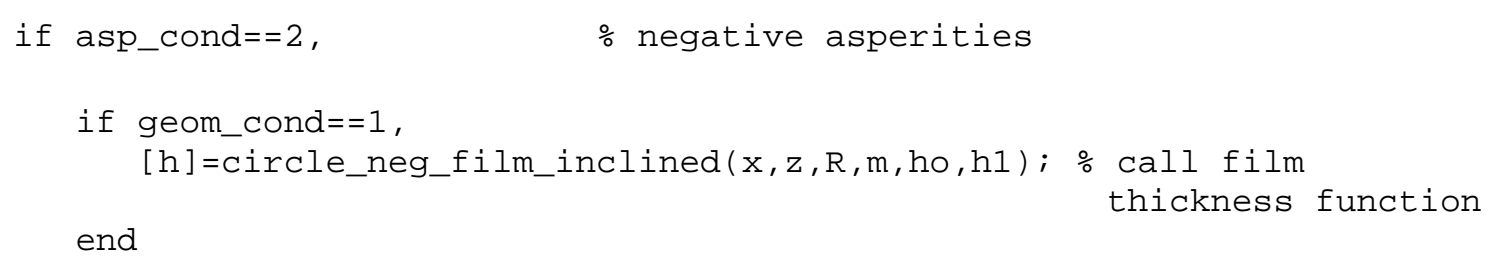




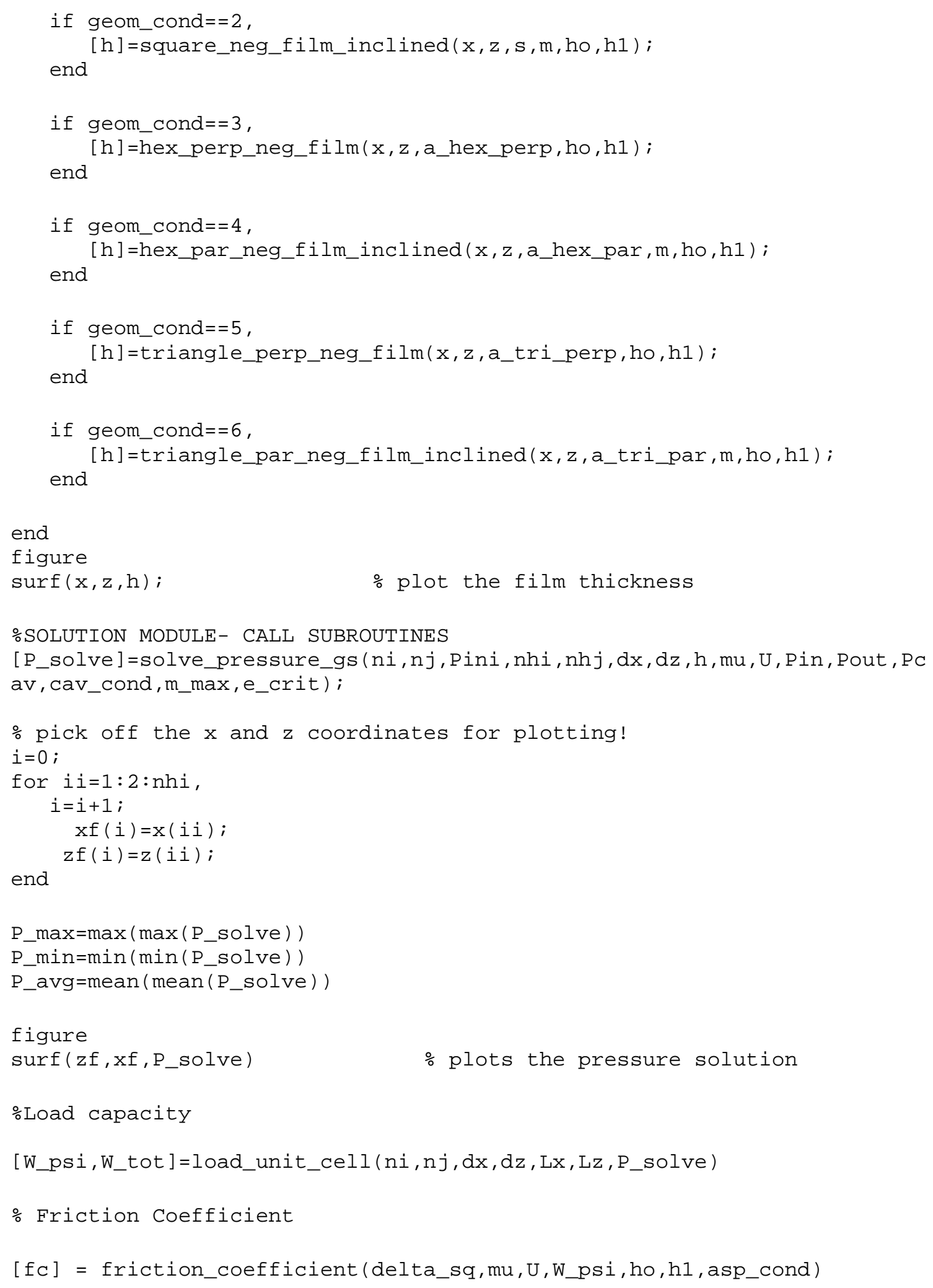




\section{A.2 MATLAB ${ }^{\circledR}$ function to compute film thicknesses}

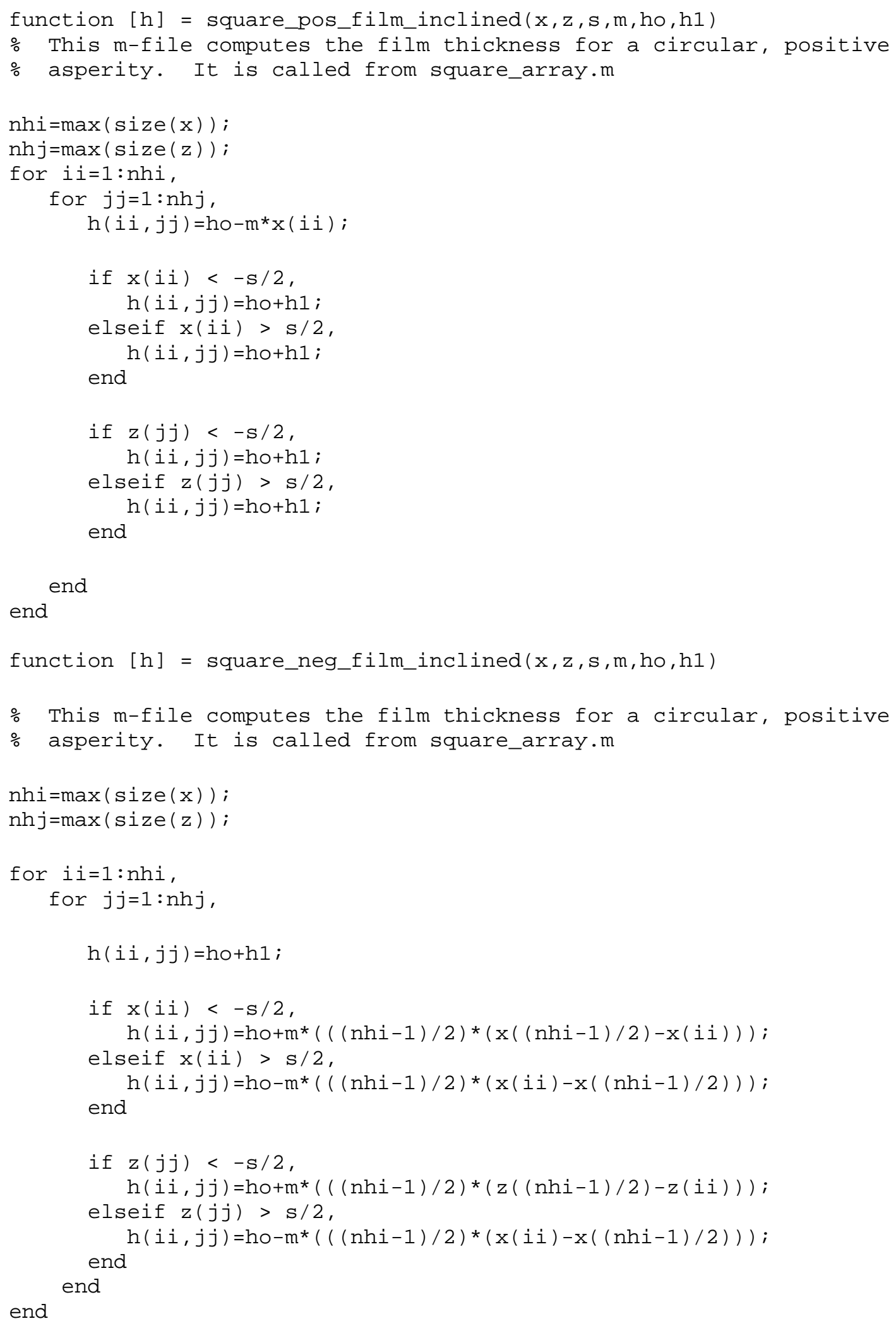




\section{A.3 MATLAB ${ }^{\circledR}$ function to solve for pressure distribution}

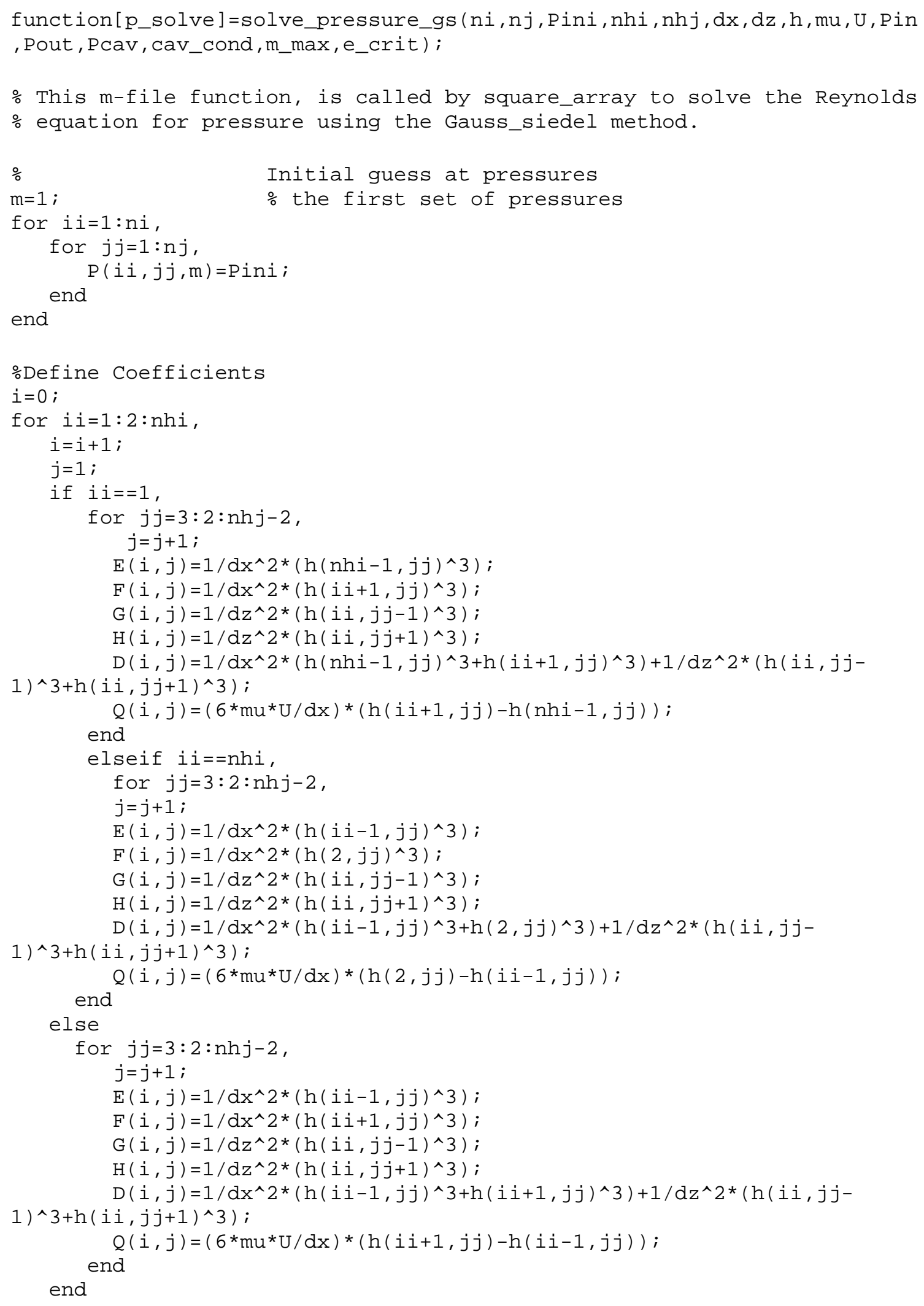




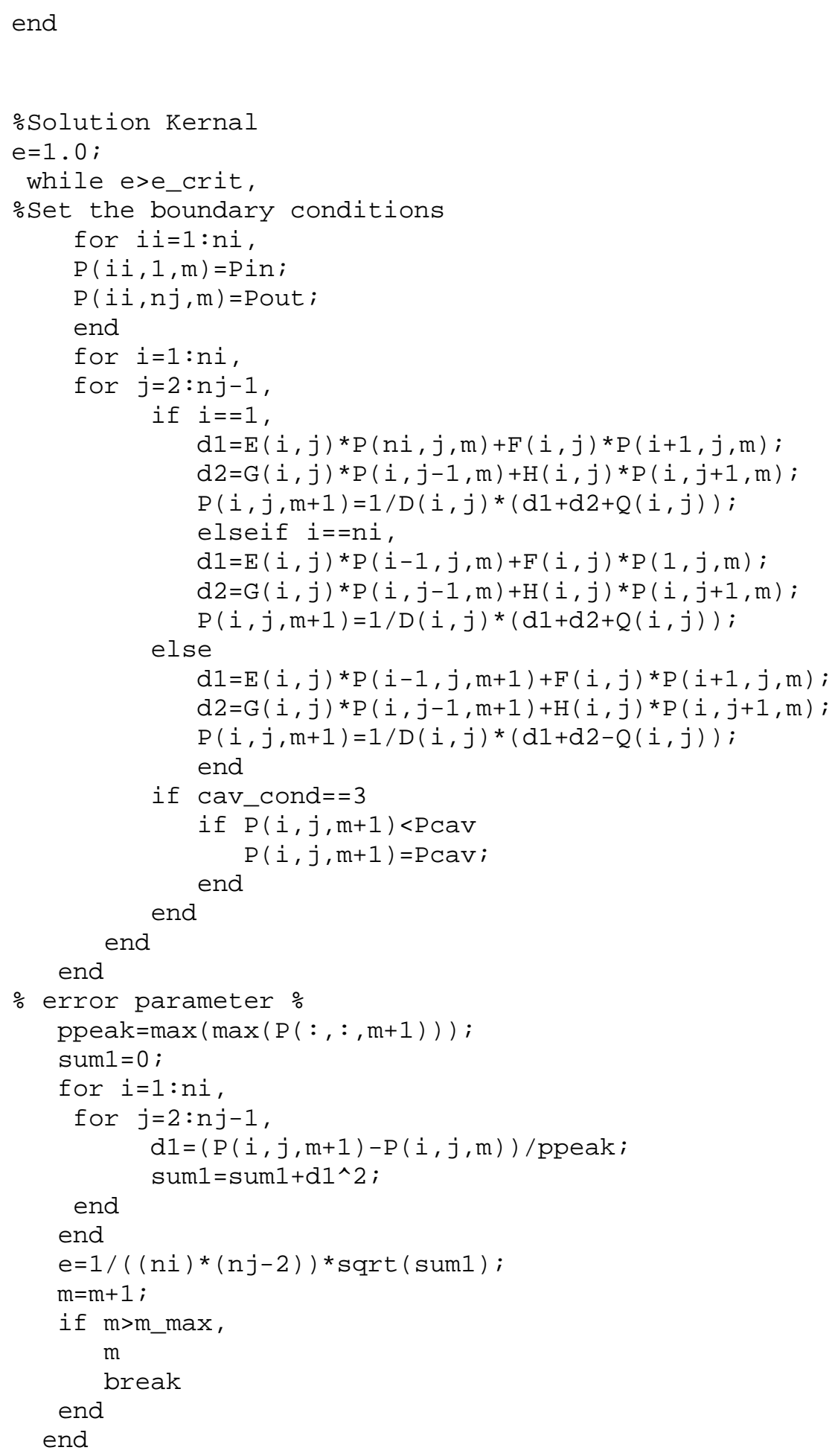

\%Set the boundary conditions on the final iteration for $i i=1: n i$, 


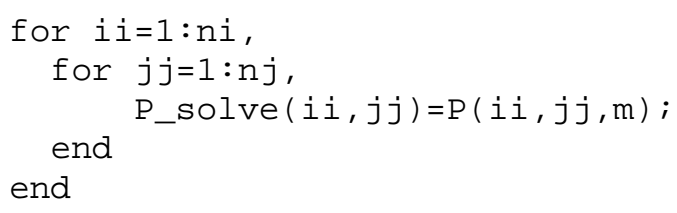

\section{A.4 MATLAB ${ }^{\circledR}$ function to compute load capacity and friction coefficient}

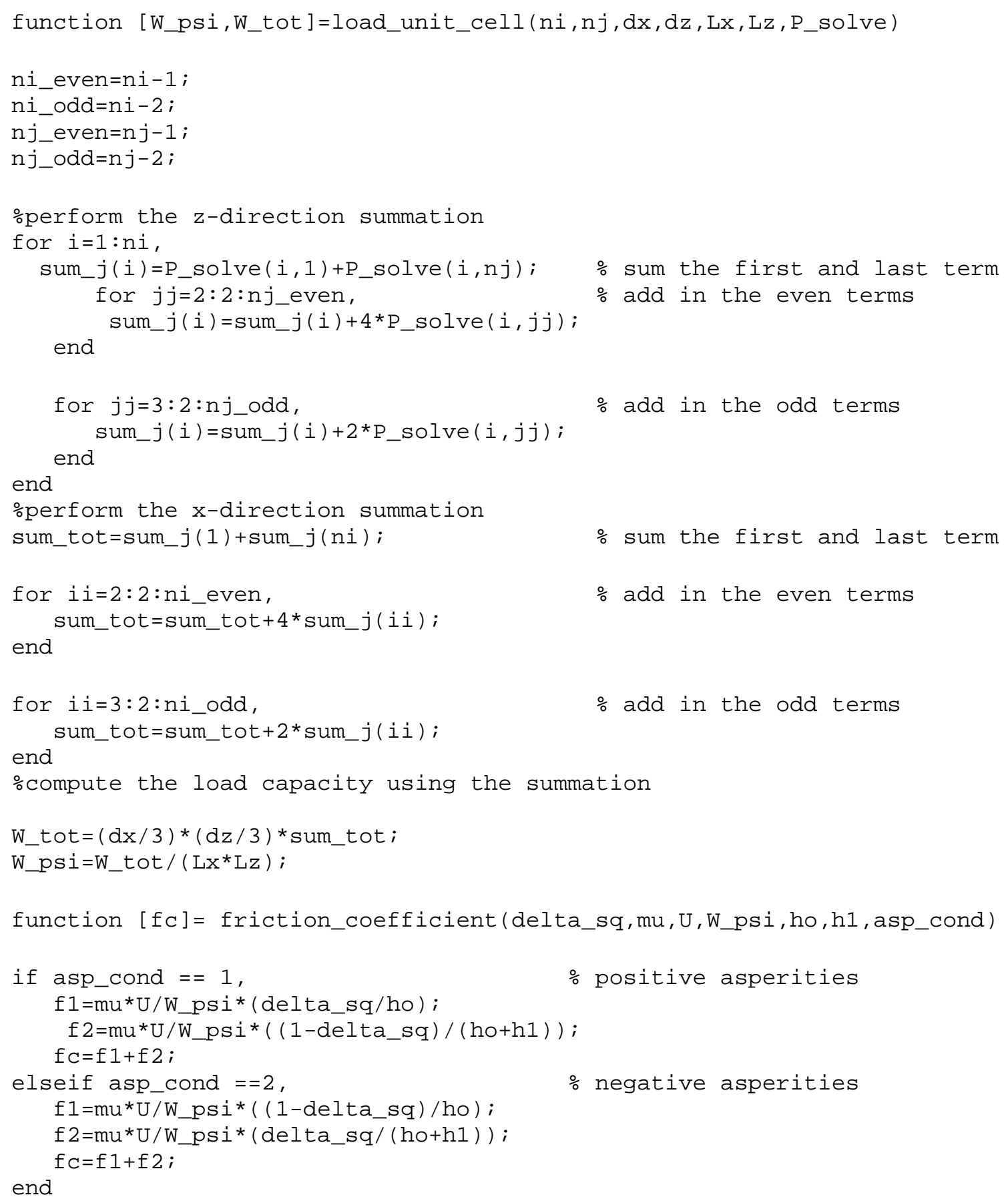




\section{REFERENCES}

[1] Evans, C, J., Bryan, J, B., (1999), "Structured, Textured or Engineered Surfaces", Annals of the CIRP, Vol. 48, $\mathrm{p} 2$.

[2] http://www.timken.com/innovation/metrology/surface.asp

[3] Burton, R.A., (1963),"Effect of two-dimensional, sinusoidal roughness on the load support characteristics of a lubricant film", Journal of Basic Engineering, Transactions of ASME, Ser.D,85,pp 258-264.

[4] Pecht,G.G., Carter, D., (1989), "System design and performance of a spiral groove gas seal for hydrogen service", Tribology Transactions, 46 (9),pp. 607-612.

[5] Shellef, R.A., Johnson, R.P., (1992), “A bi-directional gas face seal”, Tribology Transactions, 35(1), pp.53-58.

[6] Kojabashian, C., Richardson, H.H., (1967), "A micro pad model for the hydrodynamic performance of carbon face seals", Proceedings of the Third International Conference on Fluid Sealing, BHRA, England, pp. E4-41 to E4-71.

[7] Hamilton, D.B., Walowit, J.A., Allen, C.M.,(1966), "A Theory of lubrication by Microirregularities", Transactions of ASME Journal of Basic Engineeering, 88, pp $177-185$.

[8] Anno, J.N., Walowit, J.A, Allen, C.M., (1968), "Microasperity lubrication", Journal of Basic engineering, Trans ASME, Ser. F, pp 351-355.

[9] Anno, J.N., Walowit, J.A, and Allen, C.M., (1969), "Load support and leakage from microasperity lubricated face seal", Journal of Basic engineering, Trans ASME, Ser. F, pp 726-731.

[10] Etsion, I., Burstein, L., (1996),"A model for mechanical seals with regular microsurface structure", Tribology Transactions, 39, 3, pp 677-683.

[11] Etsion, I., Kligerman, Y. and Halperin, G., (2002), "Analytical and experimental investigation of laser-textured mechanical seal faces", Tribology Transactions, 42, pp 511-516.

[12] Wang, X and Kato, K., (2003), "Improving anti-seizure ability of SiC seal in water with RIE Texturing", Tribology Letters, 14, 4, pp 275-280. 
[13] Stephens, L.S., Siripuram, R., Hayden, M., and McCartt, B., (2004), "Deterministic Micro Asperities on Bearings and Seals using a modified LIGA Process", Journal of engineering for Gas Turbine and Power, Transactions of ASME, Vol. 126, pp 147154.

[14] Siripuram, R.B., Stephens, L.S.,(2004), "Effect of deterministic asperity geometry on Hydrodynamic Lubrication", Journal of Tribology, Transactions of ASME, Vol. 126 , Issue 3, pp 527-534.

[15] Kortikar, S., (2004), "Fabrication and Characterization of deterministic asperities on thrust surfaces", MS Thesis, University of Kentucky.

[16] Cliffone, J.G., (1996),"Lapping, Polishing and Flatness", Course notes from John Crane Mechanical Maintenance and Training Center manual.

[17] Indge, J.,H., (1992), ”Lapping, Honing and Polishing”, Engineered Materials Handbook, ASM International, Vol. 4: Ceramics and Glasses.

[18] Madou, M.,J., (2002), "Fundamentals of Microfabrication", CRC Press, LLC., USA.

[19] Schlesinger, M., Paunovic, M., (2000), “Modern Electroplating”, John Wiley and Sons, Inc., USA.

[20] Tuma, J.,P., (2002), "The rapid template fabrication process for producing a LIGA heat exchanger bonded to a mechanical seal”, MS Thesis, Louisiana State University.

[21] ASTM standard B 254,"Standard Practice for preparation of and electroplating on stainless Steel".

[22] Miyoshi, K., (2002), "Surface Characterization Techniques: An Overview”, NASA Technical Memorandum, 2002-211497.

[23] "Surface Texture Parameters", (1999), Metropro manual, Zygo ${ }^{\circledR}$ Corporation, Middlefield, CT, USA.

[24] Venkatesan, S., Stephens, L.S., (2004), "Characterization of fabrication errors in deterministic asperity geometry", Proceedings of the 2004 STLE Annual Meeting, Toronto, Canada.

[25] Press, W.H., Flannery, B.P., Teukolsky, S.A., Vetterling, W.T., (1989), "Numerical recipes: The art of scientific computing", Cambridge University Press, NY. 


\section{VITA}

Sriram Venkatesan

Born September 28, 1979 in Bangalore, Karnataka, India.

\section{Education:}

Bachelor of Engineering in Mechanical Engineering, 2001

Bangalore University, India

\section{Professional Positions:}

Senior Mechanical Engineer, John Crane Inc., June 2005- Present

Morton Grove, Illinois, USA

\section{Scholastic awards and Professional Membership:}

Kentucky Graduate Scholarship, 2002-2003

Student Member, American Society of Mechanical Engineers (ASME)

Student Member, Society of Tribologists and Lubrication Engineers (STLE)

\section{Professional Publications:}

- Venkatesan, S., Stephens, L.S., (2004), “Characterization of fabrication errors in deterministic asperity geometry", Proceedings of the 2004 STLE Annual Meeting, Toronto, Canada.

- Venkatesan, S., Stephens, L.S., (2005), "Surface textures for enhanced lubrication: Fabrication and characterization techniques", Proceedings of the 2005 World Tribology Conference III, Paper No. WTC2005- 64291, Washington D.C, USA.

Copyright $($ C Sriram Venkatesan, 2005 